\title{
Live Analysis of the Role of B cells in Experimental Autoimmune Encephalomyelitis
}

\author{
Doctoral Thesis
}

In partial fulfillment of the requirements for the degree 'Doctor rerum naturalium (Dr. rer. nat.)' in the Molecular Medicine Study Program at the Georg-August University Göttingen

\author{
Submitted by \\ Tanja Litke \\ born in Omsk
}

Göttingen, November 2014 


\section{Members of the Thesis Committee}

Prof. Dr. med. Alexander Flügel

Institute for Multiple Sclerosis Research

Department of Neuroimmunology

Waldweg 33, 37073 Göttingen, Germany

fluegel@med.uni-goettingen.de

Prof. Dr. med. Mikael Simons

Max-Plank-Institute of Experimental Medicine

Department of Neurology

Hermann-Rein-Str. 3, 37075 Göttingen, Germany

msimons@gwdg.de

Prof. Dr. rer. nat. Jürgen Wienands

Institute for Cellular and Molecular Immunology

Department of Cellular and Molecular Immunology

Humboldtallee 34, 37073 Göttingen, Germany

jwienan@uni-goettingen.de

Date of Disputation: 


\section{Publications}

C. Schläger, T. Litke, A. Flügel, F. Odoardi. Multiple sclerosis: methods and protocol. In vivo visualization of (auto-)immune processes in the CNS of rodents. Submitted.

A. Flach*, T. Litke*, ..., F. Lühder and A. Flügel. Autoantibody-mediated T cell re-activation within the nervous tissue triggers manifestation of CNS autoimmunity. In preparation.

F. Odoardi*, F. Lühder*, T. Litke, M. Sonneck, J. Winchenbach, N. Eckert, D. Lodygin, ..., A. Flügel. Laquinimod-mediated tightening of the blood brain barrier reduces entry of encephalitogenic effector $\mathrm{T}$ cells into the central nervous system. In preparation.

( $*$ contributed equally) 


\section{Affidavit}

Here I declare that my doctoral thesis entitled "Live analysis of the role of B cells in experimental autoimmune encephalomyelitis" has been written independently with no other sources and aids than quoted.

Tanja Litke

Göttingen, November 2014 


\section{Abstract}

During the last years it has become increasingly clear that autoantigen-specific B cells play a pathogenic role in multiple sclerosis (MS) and its animal model experimental autoimmune encephalomyelitis (EAE). However, their exact mode of action is still a matter of debate. Understanding the mechanisms of B cell contribution to the pathogenesis of MS is crucial for the development of novel specific and efficient therapies. Here we used intravital two-photon microscopy (2PM) to track myelin-reactive $\mathrm{T}$ and $\mathrm{B}$ cells during EAE development induced by recombinant rat myelin oligodendrocyte glycoprotein (rrMOG). We demonstrate that the presence of autoimmune B cells accelerated the invasion of pathogenic $\mathrm{T}$ cells into the central nervous system (CNS), resulting in an earlier clinical manifestation of the disease. Our data strongly suggest that MOG-specific B cells were dispensable for the priming of autoimmune $\mathrm{T}$ cells in the secondary lymphoid organs. Furthermore, we demonstrate that B cells did not infiltrate the CNS and therefore could not be held responsible for antigenpresentation in the CNS and the re-activation of effector T cells. Instead, our data provide evidence that autoantibodies are the pathogenic "weapon" of autoimmune B cells. MOG-specific B cells deficient in the transcription factor XBP-1 and so unable to secrete antibodies had no pathogenic effect on the EAE development. Furthermore, an intravenous transfer of anti-MOG antibody mimicked the disease-promoting effect of $\mathrm{B}$ cells. By 2PM we could demonstrate that the anti-myelin antibody accumulated in the meningeal phagocytic cells which are situated at a strategically favorable anatomical location at the boundary between the periphery and the CNS, with access to peripheral circulating encephalitogenic $\mathrm{T}$ cells and possibly to endogenous myelin antigens. In summary, our study provides evidence that autoantibodies produced by MOG-specific B cells accelerate the disease onset of EAE by playing a critical role in the initiation of effector T cells invasion into the CNS. 


\section{Contents}

List of Figures viii

List of Tables $\quad x$

List of Abbreviations $\quad$ xi

1 Introduction 1

1.1 Multiple sclerosis $(\mathrm{MS}) \ldots \ldots \ldots \ldots 1$

1.2 Role of B cells in MS . . . . . . . . . . . . . . . . . . . 2

1.3 Experimental autoimmune encephalomyelitis (EAE) - animal model of human MS . . . . . . . . . . . . . . . . . 5

1.4 B cell functions in EAE . . . . . . . . . . . . . . . . . 6

1.4.1 B cells can differentiate into plasma cells and secrete autoantibodies . . . . . . . . . . . . . . . . 7

1.4.2 B cells as antigen-presenting cells (APCs) . . . . . . . 8

1.4.3 B cells can modulate autoimmune responses by production of proinflammatory cytokines . . . . . . . . . . . . 9

1.4.4 Regulatory function of B cells . . . . . . . . . . . . . . . . 10

1.5 Principles of intravital two-photon microscopy $(2 \mathrm{PM}) \ldots \ldots$

2 Aims and objectives 13

3 Materials and Methods $\quad 14$

3.1 Standard Buffers and Media . . . . . . . . . . . . . . . . . . . . 14

3.2 Experimental Animals . . . . . . . . . . . . . . . . . . . 15

3.3 Experimental Procedures . . . . . . . . . . . . . . . . . . . . . . 16

3.3.1 T Cells and B Cells Isolation . . . . . . . . . . . . . . 16

3.3.2 CFSE Staining of Lymphocytes . . . . . . . . . . . . . . . 16

3.3.3 Isolation of Mononuclear Cells from the CNS Tissue Using Percoll Gradients . . . . . . . . . . . . . . . . . . . . 17 


\section{Contents}

3.3.4 Separation of Lymphocytes from Whole Blood . . . . . . . . 17

3.3 .5 Antigens . . . . . . . . . . . . . . . . . . . . 17

3.3.6 Induction and Assessment of EAE . . . . . . . . . . . . . 18

3.3 .7 Immunohistochemistry . . . . . . . . . . . . . . . . . . . . . . 19

3.3.8 Flow Cytometry . . . . . . . . . . . . . . . . . . . . . 19

3.3 .9 Anti-MOG Serum ELISA . . . . . . . . . . . . . . . 20

3.3.10 Quantitative Real-Time PCR . . . . . . . . . . . . . . . 21

3.3.11 Production and fluorescent labeling of monoclonal mouse antiMOG Ab . . . . . . . . . . . . . . . . . 22

3.3.12 Generation of $\mathrm{T}_{\text {MOG-NFAT/YFP-mCherry/H2B }}$ cells $\ldots \ldots . . . .22$

3.3.13 Isolation of meningeal APCs . . . . . . . . . . . . . . . . 22

3.3.14 Live cell two-photon imaging . . . . . . . . . . . . . . 23

3.3 .15 Intravital Imaging . . . . . . . . . . . . . . . . . . 23

3.3.15.1 Fluorescent Cell Labeling for Intravital Imaging . . . 23

3.3.15.2 Preparation of the Popliteal Lymph Node for Intravital Imaging . . . . . . . . . . . . . . . . . . . 23

3.3.15.3 Preparation of the Mouse Spinal Cord for Intravital Imaging . . . . . . . . . . . . . . . . . . . . . . . . . . . . . . . . .

3.3.15.4 Image Acquisition . . . . . . . . . . . . . . 26

3.3.15.5 Image Analysis . . . . . . . . . . . . . . . . 27

3.3.16 Statistical Analysis . . . . . . . . . . . . . . . . . 27

4 Results $\quad 28$

4.1 EAE model for tracking autoreactive $\mathrm{T}$ and $\mathrm{B}$ cells in vivo . . . . . . . 28

4.2 Autoreactive B cells increase the risk of a clinical manifestation of EAE and accelerate the disease onset . . . . . . . . . . . . . . . . . . 29

4.3 Autoreactive B cells accelerate the invasion of encephalitogenic T cells into the CNS . . . . . . . . . . . . . . . . . . . . 34

4.4 The priming of $\mathrm{T}_{\mathrm{MOG}}$ cells in secondary lymphoid organs is independent of MOG-specific B cells . . . . . . . . . . . . . . . . . . . . . 38

4.4.1 Intravital $2 \mathrm{PM}$ analysis of $\mathrm{T}_{\mathrm{MOG}}$ cells priming in the draining lymph nodes . . . . . . . . . . . . . . . . . 38

4.4.2 Myelin-specific activation and proliferation of $\mathrm{T}$ cells is not enhanced by myelin-reactive B cells . . . . . . . . . . . . . . 45 


\section{Contents}

4.4.3 MOG-specific B lymphocytes did not influence the expression profile of pro-inflammatory cytokines or of chemokine receptors in $\mathrm{T}_{\mathrm{MOG}}$ cells . . . . . . . . . . . . . . . . . . 49

4.4.4 Antigen-specific activation of $\mathrm{B}_{\mathrm{MOG}}$ cells . . . . . . . . . 50

4.5 MOG-specific B cells do not serve as APCs in the CNS . . . . . . . . . 52

4.5.1 Anti-MOG antibodies account for the disease-promoting effect of B cells . . . . . . . . . . . . . . . . . 55

4.6 Meningeal phagocytic cells accumulate anti-MOG antibody . . . . . . 58

4.7 Interactions with meningeal APCs in vitro lead to an activation of $\mathrm{T}$ cells . . . . . . . . . . . . . . . . . . . . 59

5 Discussion $\quad 62$

6 Summary $\quad 70$

$\begin{array}{lll}7 & \text { Acknowledgment } & 71\end{array}$

$\begin{array}{ll}\text { Bibliography } & 73\end{array}$

$\begin{array}{lr}\text { Curriculum Vitae } & 87\end{array}$ 


\section{List of Figures}

1.1 MRI brain scan shows the lesions typical for MS as multiple bright spots. 2

1.2 Simplified Perrin-Jablonsky diagram of one-, two- and three-photon absorption. . . . . . . . . . . . . . . . . . 12

3.1 Intravital imaging of the mouse popliteal lymph node. . . . . . . . . 25

3.2 Experimental setup for intravital imaging of the mouse spinal cord. . . 26

4.1 Titration of rrMOG protein for induction of a mild EAE course. . . . . 29

4.2 Autoreactive B cells increase the risk of a clinical manifestation of EAE in $\mathrm{C} 57 \mathrm{BL} / 6 \mathrm{~J}$ wt mice and accelerate the disease onset. . . . . . . . . 30

4.3 The pathogenic effect of MOG-specific B cells on EAE in OT-II TCR transgenic mice in response to a mild antigenic challenge. . . . . . . 32

4.4 MOG-specific B cells accelerate disease onset in OT-II TCR transgenic mice. . . . . . . . . . . . . . . . . . . . 33

4.5 The pathogenic effect of B cells is dependent on BCR specificity. . . . 34

4.6 Time projections of $30 \mathrm{~min}$ recordings of leptomeningeal blood vessels during the pre-clinical phase and at the disease onset. . . . . . . . 36

4.7 The invasion of $\mathrm{T}$ cells into the CNS associated with visible disruption of the BBB. . . . . . . . . . . . . . . . . . . 37

4.8 Autoreactive B lymphocytes promote the entry of T cells into the CNS compartment. . . . . . . . . . . . . . . . . 38

4.9 Intravital two-photon imaging deep within the intact popliteal lymph node enables an analysis of the behavior of fluorescently-labeled myelinspecific $\mathrm{T}$ and $\mathrm{B}$ cells within the priming phase. . . . . . . . . . . 40

4.10 Migration behavior of $\mathrm{T}_{\mathrm{MOG}}$ cells in the presence of $\mathrm{B}_{\mathrm{MOG}}$ or $\mathrm{B}_{\mathrm{NP}}$. . . 43

$4.11 \mathrm{~B}_{\mathrm{MOG}}$ cells form long-lasting motile conjugates with $\mathrm{T}_{\mathrm{MOG}}$ cells after immunization with $\operatorname{rrMOG}$ protein. . . . . . . . . . . . . 44

4.12 Upon activation small naive $\mathrm{T}_{\mathrm{MOG}}$ cells transform into large blasts. $\quad 44$ 
$4.13 \mathrm{~B}_{\mathrm{MOG}}$ cells did not accelerate or enhance $\mathrm{T}$ cell activation in the priming phase. . . . . . . . . . . . . . . . 46

4.14 Presence of $\mathrm{B}_{\mathrm{MOG}}$ cells had no effect on $\mathrm{T}$ cell proliferation. . . . . . . 47

4.15 Expansion of $\mathrm{T}_{\mathrm{MOG}-\mathrm{GFP}}$ cells in the draining lymph nodes. . . . . . . . 48

$4.16 \mathrm{~B}_{\mathrm{MOG}}$ cells did not influence the expression profile of proinflammatory cytokines or of the chemokine receptors in $\mathrm{T}_{\mathrm{MOG}}$ cells. . . . . . . . . 50

4.17 Antigen-specific activation of B cells. . . . . . . . . . . . 51

4.18 Expansion of $\mathrm{B}$ cells is dose-dependent and it is not required for the pathogenic function of $\mathrm{B}_{\mathrm{MOG}}$ cells. . . . . . . . . . . . . . 52

4.19 Histological analysis of B cells infiltrates in the spinal cord of C57BL/6J wt mice with EAE. . . . . . . . . . . . . . . . . . 54

4.20 Flow cytometric analysis of B cells infiltrates in the spinal cord of mice

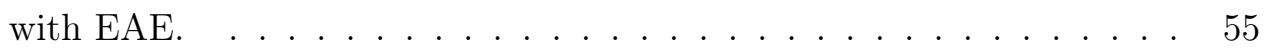

$4.21 \mathrm{~B}_{\mathrm{MOG}-\mathrm{XBP}-1^{-/-}}$cells fail to secrete anti-MOG IgG in response to rrMOG challenge and lose their disease-promoting capability. . . . . . . . . 57

4.22 Administration of anti-MOG mAb accelerates invasion of $\mathrm{T}$ cells into

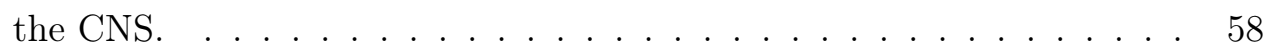

4.23 Anti-MOG antibody accumulates within the meningeal cells. . . . . . . 59

4.24 Interactions with meningeal APCs in vitro lead to a nuclear translocation of NFAT sensor in effector T cells. . . . . . . . . . . . . . . . 60 


\section{List of Tables}

4.1 3D mean $\mathrm{T}$ cells velocities at different time points after immunization with rrMOG in the presence of MOG-specific B cells. . . . . . . . . . . 44

4.2 The decrease in $\mathrm{T}$ cell motility in the draining lymph nodes was antigenspecific and $\mathrm{B}_{\mathrm{MOG}}-\mathrm{cell}$ independent. . . . . . . . . . . . . . 45 


\section{List of Abbreviations}

2PM

$\mathrm{Ab}$

ACK

APC

AQP4

AUC

$\mathrm{BBB}$

BCR

BMOG

BNP

CD

CFA

CFSE

$\mathrm{CM}$

CMTMR

CNS

CSF

d

DC two-photon microscopy

antibody

ammonium-chloride-potassium lysing buffer

antigen presenting cell

aquaporin-4

area under the curve

blood brain barrier

B cell receptor

B cells with B cell receptor specific for MOG

B cells with B cell receptor specific for NP

cluster of differentiation

complete Freund's adjuvant

carboxyfluorescein succinimidyl ester

complete medium

(5-(and-6)-(((4-chloromethyl)- benzoyl)amino)tetramethylrhodamine

central nervous system

cerebrospinal fluid

days

dendritic cell 
DMEM

EAE

ELISA

FCS

GFP

GM-CSF

HPRT

i.p.

i.v.

IFA

IFN-gamma

Ig

$\operatorname{Ig} G$

$\operatorname{IgM}$

IL-

KIR4.1

LT

$\mathrm{mAb}$

MHC

MOG

MRI

mRNA

MS

$\mathrm{n} / \mathrm{a}$
Dulbecco's modified Eagle medium

experimental autoimmune encephalomyelitis

enzyme-linked immunosorbent assay

fetal calf serum

green fluorescent protein

granulocyte macrophage colony-stimulating factor

hypoxanthine phosphoribosyltransferase

intraperetoneal

intravenously

incomplete Freund's adjuvant

interferon gamma

immunoglobulin

immunoglobulin G

immunoglobulin M

interleukin-

inwardly rectifying $\mathrm{K}+$ channel

lymphotoxin

monoclonal antibody

major histocompatibility complex

myelin oligodendrocyte glycoprotein

magnetic resonance imaging

messenger RNA

multiple sclerosis

not applicable 
NFAT

NK

NMO

NP

OCB

OD

OVA

p.i.

PBS

PCR

PFA

PP-MS

PTX

RA

ReMed

RFP

rhMOG

rpm

RR-MS

rrMOG

RT

s.c.

SEM

SP-MS nuclear factor of activated $\mathrm{T}$ cells

natural killer cells

neuromyelitis optica

4-hydroxy-3-nitrophenyl

oligoclonal bands

optical density

ovalbumin

post immunization

phosphate buffered saline

polymerase chain reaction

paraformaldehyde

primary progressive multiple sclerosis

pertussis toxin

rheumatoid arthritis

restimmulation medium

red fluorescent protein

recombinant human myelin oligodendrocyte glycoprotein

revolutions per minute

relapsing-remitting multiple sclerosis

recombinant rat myelin oligodendrocyte glycoprotein

room temperature

subcutaneous

standard error of the mean

secondary-progressive multiple sclerosis 
List of Abbreviations

TCGF

TCM

TCR

$\operatorname{tdRFP}$

$\operatorname{tg}$

TH

TMOG

TNF alpha

TOVA

wt

XBP-1
T cell growth factor

$\mathrm{T}$ cell medium

$\mathrm{T}$ cell receptor

tandem-dimer red fluorescent protein

transgenic

helper T cells

$\mathrm{T}$ cell with $\mathrm{T}$ cell receptor specific for $\mathrm{MOG}$

tumor necrosis factor alpha

$\mathrm{T}$ cell with $\mathrm{T}$ cell receptor specific for OVA

wild-type

X-box binding protein 1 


\section{Introduction}

\subsection{Multiple sclerosis (MS)}

Multiple Sclerosis (MS) is the most common cause of neurologic disability in young adults, affecting around 2.5 million people worldwide (Compston et al., 2006). It is a chronic autoimmune disease of the central nervous system (CNS) where the immune system of the body attacks the meylin sheets of the nerve cells, leading to inflammation, demyelination and axonal loss in the brain and spinal cord. The pathology of MS is characterized by multiple lesions, also known as plaques. In 1868 French neurologist Jean-Martin Charcor referred to this condition as la sclérose en plaques disseminées (Charcor, 1868), which was translated as "disseminated sclerosis" and later became known as "multiple sclerosis" (Compston et al., 2006). Modern medicine employs magnetic resonance imaging (MRI) modality to visualize asymptomatic dissemination of lesions in space and time. An MRI brain scan in Fig. 1.1 shows bright signal lesions in white matter typical for MS.

Demyelination in the brain and spinal cord leads to a varying degree of neurological disability. Initial symptoms often manifest during early adulthood and can be abrupt and severe, but also can be so subtle and mild that the patient might not seek medical advice for years (Hauser and Oksenberg, 2006). At the onset of the disease the most common symptoms are a tingling sensation and numbness that can affect the face, arms, legs and fingers. Blurred vision, double vision or even complete loss of vision in one eye are also common early signs of MS. Among the most common mobility problems for patients with MS are weakness or loss of fine coordination in one or more limbs and gait abnormalities. Bladder and bowel disfunction can occur at any time point throughout the course of the disease, profoundly affecting the quality of life of those living with MS. Fatigue, cognitive deficits and depression are also common in MS.

In about $85 \%$ of all MS patients the disease starts as relapsing-remitting MS (RR-MS) (Hauser and Oksenberg, 2006). Patients with this clinical pattern suffer from abrupt disease episodes (relapses) 1-2 times per year after which they recover 


\section{Introduction}

partially or completely (remission). However, within 10 years of disease onset about $50 \%$ of these patients do not recover well after an attack and show gradual progression of disability, converting to secondary progressive MS (SP-MS). Primary progressive MS (PP-MS) affects approximately $10 \%$ of patients with MS, and is characterized by continuous progression of disability from the onset. Patients with progressive relapsing MS (about $5 \%$ of MS patients) show a combination of gradual disease progression with relapses.

It is not known what causes MS, but several factors have been proposed to be involved, including immunological (Hohlfeld and Wekerle, 2004), environmental (Marrie, 2004) and genetic factors (Barcellos et al., 2003; Willer et al., 2003). Scientists believe that an interaction of environmental and genetic factors trigger an autoimmune response (Handel et al., 2010). Understanding the mechanisms of the autoimmune response in the pathogenesis of MS is necessary for the development of effective therapy.

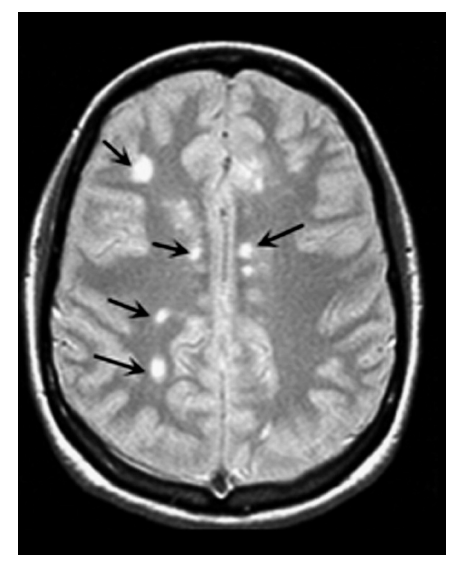

Figure 1.1: MRI brain scan shows the lesions typical for MS as multiple bright spots. Figure from (Hauser and Oksenberg, 2006).

\subsection{Role of $B$ cells in MS}

The principal function of our immune system is to differentiate between "self" and "foreign" and to destroy what it recognizes as "foreign" or pathogenic. In the autoimmune disease MS the immune system of the body mounts an inappropriate immune attack against its own CNS components without an apparent microbial invader. The general consensus is that MS is mainly mediated by the autoreactive myelin-specific $\mathrm{T}$ cells. However, it is clear that the presence of autoreactive $T$ cells alone will not cause the disease to develop. Potentially autoreactive $\mathrm{T}$ cells can often be detected in the 


\section{Introduction}

blood of healthy individuals: Burns et al. could isolate MBP-responding T cells from the blood of six out of nine healthy donors (Burns et al., 1983). In MS patients, a yet unknown cause triggers activation of the myelin-reactive $\mathrm{T}$ cells. Once activated, the effector $\mathrm{T}$ cells cross the blood-brain barrier, where they get reactivated and initiate a cascade of inflammatory events leading to demyelination, neurodegeneration and neurological disfunction. Genetic and environmental factors are recognized as risk factors, however, definite trigger(s) of $\mathrm{T}$ cell activation in MS has/have not been identified yet. It is thought that a complex interplay between different immune cell populations leads to the pathogenesis of MS. Recently developed therapies targeting B cells have shown surprising efficacy and brought B cells into the focus of MS research.

The first hint of a potential benefit from B-cell-targeting therapy in autoimmune disorders came from a study in oncology. In 2001 Cohen et al. administered rituximab to a patient with agglutinin-mediated hemolytic anemia which is an autoimmune disorder secondary to lymphoma where autoantibodies are directed against body's own red blood cells (Cohen et al., 2001). Rituximab is a chimeric monoclonal antiCD20 antibody that leads to a rapid complement- and NK cell-mediated depletion of all CD20 ${ }^{+}$B cells (Maloney et al., 1994). The treated patient achieved a rapid and complete clinical remission with a follow-up for over one year (Cohen et al., 2001). This led to the first clinical study for B-cell-depleting therapy with rituximab in patients with rheumatoid arthritis (RA) that significantly improved disease symptoms (Edwards et al., 2004).

In MS the efficacy of B-cell depletion with rituximab was assessed in patients with relapsing-remitting disease course (Bar-Or et al., 2008; Hauser et al., 2008). At week 12 after a single course of rituximab the total number of gadolinium-enhancing lesions reduced to a mean of 0.5 lesions compared to 5.5 lesions in the placebo-treated group, corresponding to a relative reduction of $91 \%$ (Hauser et al., 2008). This effect was not only sustainable for the entire 48-week trial period but also reduced further at each study week (Hauser et al., 2008). In addition, rituximab treatment significantly reduced the number of newly formed lesions and the number of relapses compared to the placebo group (Hauser et al., 2008). The mechanisms by which depletion of B cells led to a rapid and sustained reduction of disease activity are as yet unknown, but the efficacy of this study has implicated B cells as a highly promising therapeutic target in MS. Currently, clinical trials are testing modified anti-CD20 monoclonal antibodies - namely ocrelizumab (Kappos et al., 2011) and ofatumumab (Arzerra ${ }^{\circledR}$ ) (Soelberg Sorensen et al., 2010) - in RR-MS. They target the same population of $\mathrm{CD}^{2} 0^{+} \mathrm{B}$ cells as rituximab but as fully humanized antibodies they are 


\section{Introduction}

nonimmunogenic to humans and appear to cause fewer allergic reactions in treated patients (Rommer et al., 2014).

The efficacy of B-cell-depleting therapies provide a strong argument for a pathogenic role of B cells in MS. The earliest evidence that implicated humoral immunity in MS pathology dates back to the detection of intrathecal IgG with moving boundary electrophoresis by Elvin Kabat in 1942 (Kabat et al., 1942). After the invention of agar electrophoresis, Lowenthal et al. were able to separate CSF IgG bands produced by different B cell clones in patients with MS (Lowenthal et al., 1960). This fractionate IgG pattern is referred to as oligoclonal bands (OCBs). Notably, the existence of OCBs in the CSF is the most consistent marker of the disease (detected in > $95 \%$ of patients with MS (Walsh et al., 1985)) and individuals presented with clinically isolated syndrome are at a higher risk to develop clinically definite MS when OCBs are detected (Avasarala et al., 2001; Joseph et al., 2009). The presence of OCBs in the CSF but not in the peripheral circulation indicate their production within the CNS compartment (Owens et al., 2006). Indeed, in patients with MS, B cells and plasma cells are frequently found in active lesions (Prineas and Connell, 1978), in the meninges (Serafini et al., 2004) and in the CSF (Colombo et al., 2000). In SP-MS B cells were found to form ectopic meningeal lymphoid structures (Serafini et al., 2004), whose presence has been associated with a younger age at MS onset and severe cortical pathology (Magliozzi et al., 2007). Notably, the CSF IgG-proteome overlaps with the transcriptome of B cells from the CSF and the CNS tissue (Obermeier et al., 2008), providing evidence for intrathecal production of the OCBs and a humoral immune response within the CNS compartment. The deposition of antibodies and complement activation products in actively demyelinating MS lesions (Prineas and Graham, 1981; Storch et al., 1998; Gay et al., 1997; Genain et al., 1999) reinforces the pathogenic relevance of autoantibodies in MS. The most direct evidence derived from the finding of autoantibodies in neuromyelitis optica (NMO) - an MS-related disease of the CNS. Lennon et al. identified antibodies directed against the water channel protein, aquaporin-4, which is predominantly expressed in astrocytic foot processes at the BBB (Lennon et al., 2005). Furthermore, a recent study detected IgG in the serum of MS patients directed against the potassium channel KIR4.1 (inwardly rectifying $\mathrm{K}^{+}$ channel) expressed on glial cells (Srivastava et al., 2012). The anti-KIR4.1 antibodies were detected in nearly $50 \%$ of MS patients and were specific to MS. Finally, it has been reported that patients with pattern II MS lesions (antibody-/complementassociated demyelination) (Lucchinetti et al., 2000) benefited from therapeutic plasma exchange (Keegan et al., 2005), thereby supporting a role for humoral components in 
MS pathogenesis.

Thus, there is a substantial body of evidence for a pathogenic role of B lymphocytes in the development and progression of MS but their function is still unclear. In the present study we implemented a mouse model of the human MS, experimental autoimmune encephalomyelitis (EAE), to identify the underlying mechanism of B cell function. In the following chapters the EAE will be introduced and the evidence derived from it for both the pathogenic and regulatory function of $\mathrm{B}$ cells will be reviewed. Furthermore, the physical principles of the intravital imaging technique used in this study will be described.

\subsection{Experimental autoimmune encephalomyelitis (EAE) - animal model of human MS}

Experimental autoimmune encephalomyelitis (EAE) is the most widely used model of the human disease MS. Over the past 81 years since its establishment (Rivers et al., 1933), not only has EAE significantly contributed to our understanding of T cell-mediated CNS inflammation (Gold et al., 2006) but it also led directly to a successful launching of three drugs for treatment of MS, namely glatiramer acetate, mitoxantrone, and natalizumab (Steinman and Zamvil, 2006).

In active EAE, myelin-reactive $T$ cells get initially activated in the periphery following an immunization with myelin components emulsified in complete Freund's adjuvant (Freund et al., 1947). Commonly used myelin components in rodents are myelin oligodendrocyte glycoprotein (MOG), proteolipid protein (PLP), myelin basic protein $(\mathrm{MBP})$, or encephalitogenic peptides of these proteins. $\mathrm{T}$ cells can also be activated in vitro and then intravenously transferred into the host (passive EAE) eliciting paralysis in the recipient animals similar to the symptoms observed in an active-induced EAE (Ben-Nun et al., 1981). A cascade of pathogenic events follow an immunization and eventually result in an appearance of neurological signs of EAE: body weight loss followed by a progressive paralysis. Within the priming phase, the administered myelin components are taken up by the dendritic cells (DCs). They process the antigen and present peptides in the context of major histocompatibility

complex class II (MHC class II) to the myelin-specific T cells in the draining lymph nodes. The activated $\mathrm{T}$ cells proliferate extensively, resulting in a substantial enlargement of the draining secondary lymphoid organs (2-3 times compared to the initial size based on our own observation). Differentiated effector $\mathrm{T}$ helper $1\left(\mathrm{~T}_{\mathrm{H}} 1\right)$ and $\mathrm{T}$ 


\section{Introduction}

helper $17\left(\mathrm{~T}_{\mathrm{H}} 17\right)$ cells leave the draining lymph nodes via peripheral circulation, and traffic widely throughout peripheral organs (spleen, liver and lung) in search of their antigen (Ransohoff and Engelhardt, 2012). Interestingly, activated T cells do not directly invade the CNS. A previous study in our lab using transfer EAE has shown that activated autoreactive $\mathrm{T}$ cells first have to "become licensed in the lung to enter the CNS" (Odoardi et al., 2012). In the lung activated T cells profoundly modify their gene-expression profile. Upregulation of genes for chemokines and adhesion receptors enables autoreactive $\mathrm{T}$ cells to crawl along the leptomeningeal blood vessels. In the intraluminal space $T$ cells crawl preferentially against the blood flow, before squeezing through the endothelium (Bartholomäus et al., 2009). Once extravasated, $\mathrm{T}$ cells interact with phagocytes in the perivascular environment that present CNS antigens and reactivate myelin specific $\mathrm{T}$ cells. A recent publication by Lodygin et al. reports on a molecular tool that enables us to immediately identify an activation event of a $\mathrm{T}$ cell by two-photon microscopy in real-time (Lodygin et al., 2013). In a resting $\mathrm{T}$ cell the yellow fluorescent nuclear factor of activated $\mathrm{T}$ cells (NFAT/YFP) is located in the cytoplasm. Upon antigenic challenge, NFAT/YFP is rapidly translocated into the mCherry-labeled nucleus (mCherry/H2B). Lodygin et al. demonstrated that CNS-invading myelin-specific T cells translocate NFAT into the nucleus, i.e. get reactivated, once they transmigrate through the vascular wall and come into contact with phagocytes in the vicinity of the leptomeningeal vessels (Lodygin et al., 2013). These findings were confirmed in parallel by another group using a similar approach (Pesic et al., 2013). Reactivated T cells invade deep into the white and gray spinal cord matter, resulting in a massive recruitment of inflammatory immune cells, myelin damage and finally in the paralysis of the animal.

\subsection{B cell functions in $E A E$}

The fact that an immunization with myelin antigen elicited a strong $\mathrm{CD} 4^{+} \mathrm{T}$ cell response and moreover that EAE could be transferred by an adoptive transfer of autoreactive $\mathrm{T}$ cells from a sick into a healthy animal led to the prevalent view that $\mathrm{T}$ cells initiate and mediate EAE and MS. However, data derived from new transgenic animal models of EAE and, even more convincing, the rapid decline of MS activity after a depletion of B lymphocytes with Rituximab strongly argue in favor of an important role of B cells in the pathogenesis of MS and EAE.

Litzenburger et al. engineered a mouse model with endogenous myelin-reactive B cells (Litzenburger et al., 1998). By replacing the $\mathrm{J}_{\mathrm{H}}$ locus in embryonic stem cells 
with a MOG-specific VDJ region from the hybridoma 8.18-C5 (Linnington et al., 1984) they generated MOG-specific Ig heavy-chain knock-in mice ( $\mathrm{IgH}^{\mathrm{MOG}}$, also referred to as Th mice). In these mutant mice almost all B cells express exclusively transgenic heavy chains that associate with the endogenous light chains. In heterozygous $\mathrm{Th} /+$ mice about $30 \%$ and in homozygous Th/Th about $50 \%$ of B cells bind conformational epitope within the extracellular domain of MOG (Breithaupt et al., 2003). Upon immunization with $\mathrm{rMOG}$ protein $\mathrm{IgH}^{\mathrm{MOG}}$ mutants showed increased disease incidence, earlier onset and an exacerbated EAE course compared to wt mice (Litzenburger et al., 1998). The pathogenic effect of $\mathrm{B}$ cells was even more evident when $\mathrm{IgH}^{\mathrm{MOG}}$ mutants were crossed with $\mathrm{TCR}^{\mathrm{MOG}}$ mice (Bettelli et al., 2003). In TCR ${ }^{\mathrm{MOG}}$ transgenic mice over $98 \%$ of $\mathrm{CD}^{+} \mathrm{T}$ cell repertoire is specific for encephalitogenic $\mathrm{MOG}_{35-55}$ peptide, however, only in rare cases these animals develop spontaneous EAE (4\%) (Bettelli et al., 2003). In contrast, the frequency of spontaneous EAE increases drastically to around $50 \%$ in $\mathrm{TCR}^{\mathrm{MOG}} \times \mathrm{IgH}^{\mathrm{MOG}}$ double transgenic animals (Bettelli et al., 2006; Krishnamoorthy et al., 2006).

Experiments with B-cell-deficient mice (Kitamura et al., 1991) suggest an involvement of B cells in triggering the CNS autoimmunity. Lyons et al. have shown that $\mathrm{B}$ cell-deficient C57BL/6 mice were completely protected from EAE when immunized with recombinant human MOG (rhMOG) protein while wild-type littermates were readily susceptible with $90 \%$ disease incidence (Lyons et al., 1999).

Different effector mechanisms of B cells are speculated to be involved in the pathogenesis of MS and EAE:

1. Production of autoantibodies;

2. Antigen-presentation;

3. Production of pro- or anti-inflammatory cytokines.

\subsubsection{B cells can differentiate into plasma cells and secrete autoantibodies}

It remains controversial whether the presence of autoantibody is a secondary phenomenon of immune disfunction or part of the cause. EAE induced by recombinant rat or human MOG proteins is associated with a robust antibody response against MOG (Oliver et al., 2003). Spontaneous EAE in TCR ${ }^{\mathrm{MOG}} \times \mathrm{IgH}^{\mathrm{MOG}}$ (Bettelli et al., 2006; Krishnamoorthy et al., 2006) and RR mice (SJL/J mice with TCR specific for MOG $_{92-106}$ ) (Pöllinger et al., 2009) is also accompanied by high titers of anti- 


\section{Introduction}

MOG antibody. Furthermore, similar to MS pattern II lesions with antibody- and complement-mediated damage, B cells, plasma cells and antibodies were detected in areas of myelin breakdown in EAE in common marmoset monkeys (Merkler et al., 2006).

CNS-reactive antibodies alone without immunization cannot induce EAE (Schluesener et al., 1987). However, a number of previous studies demonstrated pathogenic function of autoantibodies in various EAE models. SJL mice with chronic relapsing EAE that were recovering from an attack suffered a lethal relapse after an i.p. administration of anti-MOG monoclonal antibody (8.18-C5, Linnington et al. 1984) (Schluesener et al., 1987). In MBP-induced acute EAE in Lewis rats, administration of the same antibody resulted in an accelerated disease onset with a rapid disease progression causing death in most treated animals at the time point when the control animals still had no signs of the disease. EAE in the Lewis rat is characterized by inflammation in the CNS and BBB dysfunction, however, with limited or no demyelination (Lassmann et al., 1988). In contrast, peripheral administration of 8.18-C5 antibody resulted in the formation of large demyelinated lesions in Lewis rats during active (Schluesener et al., 1987) and transfer EAE (Linington et al., 1988). The demyelinating activity of sera from EAE animals was demonstrated in vitro (Bornstein and Appel, 1961; Seil et al., 1968) and in vivo (Brosnan et al., 1977; Lassmann et al., 1981). Furthermore, a transfer of serum from MOG-primed wt mice restored the EAE susceptibility in B-cell-deficient mice in response to rhMOG protein (Lyons et al., 2002).

In contrast to the studies discussed above, a recent study by Molnarfi et al. suggested a dispensable role of autoantibodies in EAE (Molnarfi et al., 2013). They reported that $\mathrm{IgH}^{\mathrm{MOG}-\mathrm{mem}}$ mice with B cells specific for MOG but unable to secrete antibodies, were fully susceptible to rhMOG-induced EAE.

\subsubsection{B cells as antigen-presenting cells (APCs)}

For the development of EAE, CD4 ${ }^{+} \mathrm{T}$ cells have to be first activated in the periphery and then re-activated within the CNS by APCs presenting myelin peptides in the context of MHC class II. B cells have been postulated as potent APCs in the priming of $\mathrm{T}$ cells due to their ability to bind antigen specifically via their $\mathrm{B}$ cell receptor (BCR) (Lanzavecchia, 1985; Constant et al., 1995). BCR can bind soluble antigens or antigens attached to the surface of other APCs in the secondary lymphoid organs. The localization of B cells in follicles beneath the subcapsular sinus favors B cells encounters with antigens that are presented by follicular dendritic cells (Suzuki 


\section{Introduction}

et al., 2009) and subcapsular sinus macrophages (Carrasco and Batista, 2007; Junt et al., 2007). In addition, B cells can capture antigen extrafollicular from DCs upon entry into the lymph nodes (Qi et al., 2006). Binding of an antigen cross-links BCR molecules and induces downstream signaling cascade that promotes endocytosis of BCR-antigen-complex (Yuseff et al., 2013). Inside the lysosomes the antigen is degraded into small peptides and loaded into the peptide-binding groove of MHC class II molecules. Mature MHC class II-peptide complex is exported to the cell surface and can interact with $\mathrm{T}$ cells specific for the presented peptide.

Antigen-presentation has been hypothesized to initiate the development of spontaneous EAE in RR mice (Pöllinger et al., 2009) and in $\mathrm{TCR}^{\mathrm{MOG}} \times \mathrm{IgH}^{\mathrm{MOG}}$ mice (Bettelli et al., 2006; Krishnamoorthy et al., 2006), though antibody and cytokine secretion functions could not been excluded in these models (Berer et al., 2011).

Molnarfi et al. reported that B-MHC $\mathrm{II}^{-/}$-mice were resistant to EAE induced by rhMOG protein (Molnarfi et al., 2013). After excluding an antibody-dependent function for B cells in $\mathrm{IgH}^{\mathrm{MOG}-m e m}$ mice, they argued that MHC class II-dependent antigen presentation function of $\mathrm{B}$ cells is a requirement for EAE induction. APC function of B cells was further supported by Pierson et al. who attributed a decreased incidence of transfer EAE in B-cell-deficient mice to a lack of re-activation by B cells in the CNS (Pierson et al., 2014). On the contrary, Archambault et al. demonstrated in a model with conditional expression of MHC class II in B cells, that antigen presentation by B cells alone was not sufficient for induction of EAE (Archambault et al., 2013).

\subsubsection{B cells can modulate autoimmune responses by production of proinflammatory cytokines}

Antigen-presentation to encephalitogenic $\mathrm{T}$ cells and the production of anti-myelin antibodies requires myelin-specific B cells. However, B cells can secrete cytokines irrespective of their specificity following nonspecific stimuli (Barr et al., 2012). The detection of plasma cell clones with myelin-unrelated specificity in the CSF of patients with MS (Owens et al., 2009) fueled the interest in cytokine production of B cells as a pathogenic mechanism in MS (Barr et al., 2012).

IL-6-deficient mice were reported to be completely resistant to EAE (Eugster et al., 1998; Mendel et al., 1998; Okuda et al., 1998; Samoilova et al., 1998). B cells activated via Toll-like receptors with microbial products (e.g. lipopolysaccharide) produce IL-6 (Lampropoulou et al., 2008) which is crucial for development of pathogenic Th17 cells (Korn et al., 2008). Indeed, mice with IL-6-deficiency restricted to B cells developed less severe EAE than mice with wt B cells (Barr et al., 2012). Notably, B cells from 


\section{Introduction}

patients with MS produced more IL-6 than in healthy controls (Barr et al., 2012), suggesting a pathogenic role of IL-6 secreting B cells in MS.

In addition, Bar-Or et al. reported that B cells isolated from peripheral blood of patients with RR-MS produced significantly higher amount of lymphotoxin (LT) when activated in the presence of pathogen-associated Toll-like receptor 9 ligand (BarOr et al., 2010). The presence of Th1 cytokine IFN- $\gamma$ induced significantly greater secretion of LT and tumor necrosis factor- $\alpha$ (TNF $\alpha$ ) (Bar-Or et al., 2010). The group proposed that the episodic overproduction of LT and TNF $\alpha$ by B cells, possibly associated with infections, triggered "bystander activation" of encephalitogenic T cells, resulting in new MS relapses (Bar-Or et al., 2010).

\subsubsection{Regulatory function of B cells}

The studies discussed above suggest a pathogenic role of B cells in MS/EAE. However, an opposing role of $\mathrm{B}$ cells in restraining CNS autoimmunity has also been demonstrated. B-cell deficient mice ( $\mu \mathrm{MT}$ ) (Kitamura et al., 1991) immunized with $\mathrm{MBP}_{1-11}$ peptide (Wolf et al., 1996), $\mathrm{MOG}_{35-55}$ peptide or rmMOG protein (Fillatreau et al., 2002) exhibited similar EAE incidence and severity compared to wt controls, however, unlike wt mice, $\mu \mathrm{MT}$ mice failed to recover from acute EAE. Furthermore, mice with B cells deficient in IL-10 or IL-35 also lost their ability to support a recovery from EAE (Fillatreau et al., 2002; Shen et al., 2014) suggesting that B cells may suppress ongoing CNS autoimmunity by secreting IL-10 (Fillatreau et al., 2002) and IL-35 (Shen et al., 2014). However, other studies argued that B10 cells (IL-10 secreting B cell) had no effect on ongoing EAE disease but rather regulated the initiation of the disease (Matsushita et al., 2008, 2010). Notably, B cells of patients with MS were found to secrete decreased level of IL-10 compared to B cells of healthy controls (Duddy et al., 2007).

\subsection{Principles of intravital two-photon microscopy (2PM)}

Two-photon microscopy (2PM) technique provides a powerful tool to visualize and characterize immune responses at the cellular level within the living organism in real time. The theoretical basis of two-photon excitation was established in 1931, when the physicist Maria Göppert-Mayer predicted that as a consequence of the Heisenberg uncertainty principle an atom or a molecule can absorb two photons during the same quantum event within $10^{-16}-10^{-17} \mathrm{~s}$ (Göppert-Mayer, 1931). Because multiphoton excitation requires extremely high light intensities, this prediction could only 


\section{Introduction}

be verified after the advent of laser sources. The first two-photon fluorescence microscope was developed in 1990s by Winfried Denk and his colleagues, who demonstrated optical sectioning in living cells (Denk et al., 1990).

The principle of two-photon excitation is depicted in Fig. 1.2. In conventional confocal microscopy an electron in a fluorescent molecule is excited from the ground state $S_{0}$ to the excited state $S^{*}$ with an ultraviolet or visible photon that matches the energy gap between $S_{0}$ and $S^{*}$ (in figure 1.2 it is a photon of $340 \mathrm{~nm}$ wavelength) (Diaspro et al., 2005). In nanoseconds, the electron returns back to its ground state and emits a longer wavelength photon, losing some energy via vibrational relaxation. This difference between the absorbed and emitted wavelength is known as Stokes shift and varies from one fluorophore to another. In contrast to confocal microscopy, in two-photon excitation an electron is excited to the same excited state $S^{*}$ by absorbing simultaneously two long wavelength photons, typically infrared, to generate one fluorescent photon. The wavelength required to excite a molecule in a two-photon absorption event is approximately twice the wavelength needed to excite the same molecule in a single-photon absorption event. However, this is not completely accurate because different quantum mechanical selection rules apply to two-photon and one-photon excitation events (Svoboda and Yasuda, 2006).

A two-photon excitation event necessitates extremely high photon density of about $10^{30}$ photons $\mathrm{s}^{-1} \mathrm{~m}^{-2}$ (Diaspro et al., 2005). This can be achieved with a high-power continuous wave laser, although this would lead to a high thermal load on the sample. To reduce heating on the sample and still have a high probability of two-photon excitation the illumination light has to be a tightly focused short-pulsed laser (Denk et al., 1990), or in other words, photons arriving at the focus have to be concentrated in time and space.

One advantage of imaging with near infrared light compared to ultraviolet or visible light is that longer wavelength infrared light gets much less absorbed and scattered by biological tissue, owing to the fact that the scattering cross section of a molecule is inversely proportional to the forth power of wavelength (Diaspro et al., 2005). Reduced absorption and reduced scattering allows deep penetration of excitation light in highly scattering biological samples. A further and the main advantage of twophoton microscopy over confocal microscopy is the highly localized excitation. In a confocal microscope emitted fluorescence is detected through a pinhole that rejects scattered light and fluorescence generated out-of-focus. Since biological samples are usually composed of light-scattering material, most of the photons get scattered on their path through the tissue and will be rejected by the pinhole. Consequently, in 


\section{Introduction}

confocal microscopy most of the excited fluorescence is wasted. In contrast, in twophoton microscopy the fluorescence can only be excited at the focus where a large number of photons arrive simultaneously. Since there is no out-of-focus excitation, there is no need for a pinhole in front of the detector and all light emitted from the sample can be collected. The absence of out-of-focus excitation is not only beneficial for the detection of emitted fluorescence, but it also results in reduced photodamage and photobleaching away from the focal plane. Based on these advantages two-photon imaging has been the method of choice for visualizing lymphocyte motility and the interactions between various immune cells within native tissue environment since its introduction in 2002 in the field of immunology (Bousso et al., 2002; Miller et al., 2002; Stoll et al., 2002).

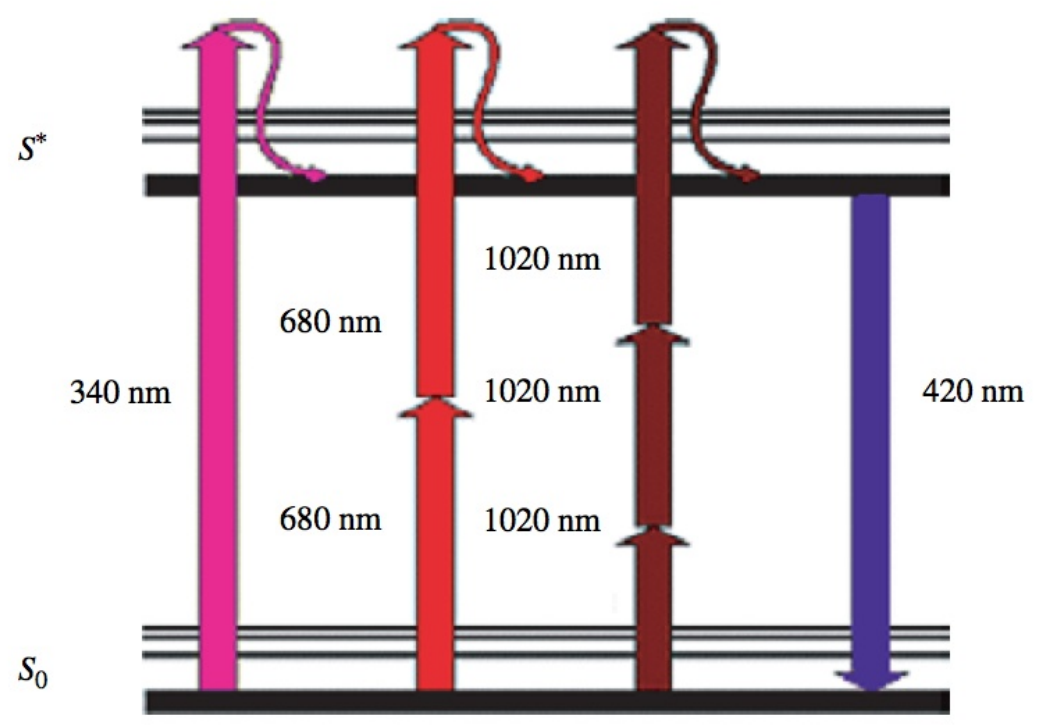

Figure 1.2: Simplified Perrin-Jablonsky diagram of one-, two- and three-photon absorption. An electron can be excited from the ground state $S_{0}$ to the same excited state $S^{*}$ by either absorbing one short-wavelength photon, or two or more long-wavelength photons. In all three cases, the electron relaxes back to the ground state by emitting fluorescence. Figure from Diaspro et al. 2005. 


\section{Aims and objectives}

The aim of this study was to identify the function of MOG-specific B cells in rrMOGinduced EAE.

The objectives were:

1. Establish an rrMOG protein-induced EAE mouse model with a limited number of MOG-specific T and B lymphocytes within an otherwise non-autoimmune system.

2. Evaluate whether or not B cells are pathogenic by testing the effect of B cells on the EAE clinical outcome.

3. Determine whether pathogenic function is based on antigen-presentation capacity of B cells by tracking auto-immune $\mathrm{T}$ and $\mathrm{B}$ cells using intravital two-photon imaging in the priming and effector phases.

4. Determine which effect B cells have on the activation, proliferation and differentiation of $\mathrm{T}$ cells using intravital microscopy, flow cytometry and qPCR analysis.

5. Analyze whether the humoral immune response is the pathogenic function of B cells using transgenic animals with deficient humoral immune response and intravital as well as live cell two-photon imaging. 


\section{Materials and Methods}

\subsection{Standard Buffers and Media}

All standard solutions were prepared in Milli-Q purified water (Merck Millipore). All chemicals were purchased from Merck or Sigma unless stated otherwise.

\section{Ammonium-Chloride-Potassium (ACK) Lysing Buffer}

ACK buffer was prepared by diluting $0.15 \mathrm{M} \mathrm{NH} \mathrm{H}_{4} \mathrm{Cl}, 10 \mathrm{mM} \mathrm{KHCO}_{3}, 0.1 \mathrm{mM}$ EDT A $2 \mathrm{Na}$ in $\mathrm{H}_{2} \mathrm{O}$ and the $\mathrm{pH}$ was adjusted to $7.2-7.4$ with $1 \mathrm{~N} \mathrm{HCl}$.

\section{Decalcification Buffer}

For decalcification $14 \%$ EDTA tetrasodium salt hydrate was added to 1x PBS and the $\mathrm{pH}$ was adjusted to 7.4 with $\mathrm{CH}_{3} \mathrm{COOH}$.

\section{Dulbecco's Modified Eagle Medium (DMEM)}

133.8 g Gibcoß DMEM powder (Life Technologies) was diluted in $10 \mathrm{~L}$ water and supplemented with $37 \mathrm{~g} \mathrm{NaHCO}_{3}$.

\section{Eagle's HEPES (EH) Medium}

133.8 g Gibco@ DMEM powder (Life Technologies) was diluted in $10 \mathrm{~L}$ water and supplemented with $37 \mathrm{~g} \mathrm{NaHCO}$ and 25 mM HEPES (Life Technologies).

\section{FACS-Buffer}

1x PBS was supplemented with $0.1 \%$ BSA (bovine serum albumin, Roth) and $0.1 \%$ $\mathrm{NaN}_{3}$. 


\section{Phosphate Buffered Saline (1x PBS)}

PBS solution was composed of $137 \mathrm{mM} \mathrm{NaCl}, 2.7 \mathrm{mM} \mathrm{KCl}, 10 \mathrm{mM} \mathrm{Na}_{2} \mathrm{HPO}_{4}$ and

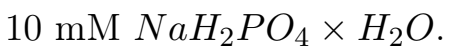

\section{RPMI 1640 Medium}

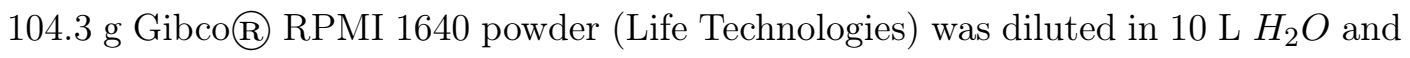
supplemented with $22 \mathrm{~g} \mathrm{NaHCO}_{3}$.

\section{T Cell Medium (TCM)}

TCM was prepared by supplementing DMEM (total volume $1 \mathrm{~L}$ ) with $10 \mathrm{~mL}$ Gibco $\mathbb{R}$ ) minimum essential medium non-essential amino acids (MEM NEAA, 100x, Life Technologies), $10 \mathrm{~mL}$ Gibcoß penicillin/streptomycin (10,000 units/ml penicillin and $10,000 \mathrm{\mu g} / \mathrm{ml}$ streptomycin, Life Technologies), $10 \mathrm{~mL}$ Gibcoß sodium pyrivate (100x, Life Technologies), $10 \mathrm{~mL}$ L-glutamine (PAN-Biotech), $10 \mathrm{~mL}$ L-asparagine monohydrate (Sigma Aldrich), 4 L 2-mercaptoethanol (Roth, $99.9 \%$ ).

\section{T Cell Growth Factor (TCGF)}

TCGF contained $10 \%$ heat-inactivated horse serum (Biochrom AG) and $5 \%$ Concanavalin A supernatant (conditioned medium from splenocytes treated with the mitogen Concanavalin A, in-house production).

\section{ReMed}

ReMed was prepared by supplementing RPMI 1640 (total volume $100 \mathrm{~mL}$ ) with $1 \mathrm{~mL}$ Gibco@ minimum essential medium non-essential amino acids (MEM NEAA, 100x, Life Technologies), $1 \mathrm{~mL}$ Gibcoß) penicillin/streptomycin (10,000 units/ml penicillin and 10,000 $\mathrm{\mu g} / \mathrm{ml}$ streptomycin, Life Technologies), $1 \mathrm{~mL}$ Gibcoß sodium pyrivate (100x, Life Technologies), 1 mL L-glutamine (PAN-Biotech), $0.2 \mu \mathrm{L}$ 2-mercaptoethanol (Roth, $99.9 \%$ ) and $5 \mathrm{~mL}$ heat-inactivated FBS (fetal bovine serum, Biochrom).

\subsection{Experimental Animals}

All animal experiments were carried out according to the regulations for animal welfare of Lower Saxony, Germany. All mice were bred in the animal facility of the University Medical Center Göttingen under specific pathogen-free conditions. The 
following C57/BL6J strains were used: wild-type, $\mathrm{GFP}^{+}$(Okabe et al., 1997), $\mathrm{RFP}^{+}$ (Luche et al., 2007), TCR ${ }^{\mathrm{MOG}}$ (also referred to as 2D2) (Bettelli et al., 2003), IgH $\mathrm{MOG}^{\mathrm{MOG}}$ (also referred to as Th) (Litzenburger et al., 1998), $\mathrm{MHCII}^{-/-}$(Madsen et al., 1999b), mb1Cre (Hobeika et al., 2006), XBP-1 ${ }^{\mathrm{f} / \mathrm{fl}}$ (Hetz et al., 2008), B1.8 (Sonoda et al., 1997), and TCR ${ }^{\text {OVA }}$ (also referred to as OT-II) (Barnden et al., 1998). Furthermore, we crossbred different mutants to produce: Th $\times$ RFP; Th $\times$ GFP; Th $\times$ mb1-Cre $\times$ XBP$1^{\mathrm{f} / \mathrm{fl}} ; \mathrm{B} 1.8 \times \mathrm{RFP} ; 2 \mathrm{D} 2 \times \mathrm{GFP} ; 2 \mathrm{D} 2 \times \mathrm{RFP} ; \mathrm{OT}-\mathrm{II} \times \mathrm{RFP}$.

\subsection{Experimental Procedures}

\subsubsection{T Cells and B Cells Isolation}

Pooled spleens and lymph nodes were forced through a $40 \mu \mathrm{m}$ mesh into the EH medium to prepare a single cell suspension. $\mathrm{CD}^{+} \mathrm{T}$ cells and $\mathrm{B} 220^{+} \mathrm{B}$ cells were obtained by negative immunomagnetic selection using EasySep Mouse T cell enrichment kit and B cell isolation kit (Stemcell Technologies), respectively, according to the manufacturer's instructions. Cell purity was confirmed by flow cytometry and was typically more than $90 \%$.

\subsubsection{CFSE Staining of Lymphocytes}

For quantification of $\mathrm{T}$ cell proliferation in vivo isolated $\mathrm{RFP}^{+} \mathrm{T}$ cells were stained with carboxyfluorescein succinimidyl ester (CFSE, Life Technologies) (Lyons and Parish, 1994). In solution CFSE is membrane permeable and non-fluorescent (Lyons, 2000). Inside the cell it is cleaved by endogenous esterases and becomes membraneimpermeable and highly fluorescent. It binds to intracellular proteins and is halved between daughter cells. A reduction in CFSE mean fluorescence intensity corresponds to a cell division and was detected by flow cytometry. After an isolation procedure as described in 3.3.1, the $\mathrm{T}$ cells were washed twice with $1 \mathrm{x}$ PBS to remove residual FCS and centrifuged at $1200 \mathrm{rpm}$ for $8 \mathrm{~min}$. For CFSE labeling, the T cells were resuspended in $1 \mathrm{x}$ PBS at a density of $10^{6}$ cells $/ \mathrm{mL}$ and incubated for $7 \mathrm{~min}$ at $37^{\circ} \mathrm{C}$ in $0.25 \mathrm{\mu M}$ CFSE. Labeling was stopped by adding $10 \mathrm{~mL}$ FCS, and cells were washed twice in $10 \%$ FCS-containing $1 x$ PBS prior to use. 


\subsubsection{Isolation of Mononuclear Cells from the CNS Tissue Using Percoll Gradients}

Mice were euthanized by $\mathrm{CO}_{2}$ inhalation and transcardially perfused with ice-cold $0.9 \% \mathrm{NaCl}$. The CNS tissue was dissected, homogenized using a syringe plunger and suspended in the percoll dilution buffer ( $1 \mathrm{~g} \alpha$-D $(+)$-glucose monohydrate (Roth), $0.1 \mathrm{~g}$ BSA (bovine serum albumin, Roth) per $100 \mathrm{~mL}$ 1x PBS). Percoll (GE Healthcare Bio-Sciences $\mathrm{AB}$ ) was diluted in the same dilution buffer to the concentrations $30 \%$, $45 \%$ and $70 \%$. The centrifuged cell pellet was resuspended in $6 \mathrm{~mL} 30 \%$ percoll. In a 15-mL falcon (BD Biosciences) $4 \mathrm{~mL} 45 \%$ percoll were added and $2 \mathrm{~mL} 70 \%$ percoll were gently pipetted under the $45 \%$ percoll layer hereby avoiding mixing the two phases. Finally, $6 \mathrm{~mL}$ cell suspension in $30 \%$ percoll were added carefully on top of the $45 \%$ phase. The gradient was centrifuged at $2300 \mathrm{rpm}$ for $20 \mathrm{~min}$ at $4{ }^{\circ} \mathrm{C}$ with minimal brake in order not to disturb the interphases. The myelin on top of the falcon was removed and discarded. Mononuclear cells were collected from both interphases into a new falcon. The cells were washed with 1x PBS and centrifuged at $1200 \mathrm{rpm}$ for $10 \mathrm{~min}$. The cell pellet was resuspended in $100 \mu \mathrm{L}$ FACS buffer and stained with appropriate antibodies.

\subsubsection{Separation of Lymphocytes from Whole Blood}

Blood collected from the tail vein was diluted in $500 \mu \mathrm{L} 1 \mathrm{x}$ PBS containing $1 \mathrm{mM}$ EDTA in an $1.5 \mathrm{~mL}$ Eppendorf tube. With a pipette tip $500 \mu \mathrm{L}$ LSM 1077 (lymphocyte separation medium, GE Healthcare) was carefully poured underneath the blood solution so that the two phases remain clearly separated from each other. For lymphocyte separation, the tube was centrifuged at $1500 \mathrm{rpm}$ for 20 min at $4{ }^{\circ} \mathrm{C}$ with a minimal brake. The lymphocytes built a clearly visible white layer at the interphase between the layers and were extracted and washed in FACS buffer prior to staining for FACS analysis.

\subsubsection{Antigens}

Myelin oligodendrocyte glycoprotein-35-55 peptide (MOG ${ }_{35-55}$, MEVGWYRSPFSRVVHLYRNGK) was purchased from Charité, Universitätsmedizin Berlin. Recombinant rat myelin oligodendrocyte glycoprotein (rrMOG, amino acids 1-125) was prepared as described in (Amor et al., 1994). The rrMOG protein is the extracellular domain of rat MOG and contains the encephalitogenic $\mathrm{MOG}_{35-55}$ peptide. 


\subsubsection{Induction and Assessment of EAE}

Isolated $\mathrm{T}$ and $\mathrm{B}$ cells were administered via the tail vein into the adult male and female mice ( $\geq 10$ weeks of age) two days before immunization. As indicated for each experiment the $\mathrm{T}$ cells were transferred either alone or in combination with $\mathrm{B}_{\mathrm{MOG}}$, $\mathrm{B}_{\mathrm{MOG}-\mathrm{XBP}-1^{-/-}}$or $\mathrm{B}_{\mathrm{NP}}$ cells. In some experiments a control group injected with PBS was included. In rrMOG titration experiment C57BL/6J wt mice were immunized without adoptive cell transfer. Wt and OT-II mice received $2 \times 10^{6} \mathrm{~T}$ cells $\pm 4 \times 10^{6}$ $\mathrm{B}$ cells in combination with $7.5 \mathrm{\mu g}$ rrMOG. In some experiments OT-II mice were injected $3.5 \times 10^{6} \mathrm{~T}$ cells $\pm 10 \times 10^{6} \mathrm{~B}$ cells in combination with $20 \mathrm{\mu g} \mathrm{rrMOG}$.

Two days after adoptive transfer of $\mathrm{T}$ and $\mathrm{B}$ cells the mice were anesthetized by an i.p. injection of ketamine $(80 \mathrm{mg} / \mathrm{kg}$, Medistar $)$ and xylazine $(8 \mathrm{mg} / \mathrm{kg}$, Riemser Arzneimittel). EAE was induced by s.c. injection into the tail base (50 $\mu$ each side) with rrMOG emulsified in complete Freund's adjuvant (CFA). CFA was prepared by mixing $1 \mathrm{mg} / \mathrm{mL}$ heat-inactivated Mycobacterium tuberculosis H37Ra (Difco Laboratories, US) with incomplete Freund's adjuvant (IFA, Difco Laboratories, US). 200 ng pertussis toxin (PTX, List Biological Laboratories, US) was injected i.p. on days 0 and 2 of the immunization.

All immunized mice were weighed and examined for EAE signs daily, starting on day 6 - 7 post immunization. The severity of EAE was assessed according to the following criteria:

Score 0: no obvious motor deficits when the mouse is walking; when mouse is picked up by base of tail, the tail is tensed and hind legs usually spread apart;

Score 1: reduced tail tone; when mouse is walking only the tip of the tail is hanging down;

Score 2: $\quad$ flaccid tail paralysis; when picked up by base of tail, the tail is not moving;

Score 3: absent body righting when walking;

Score 4: gait ataxia;

Score 5: moderate paralysis of the hind extremities;

Score 6: partial paralysis of hind limb or complete paralysis of only one hind leg;

Score 7: complete hind limb paralysis;

Score 8: $\quad$ tetraparesis; 


\section{Materials and Methods}

Score 9: moribund state;

Score 10: dead.

Mice displaying a score of $\geq 5$ were provided with wet food on the floor of the cage for an easy accessibility. For ethical reasons, mice with a score $\geq 7$ were sacrificed.

\subsubsection{Immunohistochemistry}

Animals were euthanized by $\mathrm{CO}_{2}$ inhalation and transcardially perfused with ice-cold $0.9 \% \mathrm{NaCl}$ followed by $4 \% \mathrm{PFA}$. Depending on the experiment, the appropriate organs were dissected and postfixed in $4 \%$ PFA for 1-2 days and then transferred into $30 \%$ sucrose solution in PBS for a further 2 to 3 days. Samples were embedded in Tissue-Tek@ O.C.T. ${ }^{\mathrm{TM}}$ Compound (Sakura) and frozen on dry ice. Frozen tissue was stored by $-20{ }^{\circ} \mathrm{C}$ or cut directly into $12-16 \mu \mathrm{m}$-thick sections using Cryostat Leica CM3050 S. Cryosections were placed onto glass slides (Superfrost@ Plus, Thermo Scientific) and dried at $37{ }^{\circ} \mathrm{C}$ for $30 \mathrm{~min}$ on the Leica HI1220 flattening table. The samples were mounted using Fluoromount-GR) (SouthernBiotech). Images were acquired with Axio Observer Fluorescence Microscope (Zeiss) or with Laser Scanning Confocal Microscope 710 (Zeiss) and processed using AxioVision 4.8 (Zeiss), Zen 2011 (Zeiss) or ImageJ (National Institutes of Health).

For a preparation of paraffin sections samples were routinely embedded in paraffin after fixation in $4 \%$ PFA. For immunohistochemical staining for B220 $3 \mu \mathrm{m}$ thick paraffin sections were deparaffinized and rehydrated. The standard heat-induced antigen retrieval method with sodium citrate was applied before staining with rat anti-mouse B220 antibody (RA3-6B2, BD Pharmingen ${ }^{\mathrm{TM}}$ ) diluted at 1:200.

\subsubsection{Flow Cytometry}

For flow cytometric analysis, cells were resuspended in FACS buffer and stained with appropriate antibodies usually for $15 \mathrm{~min}$ at $4{ }^{\circ} \mathrm{C}$. After washing in FACS buffer, cells were stained with secondary antibody if appropriate $\left(15 \mathrm{~min}, 4{ }^{\circ} \mathrm{C}\right)$. Data were acquired using a FACSCalibur (BD Biosciences) and analyzed using FlowJo V10 (Tree Star, Inc., USA). In this study the following antibodies were used: APC mouse (BALB/c) anti-mouse I-A ${ }^{\mathrm{b}}$ (AF6-120.1, BioLegend), PE mouse anti-mouse I$\mathrm{A}^{\mathrm{b}}$ (AF6-120.1, BD Pharmingen $\left.{ }^{\mathrm{TM}}\right)$, FITC mouse (BALB/c) anti-mouse I-A ${ }^{\mathrm{b}}$ (AF6120.1, BioLegend), APC Armenian hamster anti-mouse CD3ع (145-2C11, BioLegend), $\mathrm{Pe} / \mathrm{Cy} 5$ rat anti-mouse CD4 (H129.19, BioLegend), PE rat anti-mouse CD4 (GK1.5, 
BD Pharmingen ${ }^{\mathrm{TM}}$ ), FITC rat anti-mouse CD8 $\alpha$ (53-6.7, BioLegend), APC rat antimouse/human CD44 (IM7, BioLegend), APC rat anti-mouse CD45R/B220 (RA36B2, BioLegend), PE rat anti-mouse CD45R/B220 (RA3-6B2, BD Pharmingen ${ }^{\mathrm{TM}}$ ), PE hamster anti-mouse CD69 (H1.2F3, BD Pharmingen ${ }^{\mathrm{TM}}$ ), FITC Armenian hamster anti-mouse CD69 (H1.2F3, BioLegend), PE rat anti-mouse CD86 (GL1, BD Pharmingen ${ }^{\mathrm{TM}}$ ), FITC rat anti-mouse CD86 (GL-1, BioLegend), PE rat anti-mouse V $\beta 11$ TCR (RR3-15, BD Pharmingen ${ }^{\mathrm{TM}}$ ), Alexa Fluor@ 647 rat anti-mouse V $\beta 11$ TCR (KT11, BioLegend), FITC rat anti-mouse V $\beta 11$ TCR (RR3-15, BD Pharmingen), PE/Cy5 Streptavidin (Biolegend).

\subsubsection{Anti-MOG Serum ELISA}

Peripheral blood was collected from the tail tip and allowed to coagulate at $4{ }^{\circ} \mathrm{C}$. By centrifugation serum was separated from blood clots and stored at $-20{ }^{\circ} \mathrm{C}$. The titer of anti-MOG protein IgM and IgG in the sera was determined by ELISA. For this, 96-well ELISA plates were coated with $4 \mathrm{\mu g} / \mathrm{mL}$ rrMOG in PBS at $4{ }^{\circ} \mathrm{C}$ over night (total volume $50 \mu \mathrm{L} /$ well). After washing away the unbound antigen with $200 \mu \mathrm{L} /$ well PBS containing $0.05 \%$ Tween ${ }^{\circledR} 20$ (SIGMA-ALDRICH ${ }^{\circledR}$ ), the unoccupied well sites were blocked with $5 \% \mathrm{BSA} / \mathrm{PBS}$ buffer $(1 \mathrm{~h}$ at RT) and washed once more as before. The sera samples were diluted 1:100 and 1:1.000 in blocking buffer and triplicates of each sample were added to the antigen-coated ELISA plate $(50 \mu \mathrm{L}$ per well). After an incubation for $2 \mathrm{~h}$ at RT the unbound sample constituents were washed away. The detection antibody against mouse total IgG or IgM linked to the enzyme horseradisch peroxidase (SIGMA-ALDRICH ${ }^{\circledR}$ ) was diluted 1:250 in blocking buffer $(50 \mu \mathrm{L} /$ well) and incubated with the analyte for $1 \mathrm{~h}$ at RT and washed (6x). For detection of $\operatorname{IgG}$ subclasses antibodies against mouse IgG1, IgG2a, IgG2b and IgG3 (Biolegend) were diluted at 1:500 and incubated with the analyte in the presence of horseradisch peroxidase (Biolegend) diluted at 1:250. Substrate TBM (3,3',5,5'-Tetramethylbenzidine, BD) was added to each well $(100 \mu \mathrm{L} /$ well $)$. After $30 \mathrm{~min}$ at $\mathrm{RT}$ the reaction was stopped by adding $1 \mathrm{M} \mathrm{H}_{2} \mathrm{SO}_{4}$. The color intensity in each well is proportional to the amount of anti-MOG antibody specifically bound and was measured as optical density at $450 \mathrm{~nm}$ (OD $450 \mathrm{~nm}$ ) using Sunrise ${ }^{\mathrm{TM}}$ ELISA plate reader (Tecan) equipped with Megallan $^{\mathrm{TM}}$ data analysis software. 


\section{Materials and Methods}

\subsubsection{Quantitative Real-Time PCR}

The $\mathrm{CD}^{+} \mathrm{V} \beta 11 \mathrm{TCR}^{+} \mathrm{T}$ cells were sorted using BD FACSAria II cell sorter and samples were stored in a mixture of $25 \mu \mathrm{L}$ PBS with $350 \mu \mathrm{L}$ QIAzol ${ }^{\circledR}$ lysis reagent (QIAGEN Sciences, Maryland, USA) at $-80{ }^{\circ} \mathrm{C}$ upon further processing. Total RNA was extracted using the standard Trizol procedure. cDNA was synthesized using RevertAid First Strand cDNA synthesis kit (Thermo Scientific) following the manufacturer's instructions. The RT-PCR was performed with target-specific TaqMan ${ }^{\circledR}$ probes labeled with FAM $^{\mathrm{TM}}$ (6-carboxyfluorescein) and quenched by TAMRA ${ }^{\mathrm{TM}}$ (6-carboxytetramethylrhodamine). Quantitative PCR analysis was performed using StepOnePlus Real-Time PCR system (Applied Biosystems) equipped with StepOnePlus software v2.0. Hypoxanthine phosphoribosyltransferase 1 (HPRT) was used as the house-keeping gene. All samples were assayed in duplicates.

The primer probes were: Hprt; forward, 5'-TGCTCGAGATGTCATGAAGG-3'; backward, 5'-TATGTCCCCCGTTGACTGAT-3'; probe, 5'-ATCACATTGTGGCCC TCTGT-3'. Ifng; forward, 5'-TCAAGTGGCATAGATGTGGAAGAA-3'; backward, 5'-TGGCTCTGCAGGATTTTCATG-3'; probe, 5'-TCACCATCCTTTTGCCAGTT CCTCCAG-3'. Gm-csf; forward, 5'-GGGCGCCTTGAACATGAC-3'; backward, 5'CGCATAGGTGGTAACTTGTGTTTC-3'; probe, 5'-CCCCCCAACTCCGGAAAC GGA-3'. Il1'7a; forward, 5'ACTTTCAGGGTCGAGAAGATGCT-3'; backward, 5'TTCTGAATCTGCCTCTGAATCCAC-3'; probe, 5'-TGGGTGTGGGCTGCACCT GC-3'. Il2; forward, 5'-CAGGATGCTCACCTTCAAATTTT-3'; backward, 5'-CGC AGAGGTCCAAGTTCATCT-3'; probe, 5'-CTTGCCCAAGCAGGCCACAGAATT G-3'. Ccr'7; forward, 5'-CAGCCTTCCTGTGTGATTTCTACA-3'; backward, 5'ACCACCAGCACGTTTTTCCT-3'; probe, 5'-CAGAGCACCATGGACCCAGGGA AAC-3'. Cxcr3; forward, 5'CCAAGCCATGTACCTTGAGGTTAG-3'; backward, 5'-AATCGTAGGGAGAGGTGCTGTTT-3'; probe, 5'-ATGCCTCGGACTTTGCCT TTCTTCTGG-3'. Cxcr4; forward, 5'-ACCTCTACAGCAGCGTTCTCATC-3'; backward, 5'-TGTTGGTGGCGTGGACAATA-3'; probe, 5'-TGGCCTTCATCAGCCTG GACCG-3'. Ccr5; forward, 5'-TGCTCAACCTGGCCATCTCT-3'; backward, 5'CCCACTCATTTGCAGCATAGTG-3'; probe, 5'-CTGCTCTTCCTGCTCACACTA CCATTCTGG-3'. Cer6; forward, 5'-TCGTCCAGGCAACCAAATC-3'; backward, 5'-CCACACTGCCACACAGATGAC-3'; probe, 5'-TTCCGGGTACGCTCCAGAAC ACTGA-3'. 


\subsubsection{Production and fluorescent labeling of monoclonal mouse anti-MOG Ab}

The mouse monoclonal anti-MOG antibody was produced from 8.18-C5 hybridoma cells (Linnington et al., 1984) (kindly provided by Naoto Kawakami, Max Planck Institute of Neurobiology, Ludwig-Maximilians-University, Munich). The supernatant from the 8.18-C5 hybridoma culture was harvested and anti-MOG antibody purified by affinity chromatography using $1 \mathrm{~mL}$ HiTrap protein G High Performance column (GE Healthcare) following manufacturer instructions. The eluted IgG fraction was desalted using the PD-10 desalting column (GE Healthcare). The purified antibody was eluted with PBS. The concentration was determined using NanoDrop (Peqlab) and specificity was tested via ELISA. For imaging experiments purified anti-MOG antibody was conjugated to SeTau-647-di-NHS (SETA BioMedicals) according to the manufacturers instruction. The dye-protein conjugate was separated from nonconjugated dye using PD-10 desalting column (GE Healthcare).

\subsubsection{Generation of $\mathrm{T}_{\text {MOG-NFAT/YFP-mCherry/H2B }}$ cells}

2D2 donor mice were immunized with $100 \mu \mathrm{g} \mathrm{MOG}_{35-55}$ peptide s.c. (tale base and fore limbs) and injected with $200 \mathrm{ng}$ PTX (d0 and d2 p.i.). On d10 p.i. (before onset of clinical EAE) draining lymph nodes were extracted and under sterile conditions forced through a $40 \mu \mathrm{m}$ mesh into the $\mathrm{EH}$ medium to prepare a single cell suspension. The MSCV-NFAT/YFP-Cherry/H2B retrovirus packaging cell line GP + E86 (Markowitz et al., 1988) was generated previously (Lodygin et al., 2013). For T cell transduction, packaging cells irradiated with 30 Gy were seeded at density 15.000 cells/well in a round bottom 96-well plates. Lymphocytes prepared from immunized 2D2 mice (200.000 cells/well) were added to packaging cells and cultured at $5 \% \mathrm{CO}_{2}$ and 37 ${ }^{\circ} \mathrm{C}$ in TCM supplemented with $3 \%$ mouse serum and $10 \mu \mathrm{g} / \mathrm{mL} \mathrm{MOG}_{35-55}$. On day 3 the cells were transferred into a flat bottom 96-well plate and $50 \mu \mathrm{L}$ TCGF was added to each well. On day 8 the cells were pooled and $\mathrm{T}$ cells were isolated as described in 3.3.1.

\subsubsection{Isolation of meningeal APCs}

Animals were sacrificed and immediately perfused transcardially with ice-cold $\mathrm{NaCl}$. Spinal cord tissue was extracted carefully and placed in cold EH medium. The skull was freed from its skin and since a great deal of meninges remain attached to the skull when the brain tissue is removed, the brain was extracted under a dissecting 


\section{Materials and Methods}

microscope (Stemi 2000, Zeiss). The stripped meninges were homogenized using a plastic plunger from a $1 \mathrm{~mL}$ syringe by forcing tissue through a $40 \mu \mathrm{m}$ nylon cell strainer (Stemcell ${ }^{\mathrm{TM}}$ Technologies) in a Falcon tube. For the co-culture with T cells, meningeal cells were suspended in ReMed.

\subsubsection{Live cell two-photon imaging}

$\mathrm{T}_{\text {NFAT }}$ cells and meningeal APCs were placed in a Petri dish $(5 \mathrm{~cm})$ inside a custombuilt chamber that was heated to $36-37^{\circ} \mathrm{C}$ and supplied with humidified carbogen. Time-lapse videos were recorded as described in 3.3.15.4.

\subsubsection{Intravital Imaging}

\subsubsection{Fluorescent Cell Labeling for Intravital Imaging}

For intravital microscopy of popliteal lymph nodes, $\mathrm{RFP}^{+} \mathrm{T}$ or $\mathrm{B}$ cells were additionally stained for $15 \mathrm{~min}$ at $37{ }^{\circ} \mathrm{C}$ with $3 \mu \mathrm{M}$ CMTMR (5-(and-6)-(((4-chloromethyl)benzoyl)amino)tetramethylrhodamine, Molecular Probes) in EH medium to compensate for rapid photobleaching of the tdRFP protein (tandem-dimer red fluorescent protein).

\subsubsection{Preparation of the Popliteal Lymph Node for Intravital Imaging}

$2 \times 10^{6} \mathrm{~T}$ cells and $4 \times 10^{6} \mathrm{~B}$ cells were given to recipients by injection into the tail vein. After $48 \mathrm{~h}$, the mice were anesthetized by an i.p. injection of ketamine (80 mg/kg, Medistar) and xylazine ( $8 \mathrm{mg} / \mathrm{kg}$, Riemser Arzneimittel) and immunized s.c. into the footpad with $7.5 \mu \mathrm{g}$ rrMOG emulsified in CFA. The injection volume was limited to $25 \mathrm{\mu l}$ per footpad. At the same time the mice received i.v. $100 \mathrm{\mu g}$ anti-Lselectin monoclonal antibody Mel-14 (BioXCell). For intravital imaging, immunized mice were initially anesthetized by an i.p. injection of a mixture of dorbene, ketamine and $0.9 \% \mathrm{NaCl}$ to achieve a dose of $1 \mathrm{mg} / \mathrm{kg}$ body weight for dorbene and $100 \mathrm{mg} / \mathrm{kg}$ for ketamine. The surgical plane of anesthesia was monitored by paw pinch reflex. Typically, half of the initial dose was injected i.p. every 60 min during imaging session according to the level of anesthesia. Microsurgical preparation of the popliteal lymph node for intravital microscopy was performed as reported (Mempel, 2010) with some modifications. The hind legs of mice were shaved using a small animal clipper (Pocket Pro, Wahl). Depilation cream was applied briefly to remove all the hair from the area to be surgically exposed. Mice were positioned on the custom-build microscope stage 


\section{Materials and Methods}

and were kept at $36-37^{\circ} \mathrm{C}$ with a built-in heating foil (Telemeter Electronic GmbH, Donauwörth, Germany). Body temperature was constantly monitored with a rectal temperature probe (Telemeter Electronic GmbH, Donauwörth, Germany). An oxygen stream was delivered under controlled pressure to a mask placed in front of the snout. The hind legs were restrained from both sides with sutures around one of the toes on each leg. A skin incision of about $1 \mathrm{~cm}$ was made dorsally, above the popliteal lymph node. Placing plasticine (Idena, Berlin) around the hind leg enabled the skin flaps either side of the incision to be fixed in place, making the area accessible for microsurgical lymph node preparation. The connective and adipose tissue were gently removed with fine forceps and the popliteal lymph node exposed. Care was taken to preserve blood and lymph vessels. During surgical procedure the lymph node was kept moist with $0.9 \% \mathrm{NaCl}$ solution at all times. A ring of vacuum grease around the exposed lymph node was filled with $0.9 \% \mathrm{NaCl}$. A round glass coverslip $(24 \mathrm{~mm}$ $\varnothing$, A. Hartenstein, Germany) was glued to a custom-build metal ring with a holder that was placed on the grease ring (Fig. 3.1). A fine temperature sensor that was coupled to the coverslip ring holder was placed underneath the coverslip to regulate the temperature around $36-37{ }^{\circ} \mathrm{C}$ in the created closed chamber of the popliteal lymph node. A second ring of vacuum grease was applied on top of the coverslip and filled with $0.9 \% \mathrm{NaCl}$ for the immersion of the microscope objective. The temperature in the lymph node pool was continuously monitored and noted for each acquired time-lapse video. Any videos where the temperature was too low or too high were excluded from the analysis due to the fact that lymphocyte motility is known to be extremely temperature sensitive (Miller et al., 2002). 


\section{Materials and Methods}
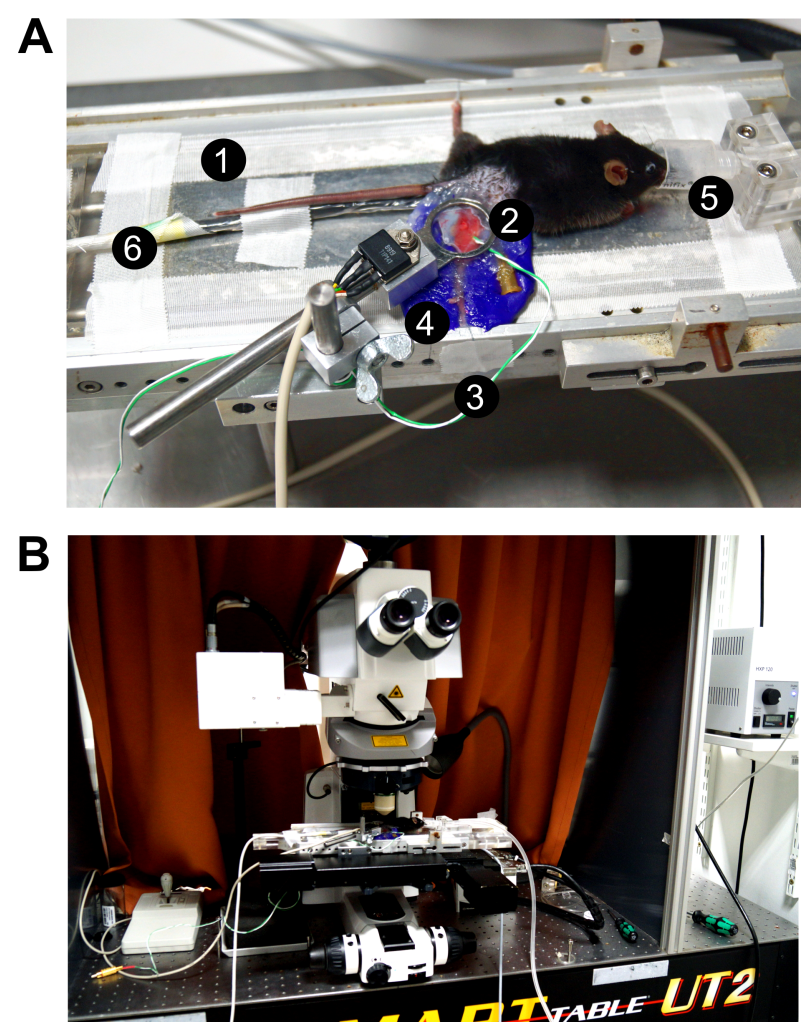

Figure 3.1: Intravital imaging of the mouse popliteal lymph node. (A) Setup for in vivo imaging of the mouse popliteal lymph node. 1. Imaging stage; 2 . Heated metal ring with a glass coverslip; 3. Thermo sensor; 4. Plasticine; 5. Oxygen face mask; 6 . Rectal thermoprobe. (B) Imaging stage under the microscope.

\subsubsection{Preparation of the Mouse Spinal Cord for Intravital Imaging}

For imaging of the spinal cord, EAE was induced as described in 3.3.6. The mouse was anesthetized and placed in a prone position on the heated stage under the dissection microscope as outlined above for intravital imaging in the lymph node. The fur on the back was shaved using small animal clippers (Pocket Pro, Wahl) and a depilation cream applied briefly. The eyes were protected from drying out with Bepanthen (Bayer). An incision of approximately $2 \mathrm{~cm}$ at the level of thoracic vertebrae was performed along the rostrocaudal axis. Tendons and muscle tissue were carefully removed from three adjacent vertebral bodies. Each of them was then mounted from both lateral sides with steel needles in a custom-built frame as depicted in Fig. 3.2. A ring of low-melting agarose $(3.5 \%$ in $0.9 \% \mathrm{NaCl})$ was applied around the surgically exposed area to create a waterproofed pool. A dorsal laminectomy was performed on 


\section{Materials and Methods}

the central of the three mounted vertebrae using a dental micromotor $\left(\right.$ FOREDOM ${ }^{\circledR}$ Electric Co.). The dura mater was removed and the exposed spinal cord immediately covered with sterile $0.9 \% \mathrm{NaCl}$. Finally, the animal on the stage was put under the microscope.
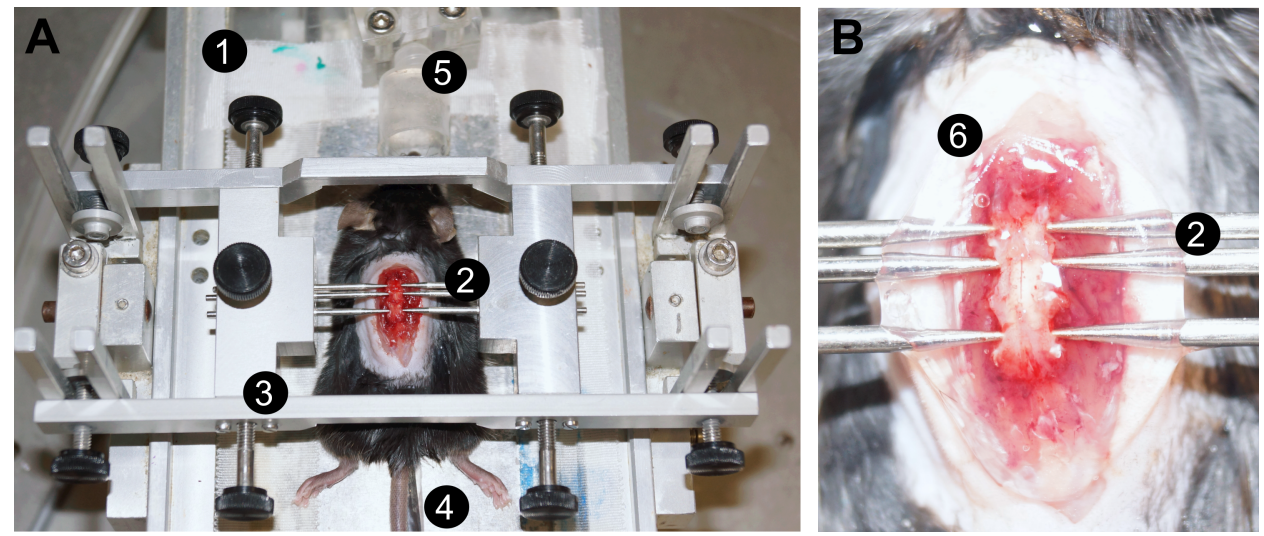

Figure 3.2: Experimental setup for intravital imaging of the mouse spinal cord. (A) For imaging of the spinal cord anesthetized animal was positioned on an imaging stage (1) with a built-in heating pad. (B) Three adjacent vertebral bodies were fixed with needles (2) within a stereotactic frame (3). The body temperature was monitored with a rectal thermoprobe (4) and oxygen provided through the face mask (5). The agarose ring (6) created a pool around the surgically exposed area.

\subsubsection{Image Acquisition}

Intravital imaging was performed using a Laser Scanning Microscope 710 from Carl Zeiss equipped with a 20x Plan-APOCHROMAT water immersion objective with a high numeric aperture (NA 0.95). A modelocked Ti:sapphire Chameleon Vision II laser system from Coherent was tuned to $1010 \mathrm{~nm}$ wavelength for two-photon excitation of GFP, RFP and CMTMR. Excited fluorescence was detected with nondescanned detectors endowed with 550/49-nm and 607/70-nm band-pass filters (Semrock, Inc.). The system was operated with Zen 2009 software (Zeiss). A field of view at the $\mathrm{T} / \mathrm{B}$ border was chosen for the analysis of $\mathrm{T}$ and $\mathrm{B}$ cell migration and interactions in the popliteal lymph node. Typically, 60 cycles of an $80 \mu \mathrm{m}$ stack of images with scan size $512 \times 512$ pixels was recorded spaced $4 \mu \mathrm{m}$ apart in the $z$ axis at $32 \mathrm{sec}$ time intervals with line averaging of two scans. 


\subsubsection{Image Analysis}

Four-dimensional $(x, y, z, t)$ image stacks were exported to TIFF files. $\mathrm{GFP}^{+}$and $\mathrm{RFP}^{+}$cells were tracked manually in all four dimensions using Imaris 7.1.1 software (Bitplane). Manual tracking was preferred to automated mode because with a high number of cells in the field of view automated tracking produced false connections between two different cells and led to other misconnections. Because the tdRFP / CMTMR signal "bled through" into the green channel, it became problematic to track red fluorescent cells. Therefore, we programmed a macro with ImageJ 1.48 (NIH) that was able to subtract the green channel signal from the red channel. The additional functions "despeckle" and "increase signal intensity" improved the quality of raw data quickly and efficiently. This macro was applied to all videos prior to analysis with Imaris software. Motility parameters were subsequently exported into Microsoft Excel and were analyzed using GraphPad Prism 5.04.

\subsubsection{Statistical Analysis}

The animals were randomly assigned to $\mathrm{T}$ cell or TB cell groups and the groups were relatively equal in size. Statistical analysis of EAE parameters were performed using two-tailed nonparametric Mann-Whitney $U$ test or 1way ANOVA nonparametric Kruskal-Wallis test (GraphPad Prism 5.04, San Diego, CA).

$P$ values were annotated as follows:

\begin{tabular}{|c|c|}
\hline$n s$ & $P>0.5$ \\
\hline$*$ & $P \leq 0.05$ \\
\hline$* *$ & $P \leq 0.01$ \\
\hline$* * *$ & $P \leq 0.001$ \\
\hline$* * * *$ & $P \leq 0.0001$ \\
\hline
\end{tabular}




\section{Results}

\subsection{EAE model for tracking autoreactive $T$ and $B$ cells in vivo}

A recent study in our lab provided evidence that MOG-reactive B cells have a diseaseaccelerating effect on the $\mathrm{MOG}_{35-55}$-peptide-induced EAE (Flach, 2014). To determine whether B cells also have a pathogenic role in EAE induced by the extracellular domain of rat MOG protein, which comprises the encephalitogenic $\mathrm{MOG}_{35-55}$ peptide, we sought to establish conditions which would reflect a physiological trigger of an immune response as accurately as possible. The aim was to avoid stimulating the immune system with a physiologically unrealistic amount of antigen. Therefore, C57BL/6J wt mice were immunized with 5, 10, 25 or $50 \mu \mathrm{g}$ rrMOG. The disease severity was dose-dependent in the range between 5 and $25 \mu \mathrm{g}$ (Fig. 4.1). Immunization with $\geqslant 25 \mu \mathrm{g}$ rMOG induced fulminant EAE with $100 \%$ disease incidence. A dose in the range between 5 and $10 \mu \mathrm{g}$ antigen $(7.5 \mu \mathrm{g})$ appeared to be appropriate for induction of mild EAE in C57BL/6J wt mice. Notably, most laboratories immunize with $100 \mu \mathrm{g}$ rrMOG to induce EAE in the same strain of mice (e.g. Oliver et al. 2003).

Development of spontaneous EAE in double-transgenic mice with $\mathrm{T}$ and $\mathrm{B}$ cells specific for the same myelin protein (Bettelli et al., 2006; Krishnamoorthy et al., 2006) suggested a pathogenic role of $\mathrm{B}$ cells in EAE. While an advantage of this model is that EAE develops spontaneously, the main pitfall is that the adaptive immune system comprises almost exclusively potentially auto-aggressive $\mathrm{T}$ lymphocytes and a large number of autoimmune B lymphocytes. The aim of this study was to develop a model which would reflect more accurately the physiological adaptive repertoire with a limited number of autoimmune $\mathrm{T}$ and $\mathrm{B}$ lymphocytes in an otherwise non-autoimmune system. Thus, a limited number of MOG-specific $\mathrm{T}$ cells ( $\mathrm{T}_{\mathrm{MOG}}$ ) (Bettelli et al., 2003) with MOG-specific B cells (B $B_{\mathrm{MOG}}$ ) (Litzenburger et al., 1998) were adoptively transferred into the $\mathrm{C} 57 \mathrm{BL} / 6 \mathrm{~J}$ mice. In addition, in order to track autoreactive $\mathrm{T}$ cells in vivo TCR ${ }^{\mathrm{MOG}}$ mice were crossbred with GFP (Okabe et al., 1997) or RFP 
(Luche et al., 2007) transgenic animals. Similar, for tracking autoreactive B cells IgH $\mathrm{H}^{\mathrm{MOG}}$ mice were crossbred with GFP or RFP mice. Two days after the cell transfer the recipients were immunized with $7.5 \mathrm{\mu g}$ rrMOG emulsified in CFA.

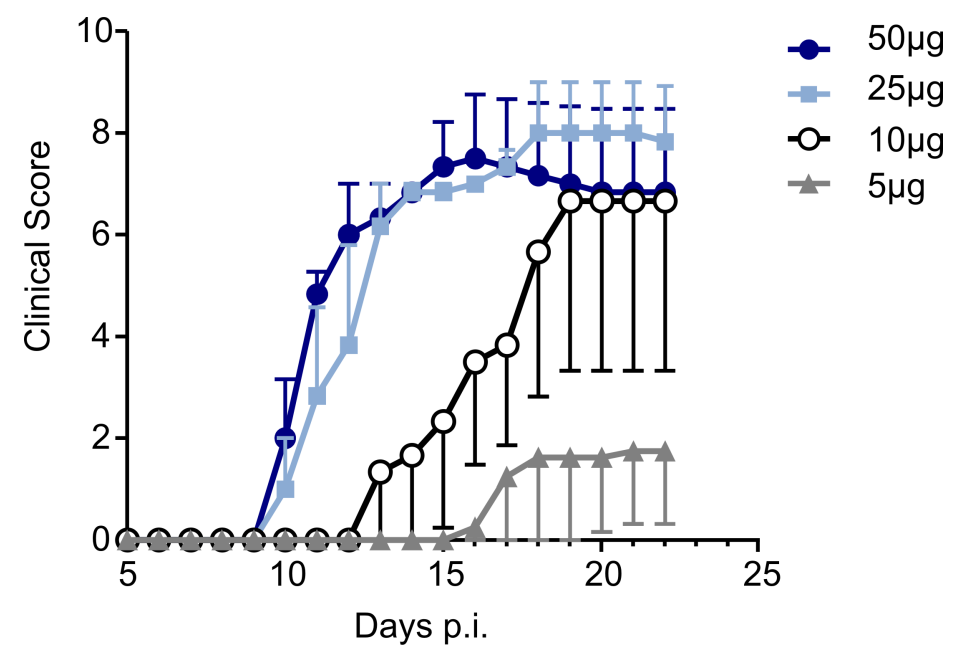

Figure 4.1: Titration of rrMOG protein for induction of a mild EAE course. C57BL/6J wt mice were immunized s.c. with $5,10,25$ or $50 \mu \mathrm{g}$ rMOG $(n=5)$ emulsified in CFA and received $200 \mathrm{ng}$ PTX i.p. on d0 and d2 p.i. Error bars represent SEM. The statistical significance was tested by 1way ANOVA nonparametric Kruskal-Wallis test with Dunn's multiple comparison with following results: $50 \mu \mathrm{g}$ versus $5 \mu \mathrm{g}$ : ${ }^{* * *} P \leq 0.001,25 \mu \mathrm{g}$ versus $10 \mu \mathrm{g}:{ }^{*} P \leq 0.05,25 \mu \mathrm{g}$ versus $5 \mu \mathrm{g}:{ }^{* * *} P \leq 0.001$.

\subsection{Autoreactive B cells increase the risk of a clinical manifestation of EAE and accelerate the disease onset}

To evaluate whether myelin-reactive B cells have a pathogenic effect on the development of rrMOG-induced EAE, $\mathrm{T}_{\mathrm{MOG}}$ cells were injected either alone or in combination with $\mathrm{B}_{\mathrm{MOG}}$ cells into the C57BL/6J mice. PBS-injected control group developed mild EAE symptoms (Fig. 4.2, A, C and D) at a low incidence rate (40 $\pm 20 \%$, Fig. 4.2, E). The disease severity was only moderately aggravated by $T_{M O G}$ cells and the incidence remained at a low level $(33 \pm 18 \%)$. In contrast, the presence of $\mathrm{B}_{\mathrm{MOG}}$ cells significantly exacerbated the disease course and substantially raised the incidence of clinical manifestation to $82 \pm 10 \%$. Furthermore, administration of $\mathrm{TB}_{\mathrm{MOG}}$ cells accelerated the disease onset on average by 4.6 days versus PBS group (10.9 \pm 0.5 versus $15.5 \pm 1.7 \mathrm{~d}$ p.i.) and by 1.9 days versus $\mathrm{T}$ cell group (12.8 \pm 1.8$)$ (Fig. 4.2, 


\section{Results}

B). The accelerated and exacerbated EAE course with an increased disease incidence in the $\mathrm{TB}_{\mathrm{MOG}}$ group suggested a pathogenic role of myelin-reactive B cells in EAE induced by rrMOG protein.
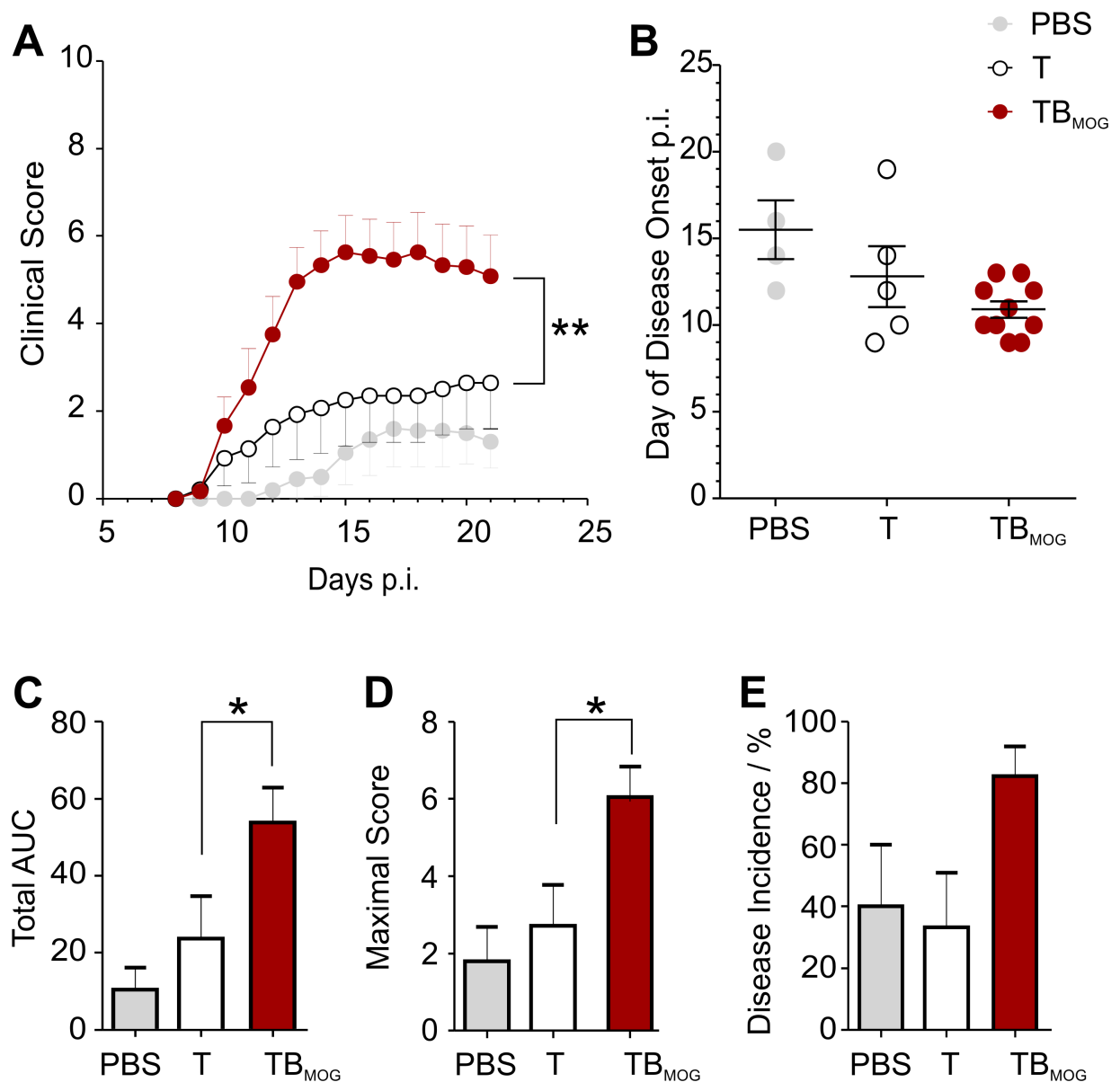

Figure 4.2: Autoreactive $B$ cells increase the risk of a clinical manifestation of EAE in C57BL/6J wt mice and accelerate the disease onset. Mice were randomly assigned to one of the three following groups: 1) $2 \times 10^{6} \mathrm{~T}_{\mathrm{MOG}}, n=14$; 2) $2 \times 10^{6} \mathrm{~T}_{\mathrm{MOG}}+4 \times 10^{6} \mathrm{~B}_{\mathrm{MOG}}$, $n=12$; 3$)$ PBS, $n=10$. The corresponding naive $\mathrm{T}_{\mathrm{MOG}}$ and $\mathrm{B}_{\mathrm{MOG}}$ cells or PBS were injected i.v. two days before immunization. Mice were immunized s.c. with 7.5. $\mu \mathrm{g}$ rrMOG emulsified in CFA and received $200 \mathrm{ng}$ PTX i.p. on d0 and d2 p.i. All parameters for TBMOG versus $T$ group were tested for statistical significance by Mann-Whitney $U$ nonparametric two-tailed test. Results are representative of three experiments. Error bars represent SEM. (A) Mean clinical score; ${ }^{* *} P=0.0058$. (B) Day of disease onset; ns, $P=0.4547$. (C) Total area under the curve (AUC) represents the area between the clinical score curve and the $x$ axis and therefore is the cumulative disease score during the whole period of observation; ${ }^{*} P=0.0449$. (D) Maximal clinical score; ${ }^{*} P=0.0354$. (E) EAE incidence; ns, $P=0.10$. 


\section{Results}

The development of EAE in wt mice after an immunization with myelin antigens is due to the presence of endogenous potentially autoreactive $\mathrm{T}$ cells which get activated upon immunization, expand and invade into the CNS. In order to eliminate the contribution of the endogenous autoreactive $\mathrm{T}$ cell pool, $\mathrm{T}_{\mathrm{MOG}}$ and $\mathrm{B}_{\mathrm{MOG}}$ cells were transferred in OT-II mice (Barnden et al., 1998), which harbor almost exclusively T cells with TCR specific for chicken ovalbumin, TOVA. As expected, these mice did not develop any neurological signs of EAE after an immunization with rrMOG protein (not shown). Yet, OT-II mice were susceptible to EAE when they were injected $\mathrm{T}_{\mathrm{MOG}}$ cells prior to immunization, although the disease onset was very late (d26 p.i.) in response to the low dose $(7.5 \mathrm{\mu g})$ of rrMOG protein (Fig. 4.3). In contrast, mice that received MOG-specific T and B cells developed severe EAE symptoms starting at d7 p.i. Although the difference between $\mathrm{T}$ and $\mathrm{TB}_{\mathrm{MOG}}$ groups was highly significant $\left({ }^{* * * *} P<0.0001\right)$, the limitation of this EAE induction protocol was a very low disease incidence $(40 \%)$ in both groups. This posed a considerable practical difficulty due to the fact that it would require a high number of experimental animals to assess the disease development. Therefore, in order to reliably induce EAE in OT-II mice the amount of antigen was increased to $20 \mathrm{\mu g}$. In addition, the numbers of transferred $\mathrm{T}$ and B cells were increased to $3.5 \times 10^{6}$ and $10 \times 10^{6}$, respectively. The clinical outcome is shown in Fig. 4.4. Both groups, $\mathrm{T}$ and $\mathrm{TB}_{\mathrm{MOG}}$, developed fulminant EAE with nearly $100 \%$ incidence (Fig. 4.4, E). However, in the presence of $\mathrm{B}_{\mathrm{MOG}}$ cells the disease onset was accelerated on average by 3.5 days $(13.3 \pm 0.6$ days p.i. in $\mathrm{T}$ cell group versus $9.8 \pm 0.5$ days p.i. in $\mathrm{TB}_{\mathrm{MOG}}$ group, Fig. 4.4, C). This resulted in a significantly higher cumulative clinical score in the presence of $\mathrm{B}_{\mathrm{MOG}}$ cells (Fig. 4.4, D). The earlier disease onset was accompanied by an earlier body weight loss (Fig. 4.4, B). These results suggested that, as was the case with wt mice, MOG-specific B cells had a disease-promoting effect in OT-II mice. 
4 Results

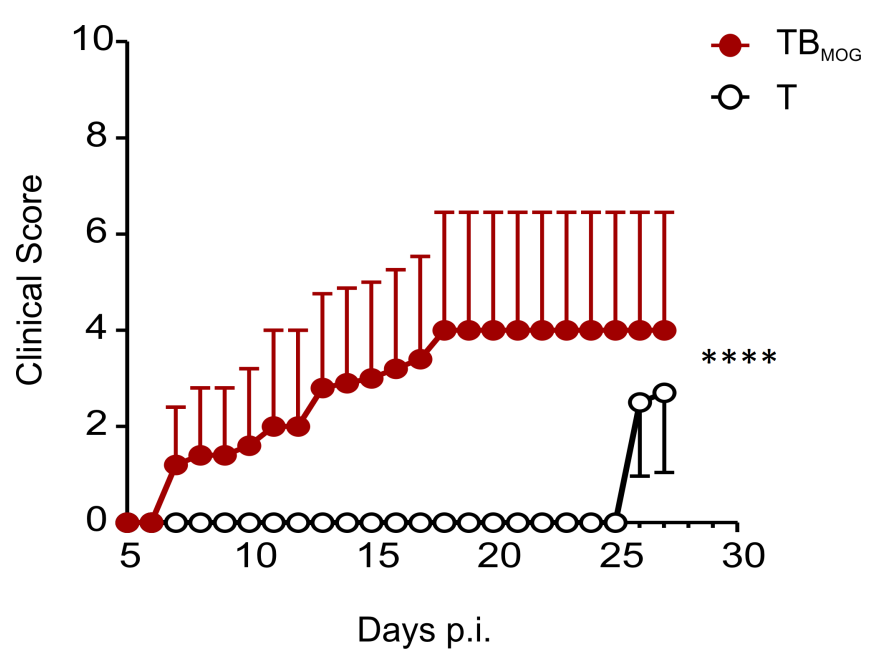

Figure 4.3: The pathogenic effect of MOG-specific B cells on EAE in OT-II TCR transgenic mice in response to a mild antigenic challenge. OT-II mice received either $2 \times 10^{6} \mathrm{~T}_{\mathrm{MOG}}$ cells alone or in combination with $4 \times 10^{6} \mathrm{~B}_{\mathrm{MOG}}$ (both groups $n=5$ ) and were immunized s.c. with $7.5 \mu \mathrm{g}$ rrMOG two days later $(200 \mathrm{ng}$ PTX i.p. on d0 and d2 p.i.). The Mann-Whitney $U$ nonparametric two-tailed test resulted in ${ }^{* * * *} P<0.0001$. Error bars represent SEM. 

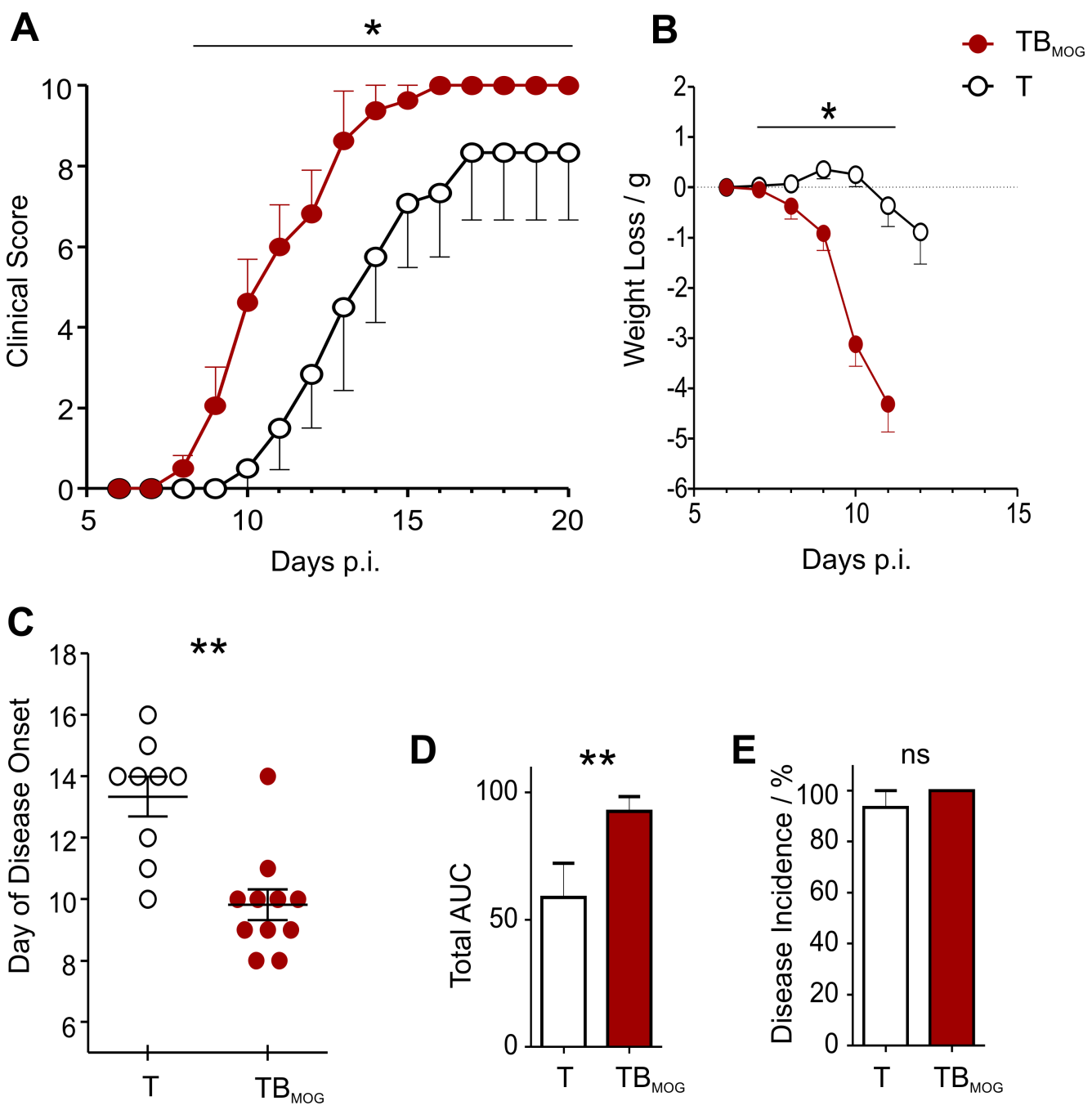

Figure 4.4: MOG-specific B cells accelerate disease onset on OT-II TCR transgenic mice. Mice received i.v. $3.5 \times 10^{6} \mathrm{~T}_{\text {MOG }}$ either alone or in combination with $10 \times 10^{6} \mathrm{~B}_{\text {MOG }}$. Two days later they were immunized s.c. with $20 \mu \mathrm{g}$ rMOG emulsified in CFA and injected i.p. $200 \mathrm{ng}$ PTX on d0 and d2 p.i. All parameters for $\mathrm{TB}_{\mathrm{MOG}}$ versus $\mathrm{T}$ group were tested for statistical significance by Mann-Whitney $\mathrm{U}$ nonparametric two-tailed test. Error bars represent SEM. (A) Mean clinical score; ${ }^{*} P=0.0194$. (B) Body weight loss until the day when none of the mice had to be sacrificed due to severe EAE symptoms; ${ }^{*} P=0.0159$. (C) Day of disease onset; ${ }^{* *} P=0.0018$. (D) Cumulative score or total AUC; ${ }^{* *} P=0.0080$. (E) Disease incidence; ns, $P=0.5050$. Mean clinical score and the cumulative score are representative of two experiments with $n=6$ in the $\mathrm{T}$ group and $n=8$ in TBMOG group. Weight loss, the day of disease onset and disease incidence were calculated from three independent experiments with $n=10$ in the $\mathrm{T}$ group and $n=11$ in TB group (in one of these experiments mice had to be sacrificed for analysis after the onset, therefore the data could not be included in the calculation for clinical disease progression). 


\section{Results}

Notably, the disease-promoting effect of B cells was dependent on BCR specificity. B cells with MOG-unrelated specificity, whose $\mathrm{IgH}$ was generated to react against 4hydroxy-3-nitrophenyl (NP) acetyl hapten $\left(\mathrm{B}_{\mathrm{NP}}\right)$ (Sonoda et al., 1997) had no effect on the course of EAE (Fig. 4.5).

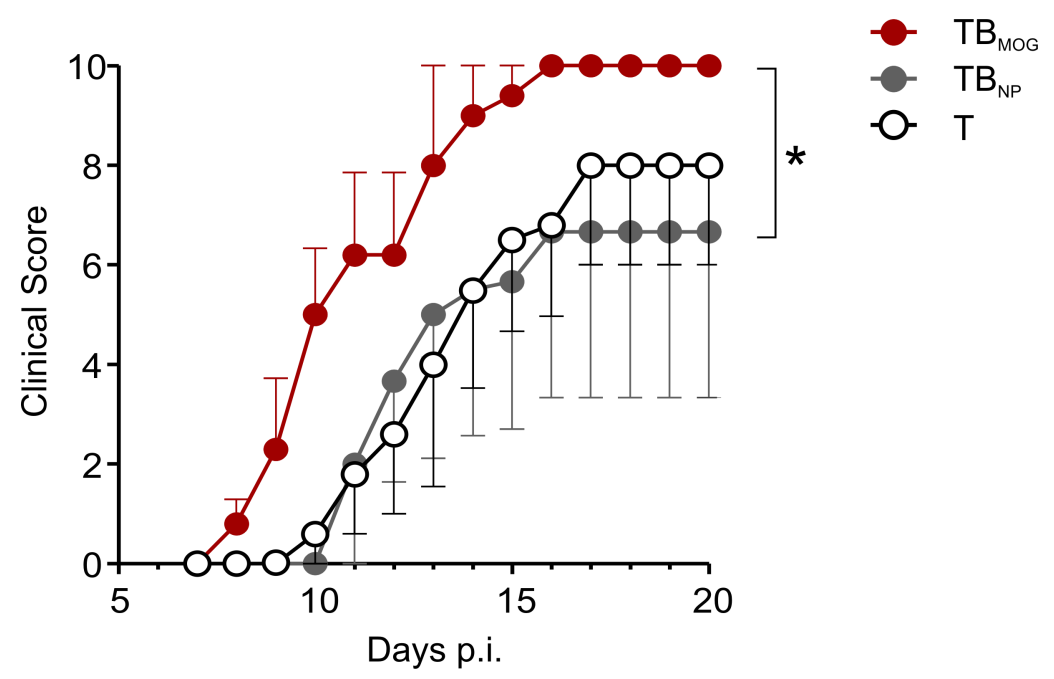

Figure 4.5: The pathogenic effect of $B$ cells is dependent on BCR specificity. $3.5 \times 10^{6} \mathrm{~T}_{\text {MOG }}$ cells were adoptively transferred either alone or in combination with $10 \times 10^{6}$ B MOG $_{\text {or }} B_{N P}$ into OT-II mice ( $n=5$ in each group). Two days later the animals were immunized with $20 \mu \mathrm{g}$ rrMOG emulsified in CFA and injected $200 \mathrm{ng}$ PTX on d0 and d2 p.i. Statistical significance was tested by 1way ANOVA nonparametric Kruskal-Wallis test with Dunn's multiple comparison with following results: $\mathrm{TB}_{\mathrm{MOG}}$ versus $\mathrm{TB}_{\mathrm{NP}}$ : ${ }^{*} P \leq 0.05$. Error bars represent SEM. B cells with BCR specific for NP had no effect on the EAE course.

\subsection{Autoreactive B cells accelerate the invasion of encephalitogenic $T$ cells into the CNS}

To investigate the reason for an accelerated disease onset by MOG-specific B cells, intravital 2PM was implemented to image cellular processes in the lower spinal cord tissue which is known to be preferentially targeted by invading $\mathrm{T}$ cells during EAE.

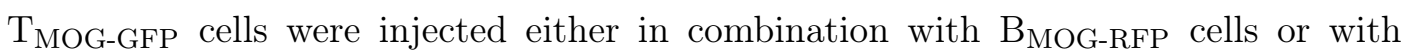
control $B_{\text {NP-RFP }}$ cells. In both groups the first $\mathrm{T}_{\text {MOG-GFP }}$ cells appeared in the CNS before the onset of clinical symptoms of EAE and before animals started to lose body weight. When mice in $\mathrm{TB}_{\mathrm{MOG}}$ group were imaged at $\mathrm{d} 8-9$ p.i. $\mathrm{T}_{\mathrm{MOG}-\mathrm{GFP}}$ cells were detected in the leptomeningeal vessels (Fig. 4.6). There they associated with the vessel wall and crawled along the intraluminal surface, making turns and changing their crawling directions. Occasionally, crawling cells were washed away again by the 


\section{Results}

bloodstream or extravasated through the vascular vessel wall. Transmigrated $\mathrm{T}$ cells initially remained in the close proximity to the blood vessel wall before they resumed their migration within the leptomeningeal milieu. Notably, the vascular leakage for high-molecular weight dextran $(70 \mathrm{kDa})$ was already detectable when $\mathrm{T}$ cells were crawling intraluminal (Fig. 4.7, A), indicating that the BBB was compromised at that time point.

In control animals ( $\mathrm{T}_{\mathrm{MOG}}$ cells alone or $\mathrm{TB}_{\mathrm{NP}}$ ) the process of $\mathrm{T}$ cell invasion into the CNS was delayed and correlated with the delayed disease onset. At d8 - 9 p.i. there were no rolling or crawling $\mathrm{T}$ cells detectable in the leptomeningeal vessels (Fig. 4.6). Instead, TMOG-GFP cells were only visible within the blood stream. In time-lapse videos these $\mathrm{T}_{\text {MOG-GFP }}$ cells appeared in a single frame reminiscent of a "shooting star". This phenomenon is illustrated in the time and maximum-intensity projection image of a 30 min time-lapse video in Fig. 4.6. In addition, at this time point the BBB was not leaky for the $70 \mathrm{kDa}$ dextran (Fig. 4.7, B). Fig. 4.8 shows representative tile scans recorded on $\mathrm{d} 10$ p.i. and demonstrates that the presence of MOG-specific $\mathrm{B}$ cells accelerated the entry of $\mathrm{T}$ cells into the CNS compartment. Notably, despite the fact that $\mathrm{T}$ cells in the absence of $\mathrm{B}_{\mathrm{MOG}}$ cells invaded the CNS several days later, their crawling behavior along the intraluminal space and transmigration was indistinguishable from that of the earlier infiltrating $T$ cells in the group with $\mathrm{B}_{\mathrm{MOG}}$ cells. 


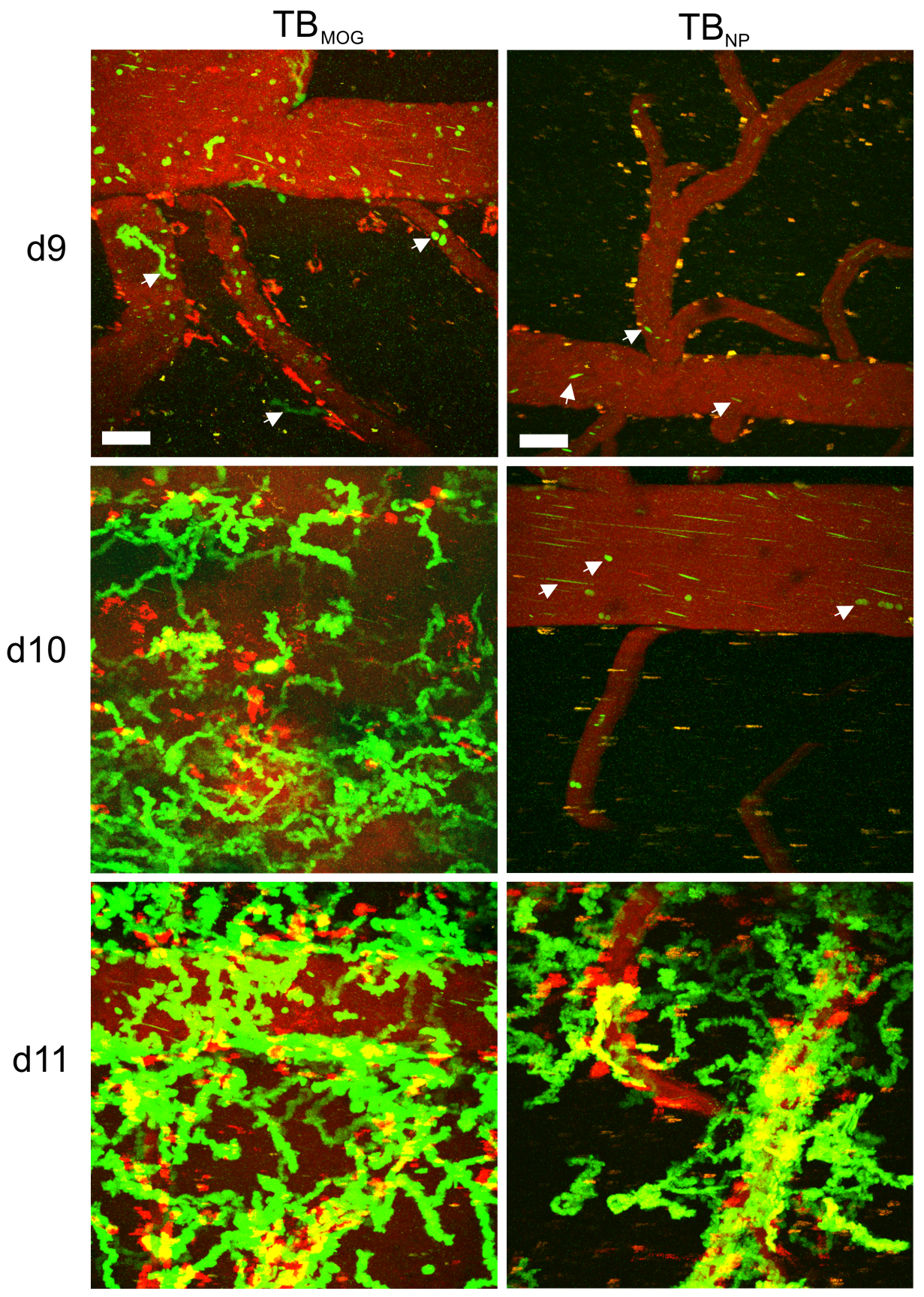

Figure 4.6: Time projections of 30 min recordings of the leptomeningeal blood vessels during the pre-clinical phase and at the disease onset. Depicted here are the pathways covered by crawling TMOG-GFP cells in the presence of BMOG cells and "flashing" $T$ cells passively transported by the blood flow in the control group. Arrows indicate T cells. Scale bars $50 \mu \mathrm{m}$. 


\section{Results}

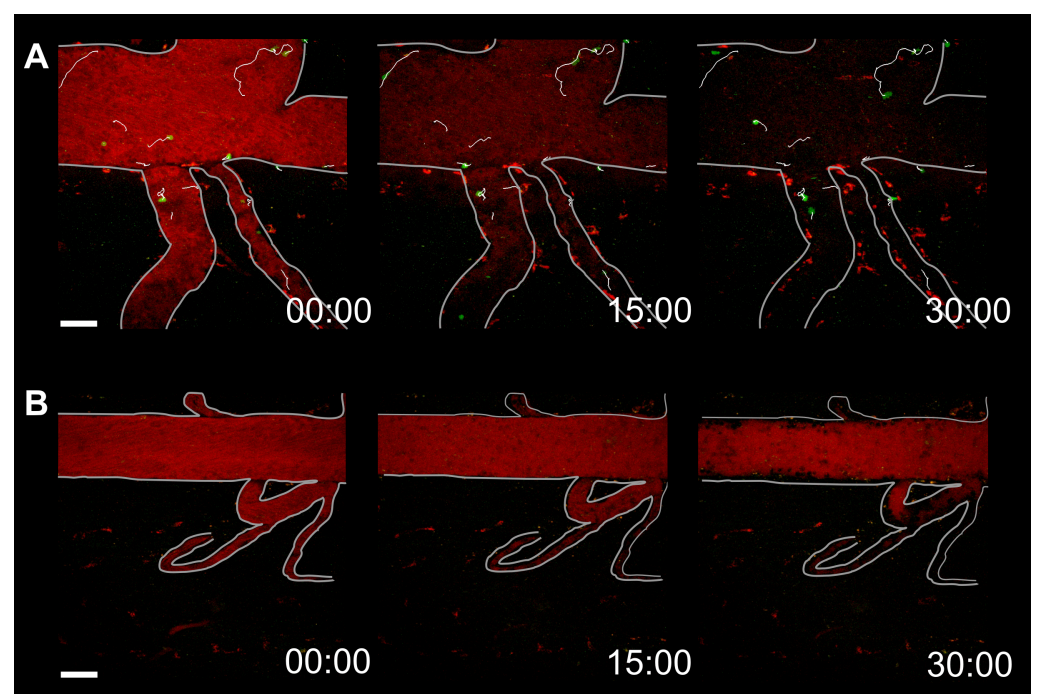

Figure 4.7: The invasion of T cells into the CNS associated with visible disruption of the BBB. Snapshots from 30 min long time-lapse movies recorded by intravital 2PM. Leptomeningeal vessels were visualized with $70 \mathrm{kDa}$ dextran Texas Red administered i.v. instantly prior to starting recording. (A) TBMOG group. Tracks of crawling cells are indicated. $15 \mathrm{~min}$ after the dextran injection the red fluorescence signal within the leptomeningeal vessels was substantially diminished and after 30 min the vessels appeared dark and the dextran was taken up by phagocytic cells along the vessels. (B) TB $B_{N P}$ group. No dextran leakage was detected in the presence of control $B$ cells, $B_{N P}$, when imaged at the same time point as in $\mathrm{TB}_{\mathrm{MOG}}$ group. Scale bars $50 \mu \mathrm{m}$. 

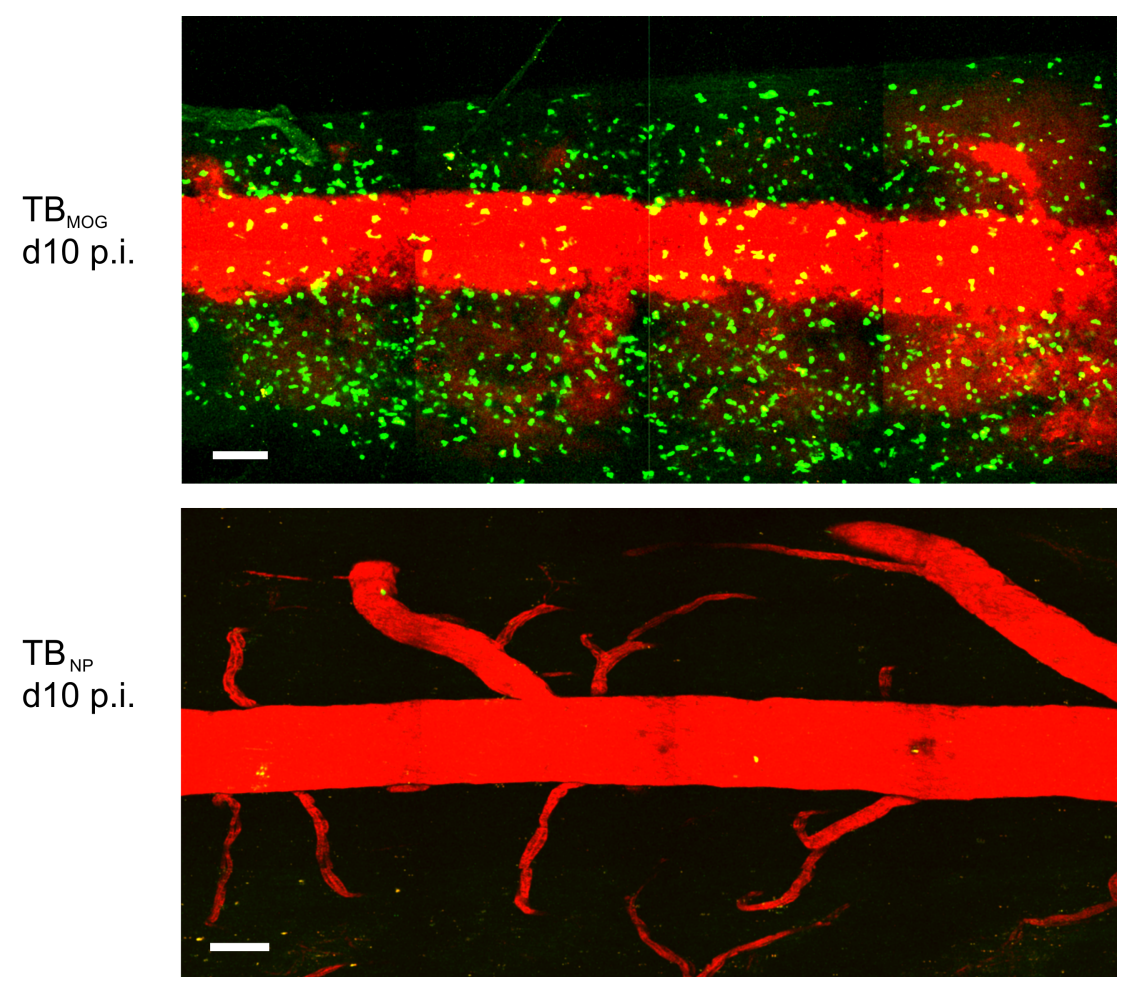

Figure 4.8: Autoreactive B lymphocytes promote the entry of T cells into the CNS compartment. Representative intravital two-photon images of TMOG-GFP cells (green) invading spinal leptomeninges in the pre-clinical phase in the presence or absence of BMOG cells. The blood vessels are visualized by $70 \mathrm{kDa}$ Texas Red dextran. Scale bar $100 \mu \mathrm{m}$.

\subsection{The priming of $\mathrm{T}_{\mathrm{MOG}}$ cells in secondary lymphoid organs is independent of MOG-specific B cells}

\subsubsection{Intravital $2 \mathrm{PM}$ analysis of $\mathrm{T}_{\mathrm{MOG}}$ cells priming in the draining lymph nodes}

Since B cells are well-known to be efficient APCs of their cognate antigen at even extraordinarily low antigen concentrations, we hypothesized that antigen-presentation by $B$ cells could accelerate or enhance $\mathrm{T}_{\mathrm{MOG}}$ cell priming and consequently accelerate the disease onset. To determine whether $\mathrm{T}$ and $\mathrm{B}$ cells formed contacts in the draining lymph node and whether the presence of $\mathrm{B}_{\mathrm{MOG}}$ cells influenced the migration behavior of $\mathrm{T}$ cells intravital imaging was performed within the popliteal lymph node. Previously reported studies demonstrated that $\mathrm{T}$ cell speed changes over time in response 


\section{Results}

to an antigenic challenge (Mempel et al., 2004; Miller et al., 2004). Therefore, we first set out to determine the kinetic of $\mathrm{T}$ cell activation in our model in the draining popliteal lymph node after immunization. Fluorescent $T_{M O G}$ cells were tracked within the popliteal lymph node in anesthetized mice before immunization and in close time intervals (every $10 \mathrm{~h}$ ) after immunization in a $\mathrm{TB}_{\mathrm{MOG}}$ setting (Fig. 4.9). Once we identified the exact time frame when the speed of $\mathrm{T}_{\mathrm{MOG}}$ cells was reduced in the presence of $\mathrm{B}_{\mathrm{MOG}}$ cells, we compared it to $\mathrm{T}_{\mathrm{MOG}}$ cells primed in the presence of control B cells, $B_{N P}$, at the same time point. Naive lymphocytes constantly recirculate between the blood and lymph nodes searching for their cognate antigen. To facilitate a synchronous activation of $\mathrm{T}$ cells in the lymph node any further homing of lymphocytes from the blood into the lymph nodes was blocked at the time of immunization by administering i.v. $100 \mu \mathrm{g}$ anti-L-selectin monoclonal antibody Mel-14 (Mempel et al., 2004). The cell adhesion molecule, L-selectin, is expressed on the surface of naive $\mathrm{T}$ and $\mathrm{B}$ cells, and permits their homing to secondary lymphoid organs via high endothelial venules (Marchesi and Gowans, 1964; Girard and Springer, 1995). In this way it could be ensured that it was only those cells that were present in the lymph node at the moment of immunization were imaged subsequently over time. 


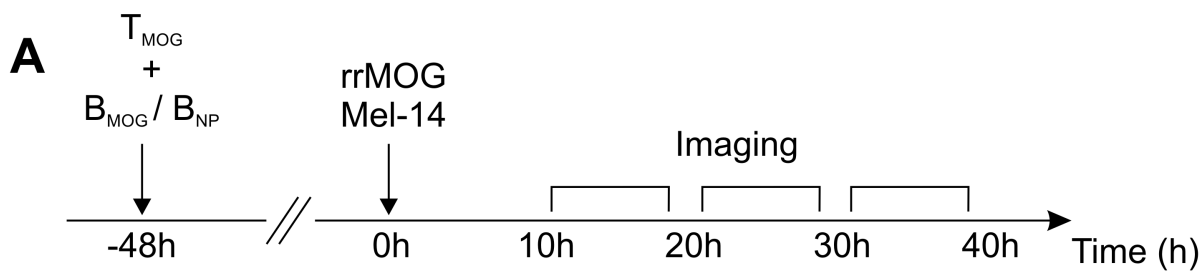

B

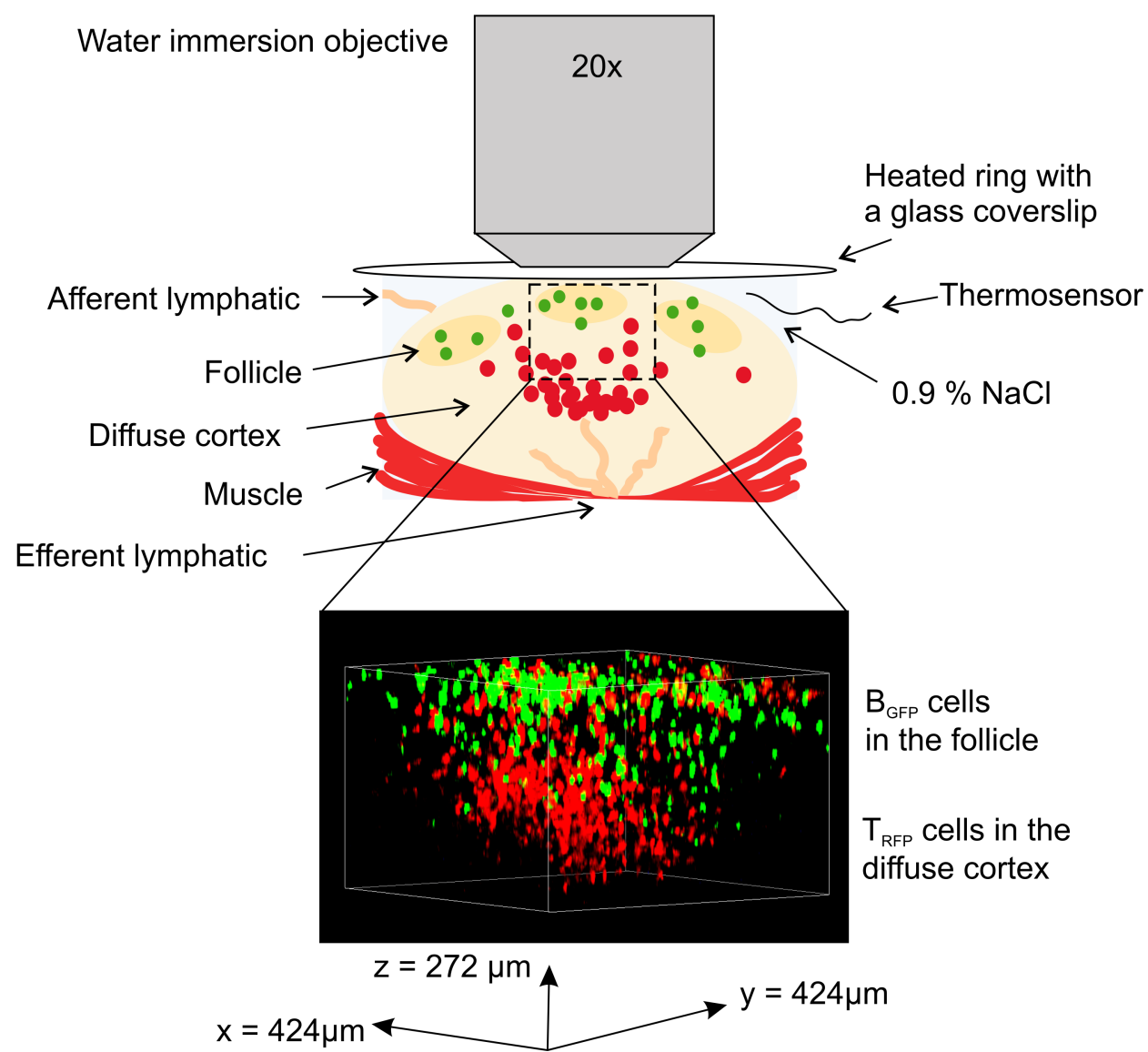

Figure 4.9: Intravital two-photon imaging deep within the intact popliteal lymph node enables analyzing the behavior of fluorescently-labeled myelin-specific $T$ and $B$ cells within the priming phase. (A) Experimental protocol. $2 \times 10^{6} \mathrm{~T}_{\text {MOG }}$ and $4 \times 10^{6}$ B $_{\text {MOG }}$ were injected i.v. into the $\mathrm{C} 57 \mathrm{BL} / 6 \mathrm{~J}$ wt mice. Control mice received $B_{N P}$ cells $\left(4 \times 10^{6}\right)$ instead of MOG-specific $B$ cells. Two days after the adoptive cell transfer, mice were immunized s.c. into the footpad with $7.5 \mu \mathrm{g}$ rMOG $(3.75 \mu \mathrm{g} /$ footpad) and received $200 \mathrm{ng}$ PTX i.p. and $100 \mu \mathrm{g} \mathrm{Mel-14}$. (B) Scheme of surgically exposed popliteal lymph node under an water-immersion microscope objective. $272 \mu \mathrm{m}$ - z stack shows the localization of $\mathrm{T}_{\text {MOG-RFP }}$ and $\mathrm{B}_{\text {MOG-GFP }}$ cells within the $\mathrm{T}$ cell zone and follicles, respectively. 


\section{Results}

Individual cells could be resolved and tracked up to 250 - $300 \mu \mathrm{m}$ beneath the capsular surface (Fig. 4.9, B). As expected, T cells localized mainly to the diffuse cortex and interfollicular areas, whereas B cells motility was restricted to the follicles directly below the surface. $\mathrm{T}$ cells were tracked in all three directions over time. The kinetic of $\mathrm{T}$ cell velocity in the presence of $\mathrm{B}_{\mathrm{MOG}}$ is displayed in a scatter plot in Fig. 4.10 where each dot corresponds to the track of a single cell.

Within each $10 \mathrm{~h}$ interval, the immune response to immunization with rrMOG of $\mathrm{T}_{\mathrm{MOG}}$ lymphocytes in the presence of $\mathrm{B}_{\mathrm{MOG}}$ can be characterized as follows:

1. Naive $\mathrm{T}$ cells were remarkably motile, moving with mean three-dimensional velocity of $12.3 \pm 0.3 \mu \mathrm{m} / \mathrm{min}$ (Fig. 4.10 and Table 4.1). B cells moved considerably slower than $\mathrm{T}$ cells $(7.5 \pm 0.2 \mu \mathrm{m} / \mathrm{min}$, not shown). Both types of lymphocytes moved without an apparent directional bias. The motility behavior of naive $\mathrm{T}$ and $\mathrm{B}$ cells was in good agreement with previously reported data (Mempel et al., 2004; Miller et al., 2004; Okada et al., 2005). As expected, no interactions between naive $\mathrm{T}_{\mathrm{MOG}}$ and $\mathrm{B}_{\mathrm{MOG}}$ cells were observed.

2. Within the first $10 \mathrm{~h}$ after antigenic challenge, $\mathrm{T}_{\mathrm{MOG}}$ cell migration behavior was indistinguishable from the naive situation. They were small in size, similar to naive $\mathrm{T}_{\mathrm{MOG}}$ cells, migrated rapidly and did not cluster. Accordingly, the mean cell speed did not change compared to that of naive $\mathrm{T}_{\mathrm{MOG}}$ cells.

3. Between 10 and $20 \mathrm{~h}$ p.i. $\mathrm{T}_{\mathrm{MOG}}$ cell velocity also did not reduce significantly, nonetheless, a population of cells shifted below the $10 \mu \mathrm{m} / \mathrm{min}$ level $(36.9 \%$, 4.1). This could be partially due to contacts $T_{\text {MOG }}$ cells formed with MOGspecific B cells. At the border between diffuse cortex and primary follicles, $\mathrm{T}_{\mathrm{MOG}}$ and $\mathrm{B}_{\mathrm{MOG}}$ cells formed motile conjugates, with $\mathrm{B}$ cells always leading the $\mathrm{T}$ cell (Fig. 4.11). The speed of $\mathrm{T}_{\mathrm{MOG}}$ cells within the conjugate reduced to that of the leading B cell (from ca. $12 \mu \mathrm{m} / \mathrm{min}$ to $7-8 \mu \mathrm{m}$ ). T-B-interactions often lasted for the entire $30 \mathrm{~min}$ time-lapse movie. However, it was difficult to determine the contact time accurately because T-B-conjugates were highly dynamic and often entered and/or left the field of view as a conjugate. Notably, we regularly observed several T-B-conjugates in each 30 min time-lapse video, however, in relation to the total number of $\mathrm{T}$ and $\mathrm{B}$ cells in the field of view the number of interacting lymphocytes was low.

4. Within 20 - $30 \mathrm{~h}$ p.i. the migration of $\mathrm{T}$ cells and T-B-interactions appeared to be similar to that observed in the previous $10 \mathrm{~h}$ time frame. The $\mathrm{T}$ cells 


\section{Results}

were small in size and did not cluster. However, quantification of the $\mathrm{T}$ cell speed indicated that nearly half of the cells $(47.1 \%)$ reduced their speed below $10 \mu \mathrm{m} / \mathrm{min}$. Accordingly, the mean $\mathrm{T}$ cell speed started to reduce within 20 30 h p.i.

5. At the next stage, $30-40 \mathrm{~h}$ p.i., the appearance and migration of $\mathrm{T}$ cells changed significantly. Initially small and rapidly migrating $\mathrm{T}$ cells turned into large T cells blasts (Fig. 4.12) that were moving with nearly half of their initial speed $(7.6 \mu \mathrm{m} / \mathrm{min})$. The majority of cells $(81 \%)$ moved with the speed below $10 \mu \mathrm{m} / \mathrm{min}$. At this stage we observed that $\mathrm{T}$ cells clustered in the diffuse cortex, suggestive of $\mathrm{T}$ cells interacting with $\mathrm{DCs}$ (that were not co-visualized here). $\mathrm{B}_{\mathrm{MOG}}$ cells were not involved in these clusters. T-B-conjugates, similar to the conjugates described at previous time points, were also observed here. Motile $\mathrm{T}$ cells blasts often stopped, adopted a round shape, and divided within 20 30 min. Immediately after division, daughter cells parted and became motile.

6. By $40 \mathrm{~h}$ p.i. half of the $\mathrm{T}$ cells $(52.7 \%)$ resumed their fast migration and the mean velocity increased to $9.8 \mathrm{\mu m} / \mathrm{min}$. T cells blasts continued dividing.

After establishing the kinetic of $\mathrm{T}$ cell activation in the presence of $\mathrm{B}_{\mathrm{MOG}}$, we analyzed $\mathrm{T}$ cell motility in the presence of control $\mathrm{B}$ cells $\left(\mathrm{B}_{\mathrm{NP}}\right)$ within the time frame when we expected the $\mathrm{T}$ cell speed to be reduced (30 - 40 h p.i.). As anticipated, we did not observe any interactions between $\mathrm{B}_{\mathrm{NP}}$ and $\mathrm{T}_{\mathrm{MOG}}$ cells after immunization with rrMOG. Importantly, the velocity of $\mathrm{T}$ cells was indistinguishable from that of $\mathrm{T}$ cells primed in the presence of $B_{M O G}$ cells $\left(7.4 \pm 0.3\right.$ in $\mathrm{TB}_{\mathrm{NP}}$ versus $7.6 \pm 0.2 \mu \mathrm{m} / \mathrm{min}$ in $\mathrm{TB}_{\mathrm{MOG}}$ setting, Fig. 4.10, $\mathrm{B}$ and Tab. 4.2). Furthermore, T cells became blasts around $30 \mathrm{~h}$ p.i., similar to what we had observed in the presence of $\mathrm{B}_{\mathrm{MOG}}$ cells. These data suggested that the antigen-specific T-B-interactions had no effect on the initial activation of $\mathrm{T}$ cells in the draining lymph nodes. The reduction of $\mathrm{T}$ cell speed was an antigen-specific response and was not triggered by the adjuvant as this effect was not observed in response to the control antigen OVA (Fig. 4.10, B and 4.2). 


\section{Results}
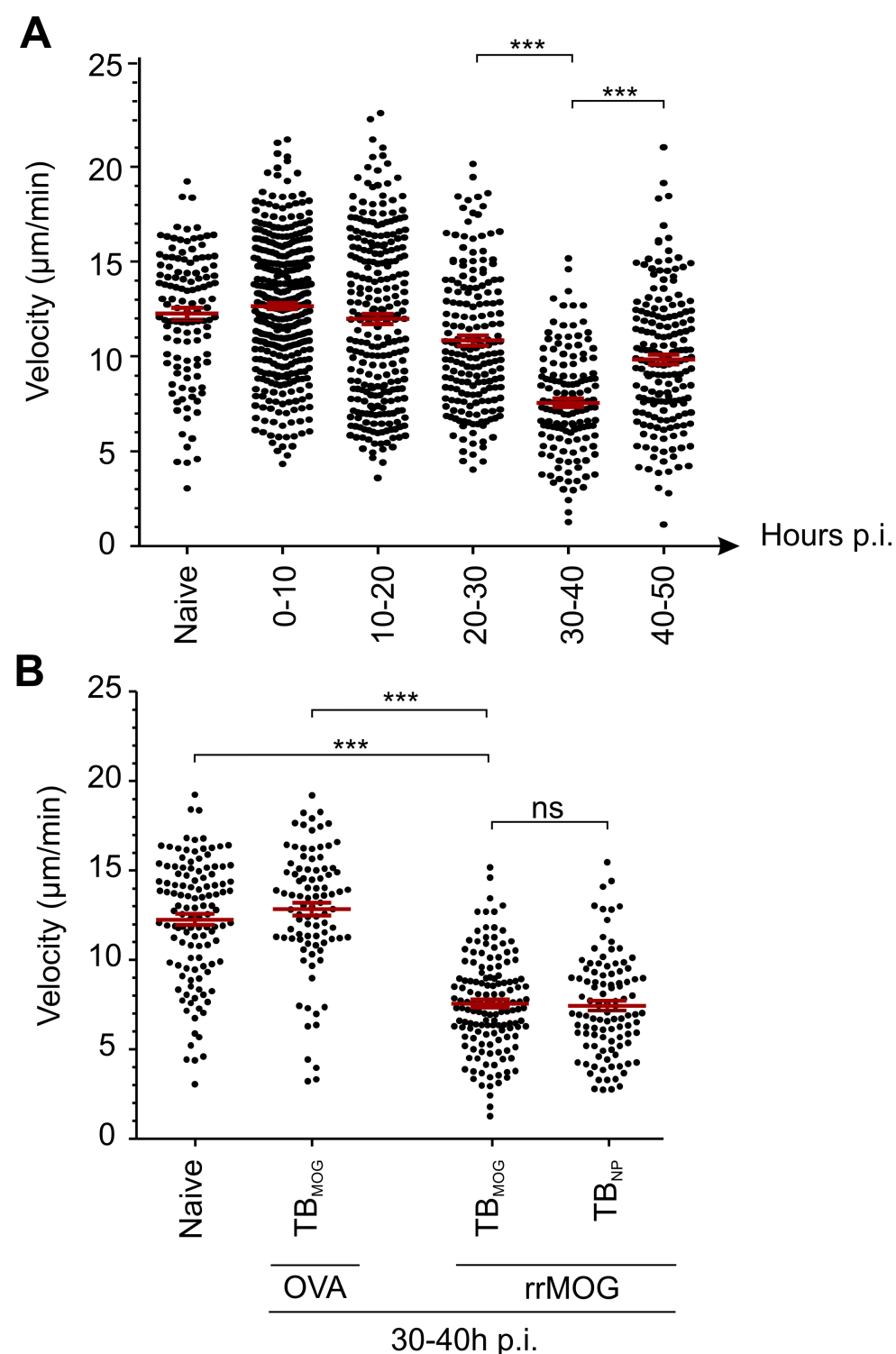

Figure 4.10: Migration behavior of $T_{M O G}$ cells in the presence of $B_{M O G}$ or $B_{N P}$. The experimental setup was as depicted in Fig. 4.9, A. (A) The kinetic of mean $\mathrm{T}_{\mathrm{MOG}}$ cell speed during priming phase in the presence of $B_{M O G}$ cells in response to $7.5 \mu \mathrm{g}$ rMOG protein. All parameters were tested by 1way ANOVA nonparametric Kruskal-Wallis test and Dunn's multiple comparison. Statistical significance was detected between the following successional groups: $20-30 \mathrm{~h}$ versus $30-40 \mathrm{~h}^{* * *} P \leq 0.001$ and $30-40 \mathrm{~h}$ versus 40 - $50 \mathrm{~h}^{* * *} P \leq 0.001$. Error bars represent SEM. (B) $30-40 \mathrm{~h}$ after challenge with rrMOG the speed of $T$ cells in the presence of MOG-specific B cells was identical to the speed of $T$ cells primed in the presence of NP-specific B cells. T cell speed in both groups, $\mathrm{TB}_{\mathrm{MOG}}$ and $\mathrm{TB}_{\mathrm{NP}}$, was significantly lower $\left({ }^{* * *} P \leq 0.001\right)$ than in the naive setting or after challenge with the control antigen OVA. 


\section{Results}
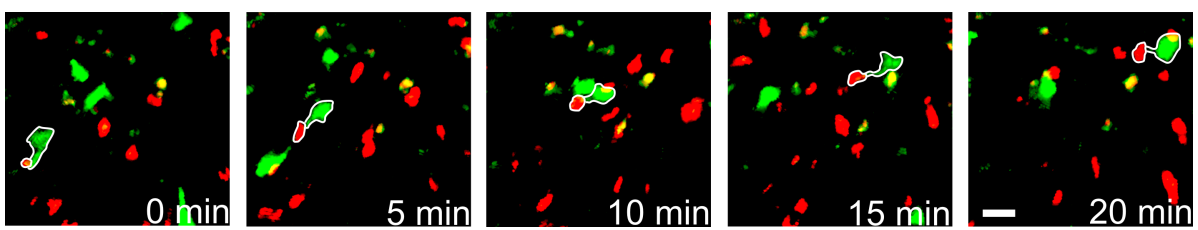

Figure 4.11: $B_{M O G}$ cells form long-lasting motile conjugates with $T_{M O G}$ cells after immunization with rrMOG protein. Sequential images in 5 min time intervals demonstrate a representative T-B-conjugate with B cell (green) leading the T cell (red). Scale bar is $20 \mu \mathrm{m}$.

naive

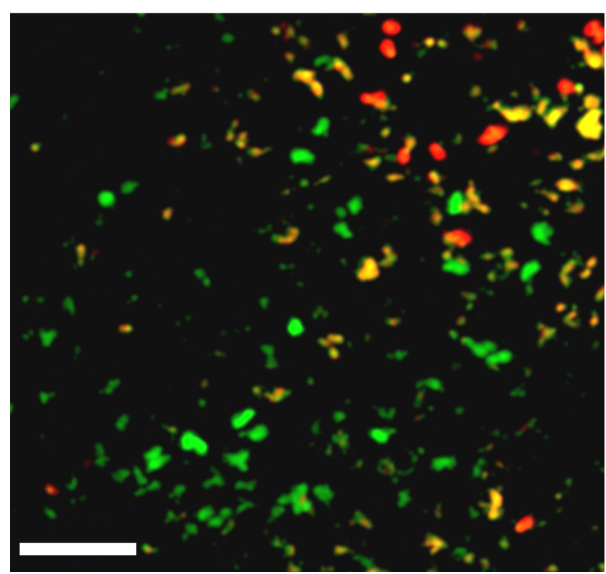

30h p.i.

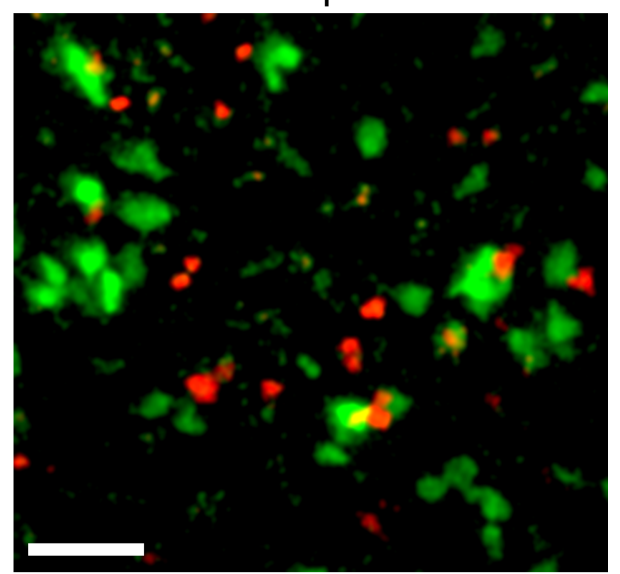

Figure 4.12: Upon activation small naive $\mathrm{T}_{\mathrm{MOG}}$ cells transform into large blasts. Intravital twophoton images. Scale bar $50 \mu \mathrm{m}$. Green: $\mathrm{T}_{\mathrm{MOG}}$ cells; red: $\mathrm{B}_{\mathrm{MOG}}$ cells.

\begin{tabular}{|c|c|c|c|c|c|c|}
\hline Time p.i. & naive & $0-10 \mathrm{~h}$ & $10-20 \mathrm{~h}$ & $20-30 \mathrm{~h}$ & $30-40 \mathrm{~h}$ & $40-50 \mathrm{~h}$ \\
\hline $\begin{array}{c}\text { Mean speed } \\
(\mu \mathrm{m} / \mathrm{min}) \\
\pm \mathrm{SEM}\end{array}$ & $12.3 \pm 0.3$ & $12.7 \pm 0.2$ & $12.0 \pm 0.3$ & $10.8 \pm 0.3$ & $7.6 \pm 0.2$ & $9.8 \pm 0.3$ \\
\hline $\begin{array}{c}\% \text { of cells } \\
\text { below } \\
10 \mathrm{~m} / \mathrm{min}\end{array}$ & 26.4 & 21.5 & 36.9 & 47.1 & 81.3 & 52.7 \\
\hline
\end{tabular}

Table 4.1: 3D mean T cells velocities at different time points after immunization with rrMOG in the presence of MOG-specific B cells. 


\begin{tabular}{|c|c|c|c|c|}
\hline Time p.i. & $\mathrm{n} / \mathrm{a}$ & \multicolumn{3}{|c|}{$30-40 \mathrm{~h}$} \\
\hline Cells transferred & $\mathrm{TB}_{\mathrm{MOG}}$ & $\mathrm{TB}_{\mathrm{MOG}}$ & $\mathrm{TB}_{\mathrm{MOG}}$ & $\mathrm{TB}_{\mathrm{NP}}$ \\
\hline Antigen & naive & OVA & rrMOG & rrMOG \\
\hline Mean velocity $(\mu \mathrm{m} / \mathrm{min}) \pm \mathrm{SEM}$ & $12.3 \pm 0.3$ & $12.8 \pm 0.4$ & $7.6 \pm 0.2$ & $7.4 \pm 0.3$ \\
\hline
\end{tabular}

Table 4.2: The decrease in $T$ cell motility in the draining lymph nodes was antigen-specific and $B_{M O G}$-cell independent.

\subsubsection{Myelin-specific activation and proliferation of $T$ cells is not enhanced by myelin-reactive $B$ cells}

Observation of long-lasting interactions between $\mathrm{T}_{\mathrm{MOG}}$ and $\mathrm{B}_{\mathrm{MOG}}$ cells raised the question of whether or not these direct contacts made an impact on $\mathrm{T}$ cells activation or proliferation. As described above, in time-lapse videos recorded by intravital imaging it appeared that $\mathrm{T}$ cells became blasts and started to divide around the same time, regardless of the presence or absence of $\mathrm{B}_{\mathrm{MOG}}$ cells. To quantify activation parameters draining lymph nodes were extracted after intravital microscopy and cell size and upregulation of the early activation marker, CD69, were characterized. Forward scatter (FSC), measured by flow cytometry is roughly proportional to the size of the cell. Thus, the enlargement of $\mathrm{T}$ cell blasts was estimated by comparing the FSC mean over time. Fig. 4.13 (A) demonstrates how the T cell population shifts upwards in the dot plot over time following an antigenic challenge. Quantification (4.13, B and C) of FCS mean and CD69 surface expression showed no difference between T cells in the $\mathrm{TB}_{\mathrm{MOG}}$ and those in the control group. The cell-adhesion molecule, CD44, is also known to be upregulated when naive $\mathrm{T}$ cells get activated but with a slower kinetic than CD69. Consistent with FCS and CD69 measurements, the CD44 high population of $\mathrm{T}$ cells (Fig. 4.13, D) also did not significantly differ in either group. Thus, these data suggests that the presence of $\mathrm{B}_{\mathrm{MOG}}$ cells did not affect activation of $\mathrm{T}_{\mathrm{MOG}}$ cells in the draining lymph nodes. 


\section{Results}

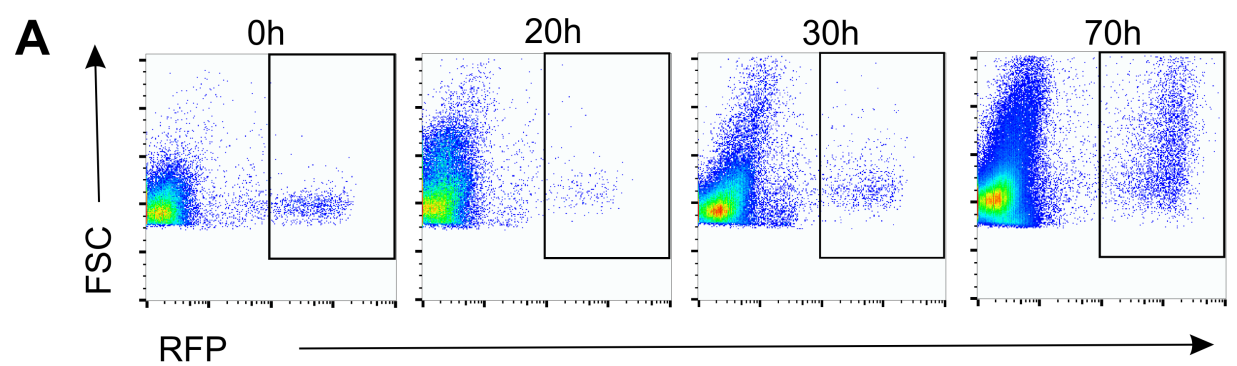

B

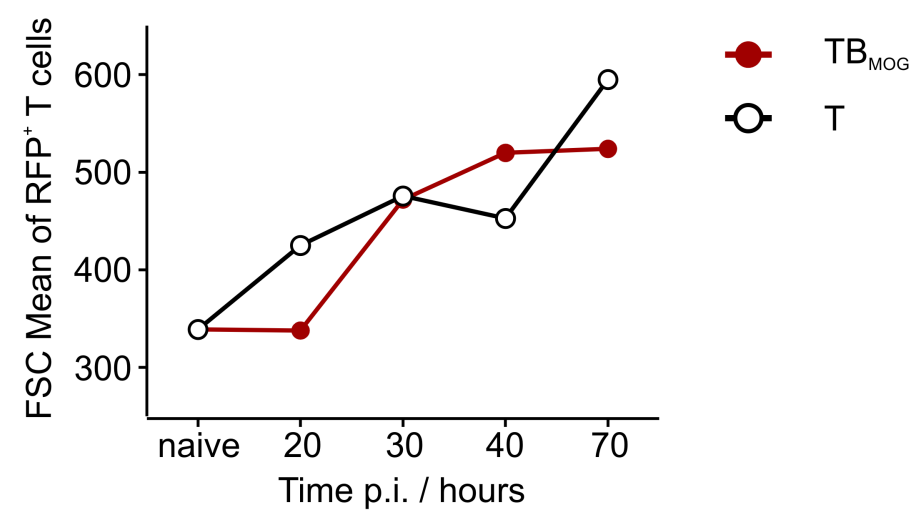

C

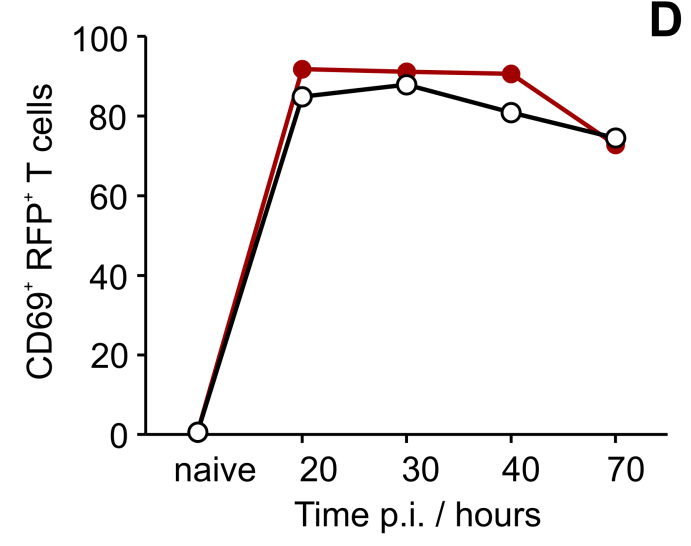

D

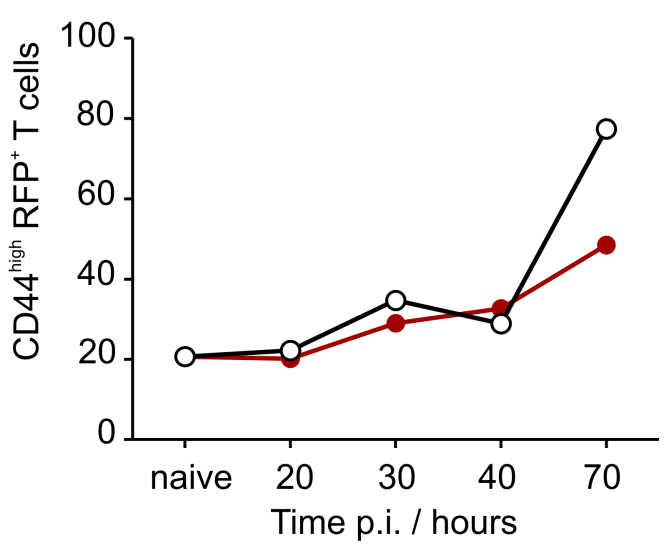

Figure 4.13: $B_{M O G}$ cells did not accelerate or enhance $T$ cell activation in the priming phase. C57/BL6J wt mice were injected i.v. $2 \times 10^{6}$ TMOG-RFP either alone or in combination with $4 \times 10^{6}$ BMOG-GFP. $48 \mathrm{~h}$ after transfer, mice were immunized with $7.5 \mu \mathrm{g}$ rrMOG/mouse s.c. into footpad. $200 \mathrm{ng}$ PTX were administered i.p. on the day of immunization (and d2 p.i. in mice that were analyzed 70 h p.i.). Cell diameter ( $A$ and $\mathrm{B})$ and surface expression ( $C$ and $\mathrm{D}$ ) were analyzed by flow cytometry. All parameters were tested for statistical significance by Mann-Whitney $U$ nonparametric two-tailed test. The difference did not reach statistical significance.

To determine whether $\mathrm{T}$ cells interaction with $\mathrm{B}_{\mathrm{MOG}}$ cells resulted in a more efficient proliferation of $\mathrm{T}$ cells after the priming phase, $\mathrm{RFP}^{+} \mathrm{T}_{\mathrm{MOG}}$ cells were stained with 


\section{Results}

CFSE dye (Lyons and Parish, 1994) before the transfer. 3d after immunization CFSE dilution in lymphocytes gated on $\mathrm{RFP}^{+} \mathrm{T}$ cells was measured by flow cytometry. The CFSE-dilution histograms in Fig. 4.14 show that in both groups $\mathrm{T}$ cells underwent extensive division and the percentage of proliferated $\mathrm{T}$ cells was identical (73\% in $\mathrm{TB}_{\mathrm{MOG}}$ versus $72.4 \%$ in $\mathrm{TB}_{\mathrm{NP}}$ ).

In addition, $\mathrm{T}_{\text {MOG-GFP }}$ cells were quantified in secondary lymphoid organs (draining and non-draining lymph nodes, spleen) and other organs such as lung, liver and the gut using flow cytometry. No significant differences were detectable between the mice that received $\mathrm{T}$ cells either alone or in combination with $\mathrm{B}_{\mathrm{MOG}}$ or $\mathrm{B}_{\mathrm{NP}}$ cells (not shown). These findings were further supported by histological analysis in C57BL/6J wt and in OT-II hosts. Fig. 4.15 shows representative images of the draining lymph nodes $3 \mathrm{~d}$ p.i. acquired by confocal microscopy (note that in contrast to the experiments described above, $\mathrm{T}$ cells used in this experiment were $\mathrm{GFP}^{+}$and $\mathrm{B}$ cells were $\mathrm{RFP}^{+}$). Thus, these data suggested that the presence of $\mathrm{B}_{\mathrm{MOG}}$ cells did not promote $\mathrm{T}$ cell proliferation.
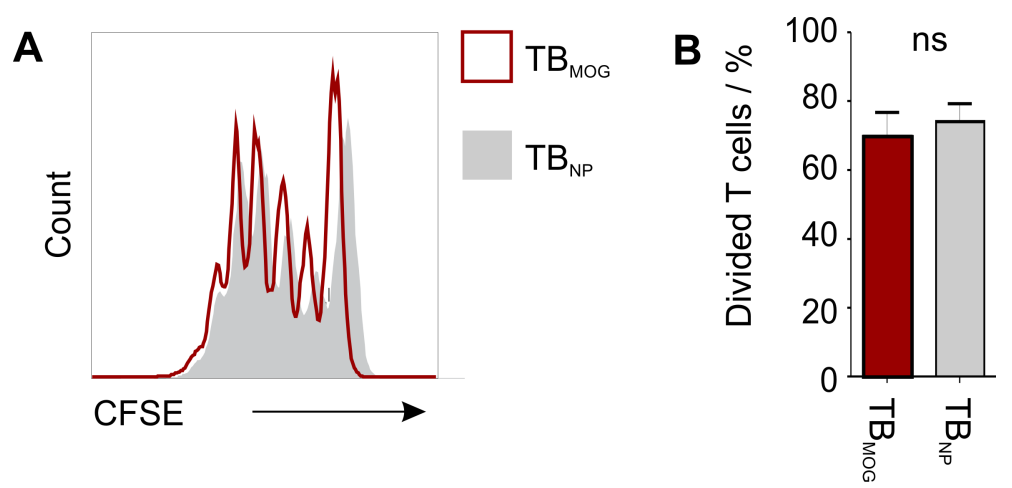

Figure 4.14: Presence of $B_{M O G}$ cells had no effect on $T$ cell proliferation. C57/BL6J wt mice were injected i.v. $2 \times 10^{6} \mathrm{~T}_{\text {MOG RFP/CFSE }}$ with $4 \times 10^{6} \mathrm{~B}_{\text {MOG }}$ or $\mathrm{B}_{\mathrm{NP}}$ cells. $48 \mathrm{~h}$ after cell

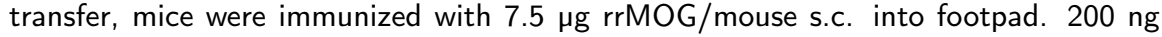
PTX were administered i.p. on d0 and d2 p.i. CFSE dilution was measured by flow cytometry on d3 p.i. in draining lymph nodes (popliteal lymph nodes). Statistical significance was tested by Mann-Whitney $U$ nonparametric two-tailed test. 


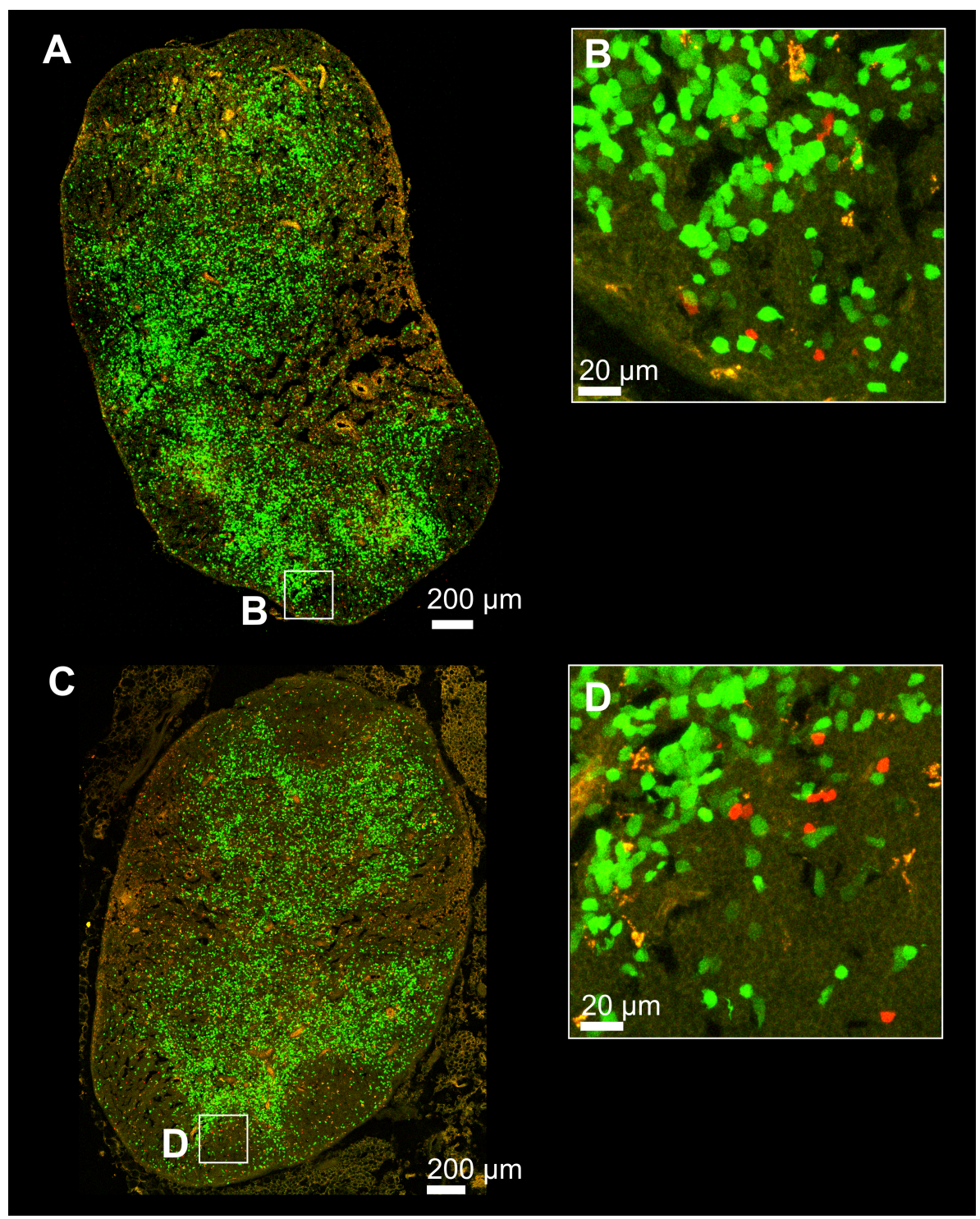

Figure 4.15: Expansion of TMOG-GFP cells in the draining lymph nodes. OT-II mice were injected

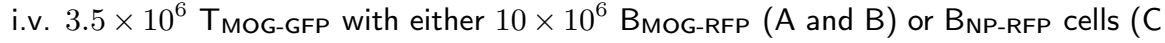
and D). $2 \mathrm{~d}$ after cell transfer, mice were immunized with $20 \mu \mathrm{g} r \mathrm{rMOG} / \mathrm{mouse}$ s.c. at the tail basis. $200 \mathrm{ng}$ PTX were administered i.p. on d0 and d2 p.i. Inguinal lymph node were cut in $20 \mu \mathrm{m}$-thick cryosections on d 3 p.i. Images represent maximum intensity projections of $20 \mu \mathrm{m}$ z-stacks, acquired with a confocal microscope at $4 \mu \mathrm{m}$ space intervals. 


\subsubsection{MOG-specific B lymphocytes did not influence the expression profile of pro-inflammatory cytokines or of chemokine receptors in $\mathrm{T}_{\text {MOG }}$ cells}

To determine whether $\mathrm{B}_{\mathrm{MOG}}$ cells had an effect on the proinflammatory cytokine expression profile in $\mathrm{T}_{\mathrm{MOG}}$ cells (IFN- $\gamma$, IL-17, GM-CSF and IL-2) quantitative RTPCR was performed on $\mathrm{T}_{\mathrm{MOG}}$ cells isolated from the draining lymph nodes after the priming phase (d5 p.i.). As shown in Fig. 4.16 no significant difference was detectable between the $\mathrm{T}$ cells primed in the presence of $\mathrm{B}_{\mathrm{MOG}}$ cells and those $\mathrm{T}$ cells isolated from both control groups $\left(\mathrm{T}_{\mathrm{MOG}}\right.$ alone or $\left.\mathrm{TB}_{\mathrm{NP}}\right)$. Furthermore, the extent of upregulation of various chemokine receptors previously described to be involved in the transmigration process through the blood brain barrier was investigated. The mRNA expression levels of CXCR3, CXCR4, CCR5, CCR6 and CCR7 were compared. However, no significant change in their expression profile was detected here either. Thus, this experiment indicated that $\mathrm{B}_{\mathrm{MOG}}$ cells did not promote a pro-inflammatory gene expression profile nor did they enhance the expression of genes that could account for an earlier $\mathrm{T}$ cell invasion into the CNS. 


\section{Results}

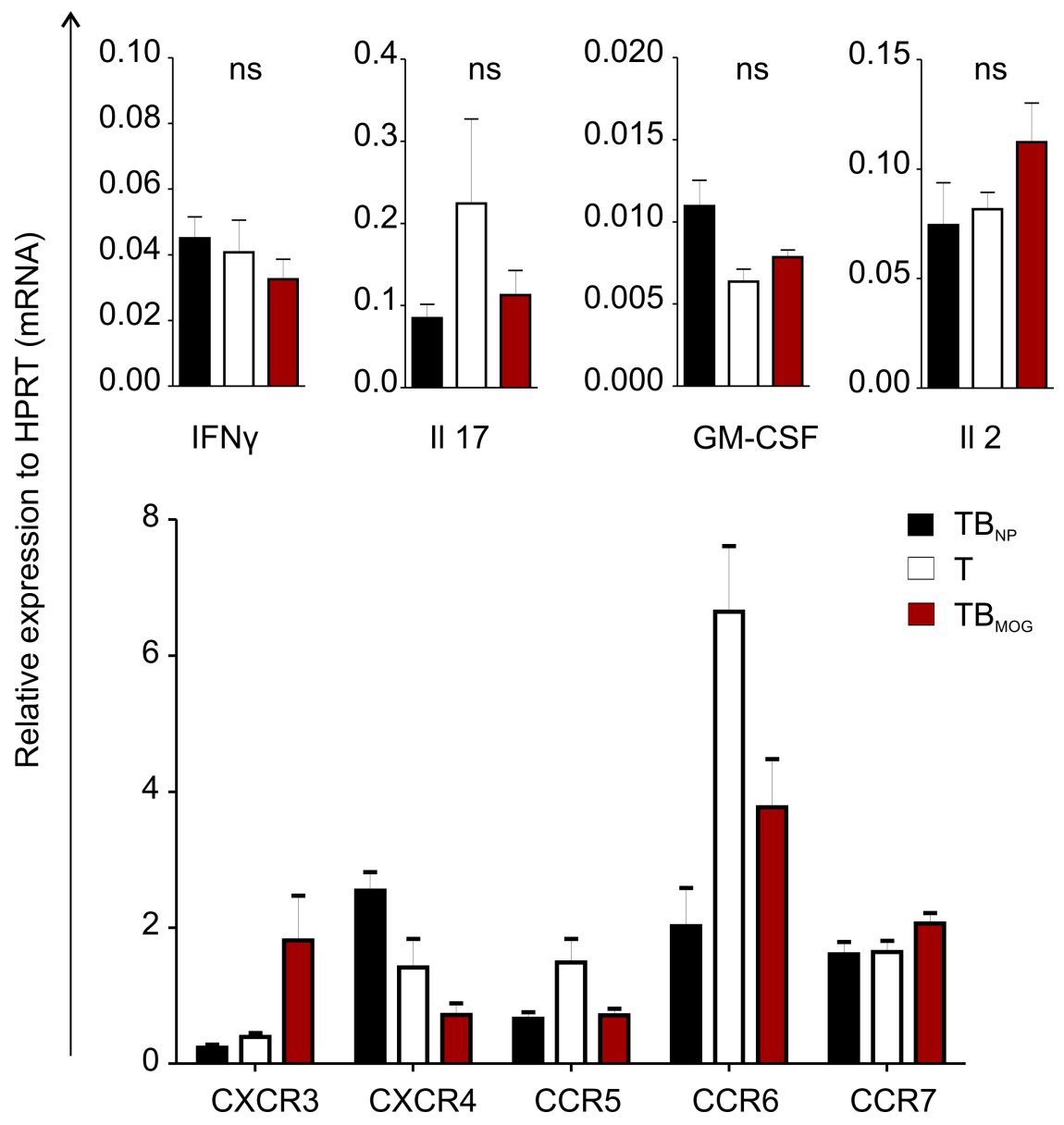

Figure 4.16: $B_{M O G}$ cells did not influence the expression profile of proinflammatory cytokines or of the chemokine receptors in $\mathrm{T}_{\text {MOG }}$ cells. $3.5 \times 10^{6} \mathrm{~T}_{\text {MOG }}$ cells and $10 \times 10^{6} \mathrm{~B}_{\mathrm{MOG}}$ cells were adoptively transferred into OT-II host. Two control groups received either $3.5 \times 10^{6} \mathrm{~T}_{\text {MOG }}$ cells alone or in combination with $10 \times 10^{6} \mathrm{~B}_{\mathrm{NP}}$ cells. Two days later mice were immunized with $20 \mu \mathrm{g}$ rrMOG and received PTX on d0 and d2 p.i. In addition mice received i.v. $100 \mu \mathrm{g}$ anti-L-selectin monoclonal antibody Mel-14. On d5 p.i. $\mathrm{CD}^{+} \mathrm{V} \beta 11 \mathrm{TCR}^{+} \mathrm{T}_{\mathrm{MOG}}$ cells were sorted from the draining lymph nodes and RTPCR of the indicated genes was performed. All parameters were tested by 1way ANOVA nonparametric Kruskal-Wallis test and Dunn's multiple comparison. All comparisons were statistically not significant.

\subsubsection{Antigen-specific activation of $B_{M O G}$ cells}

Naive B cells get activated and upregulate MHCII and co-stimulatory molecule CD86 upon an encounter with their cognate antigen. Antigen-specific interactions with $\mathrm{T}$ cells provide B cells with cytokine signals necessary for their survival and proliferation (Mills and Cambier, 2003). We measured by flow cytometry the activation status of 


\section{Results}

B cells in our model 3d after immunization with $7.5 \mu \mathrm{g}$ rrMOG. MOG-specific B cells expressed a higher level of MHCII and CD86 on their surface compared to NP-specific $\mathrm{B}$ cells (Fig. 4.17) indicating an antigen-specific activation of B cells.

Although, MOG-specific B cells were activated they did not proliferate in secondary lymphoid organs in response to $7.5 \mu \mathrm{g}$ (Fig. 4.18, C, D) or $20 \mu \mathrm{g} \mathrm{rrMOG}$ (not shown). Only after a challenge with a higher dose of antigen (50 $\mathrm{gg}$ rrMOG) did we detect a substantial proliferation of $\mathrm{B}$ cells in follicles in the draining lymph nodes at $\mathrm{d} 5$ p.i. (Fig. 4.18, A, B). These data suggest that the proliferation of B cells was not absolutely required to insert their disease promoting effect.

A
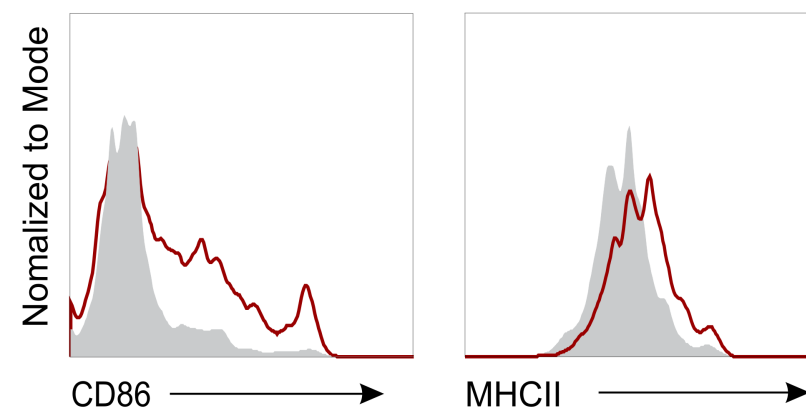

B
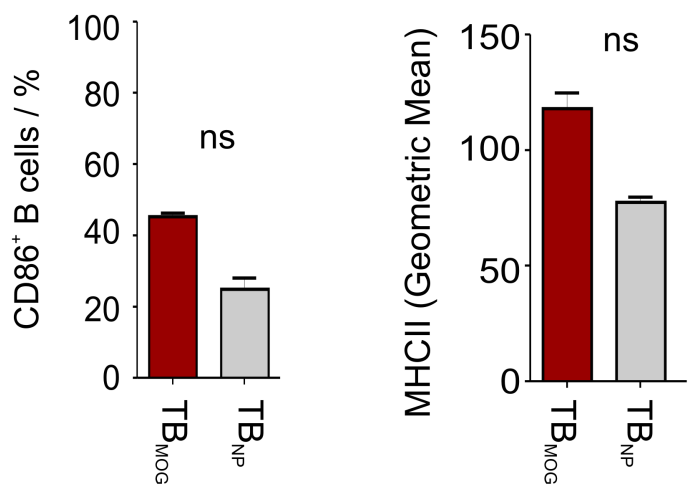

Figure 4.17: Antigen-specific activation of B cells. C57/BL6J wt mice were injected i.v. $2 \times 10^{6}$ $\mathrm{T}_{\text {MOG }}$ with $4 \times 10^{6} \mathrm{~B}_{\text {MOG-RFP }}$ or $\mathrm{B}_{\text {NP-RFP }}$ cells $(n=3$ in each group). Mice were immunized with $7.5 \mu \mathrm{g}$ rMOG and received $200 \mathrm{ng}$ PTX i.p. on d0 and d2 p.i. The surface expression of activation markers was measured by flow cytometry on $\mathrm{d} 3 \mathrm{p}$.i. in draining lymph nodes (A) and quantified (B). Both parameters were tested for statistical significance by Mann-Whitney $U$ nonparametric two-tailed test. The difference did not reach statistical significance. Error bars in (B) represent SEM. 

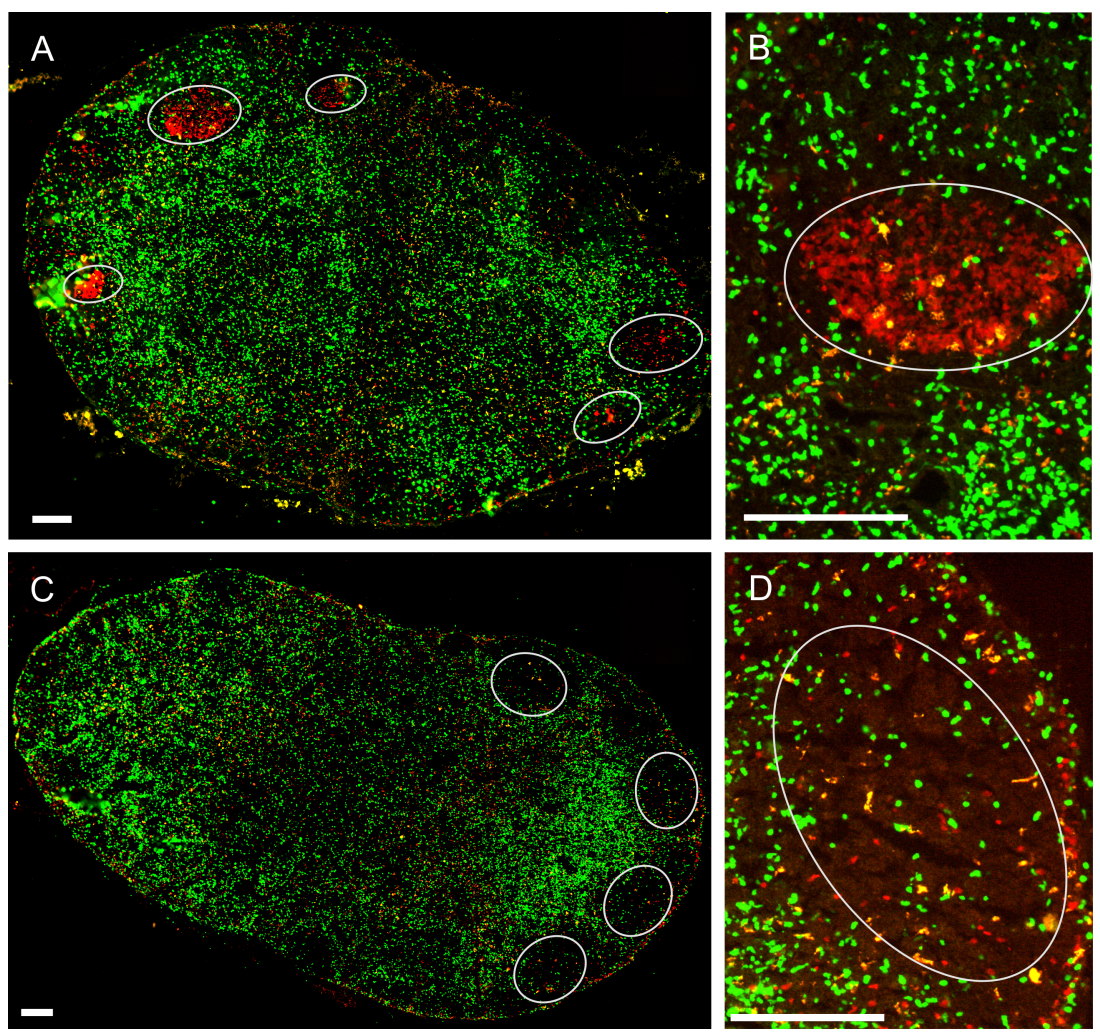

Figure 4.18: Expansion of $B$ cells is dose-dependent and it is not required for the pathogenic function

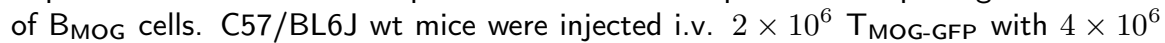
BMOG-RFP and immunized 2d later either with $7.5 \mu \mathrm{g}$ or $50 \mu \mathrm{g}$ rMOG s.c. (200 $\mathrm{ng}$ PTX d0 and $d 2$ p.i.). Cryosections of inguinal lymph nodes were prepared $5 \mathrm{~d}$ p.i. after challenge with $50 \mu \mathrm{g}(\mathrm{A}$ and $\mathrm{B})$ and $7.5 \mu \mathrm{g}$ rMOG $(C$ and $D)$. Fluorescence microscope images. Scale bar $200 \mu \mathrm{m}$. B cell follicles are outlined white. Green: T cells, red: B cells.

\subsection{MOG-specific B cells do not serve as APCs in the CNS}

Since there was no evidence for a pathogenic effect of B cells during the initial activation and proliferation of $\mathrm{T}$ cells in the periphery, we turned our attention to the CNS. Previous studies have suggested antigen-presentation function of B cells within the CNS (Pierson et al., 2014). To test whether B cells infiltrated the CNS spinal cord paraffin sections were stained for B220 expression. We detected aggregates of B220 ${ }^{+}$ cells in the meninges (Fig. 4.19, A-F), similar to those demonstrated by Bettelli et al. (Bettelli et al., 2006). However, they were present in all EAE-affected mice, independent of the presence or absence of MOG-specific B cells. Surprisingly, a histological 


\section{Results}

analysis of the CNS tissue could detect no B BOG-RFP cells in the meninges or in the parenchyma of the spinal cord (Fig. 4.19, G, H), or the brain (not shown). Moreover, we could detect a large number of B220 ${ }^{+}$cells in the CNS by flow cytometry in mice that received $\mathrm{T}_{\text {MOG-GFP }}$ together with $\mathrm{B}_{\mathrm{MOG}-\mathrm{RFP}}$ or $\mathrm{B}_{\mathrm{NP}-\mathrm{RFP}}$, but none of the $\mathrm{B} 220^{+}$ cells were $\mathrm{RFP}^{+}$(Fig. 4.20). In secondary lymphoid organs $\mathrm{RFP}^{+} \mathrm{B}$ cells were detectable (Fig. 4.20), thus their absence in the CNS was not an issue of a technical limitation. With intravital imaging in the spinal cord we also did not detect any BMOG-RFP cells in the CNS (Fig. 4.8), either in the pre-clinical phase or at the onset or in the acute phase. Thus, these results show that the pathogenic MOG-specific $\mathrm{B}$ cells did not infiltrate the CNS compartment and exclude their function as APCs responsible for the reactivation of $\mathrm{T}$ cells in the CNS. 


\section{Results}
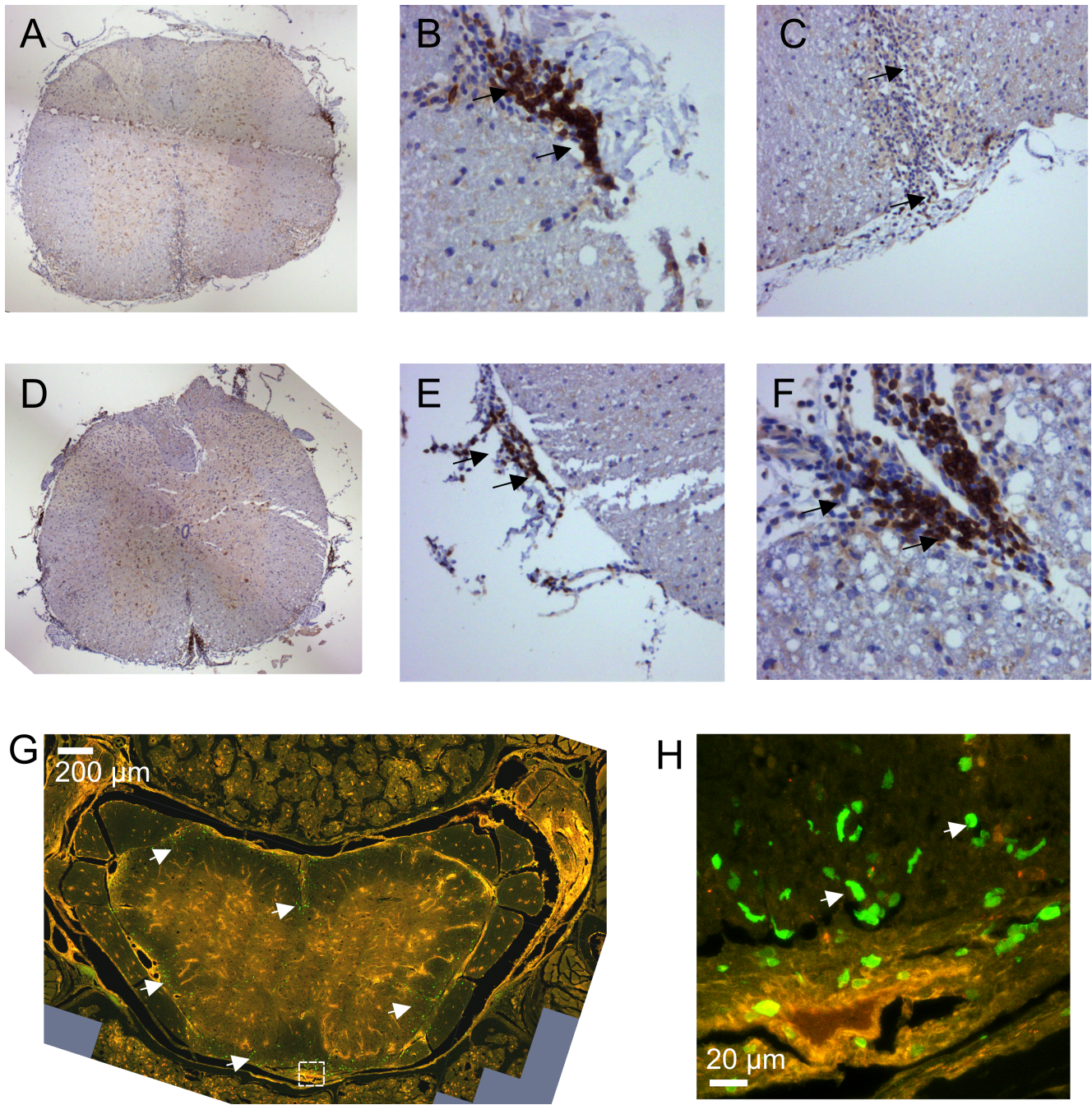

Figure 4.19: Histological analysis of $B$ cells infiltrates in the spinal cord of $C 57 \mathrm{BL} / 6 \mathrm{~J}$ wt mice with EAE. (A-F) Paraffin sections stained for $\mathrm{B}_{22} \mathrm{O}^{+}$cells. (A-C) Animal supplemented with TBMOG cells, d16 p.i. score 8. (D-F) Animal supplemented with T cells alone, d16 p.i. score 8. (E) Cryosection; confocal microscope data. Animal supplemented with TMOG-GFP and BMOG-RFP cells, d12, score 8. 
Spinal Cord

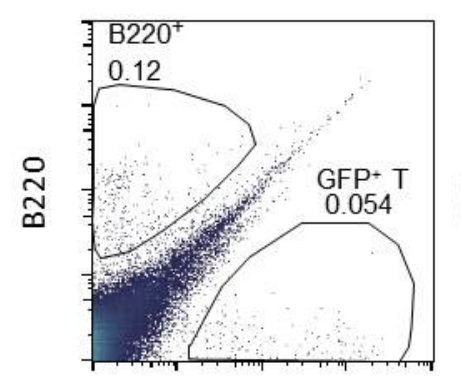

Spinal Cord

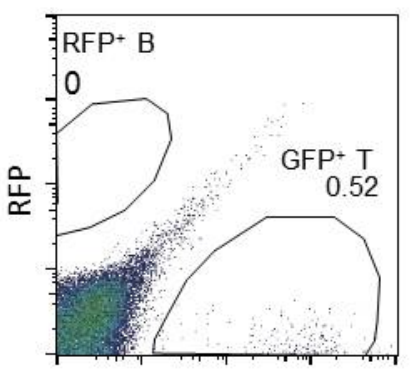

Spleen

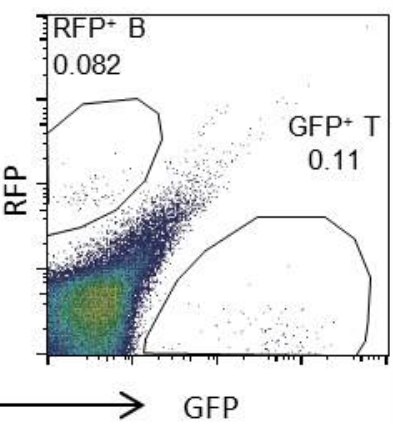

Figure 4.20: Flow cytometric analysis of $B$ cells infiltrates in the spinal cord of mice with $E A E$ (score 7). $\mathrm{GFP}^{+} \mathrm{T}$ cells and $\mathrm{B}_{220^{+}}$cells were detectable in the spinal cord. RFP ${ }^{+} \mathrm{B}_{\mathrm{MOG}}$ cells were present in the spleen but not in the CNS.

\subsubsection{Anti-MOG antibodies account for the disease-promoting effect of B cells}

The autoantibody-dependent function of B cells in EAE is still a highly controversial issue. To determine whether the production of CNS-reactive antibodies by MOGspecific B cells accounts for the disease-accelerating effect of autoreactive B cells in our model we implemented MOG-specific B cells lacking the transcription factor Xbox binding protein 1 (XBP-1). The XBP-1 deficiency did not diminish their capacity to present rrMOG to $\mathrm{T}$ cells in vitro and induce antigen-specific $\mathrm{T}$ cell proliferation (Flach, 2014). However, XBP-1 is required for the transition of mature B cells to antibody-secreting plasma cells (Reimold et al., 2001). Accordingly, XBP-1 deficient $\mathrm{B}_{\mathrm{MOG}}$ cells failed to secrete a detectable amount of anti-rrMOG IgG (Fig. 4.21, A and $\mathrm{B}$ ). The serum levels of $\operatorname{IgG}$ were identical in mice that received $\mathrm{T}$ cells alone, or in combination with $\mathrm{B}_{\mathrm{MOG}-\mathrm{XBP}-1^{-/}}$cells (measured at the day of disease onset). In contrast, in the presence of XBP-1-intact $\mathrm{B}_{\mathrm{MOG}}$ cells mice had a high titer of anti-rrMOG IgG (mainly IgG2A) in the serum. Importantly, together with losing the capacity to secrete antibodies, $\mathrm{B}_{\mathrm{MOG}-\mathrm{XBP}-1^{-/-}}$cells also lost their pathogenic effect on EAE development (Fig. 4.21, C). 
4 Results
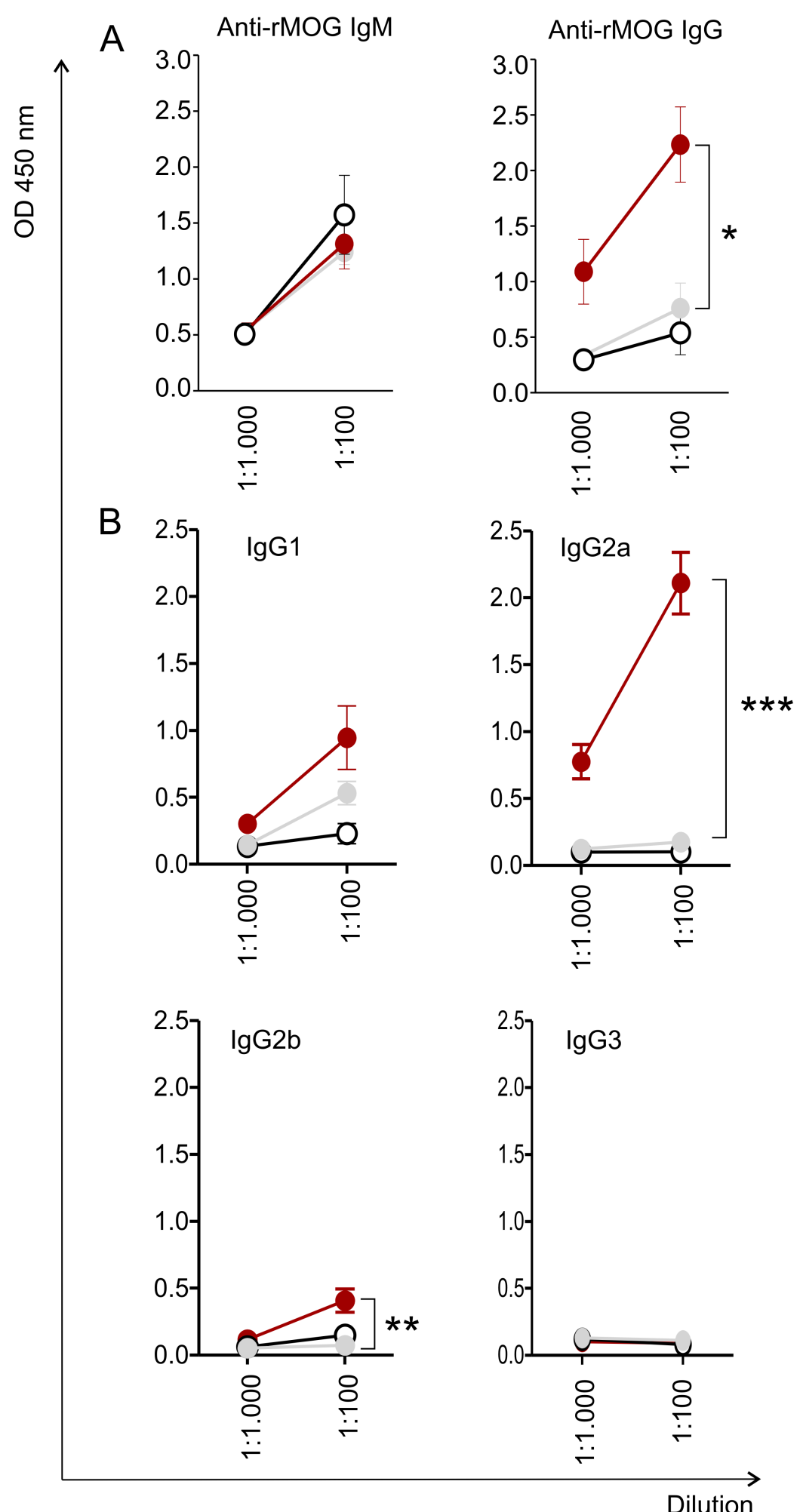


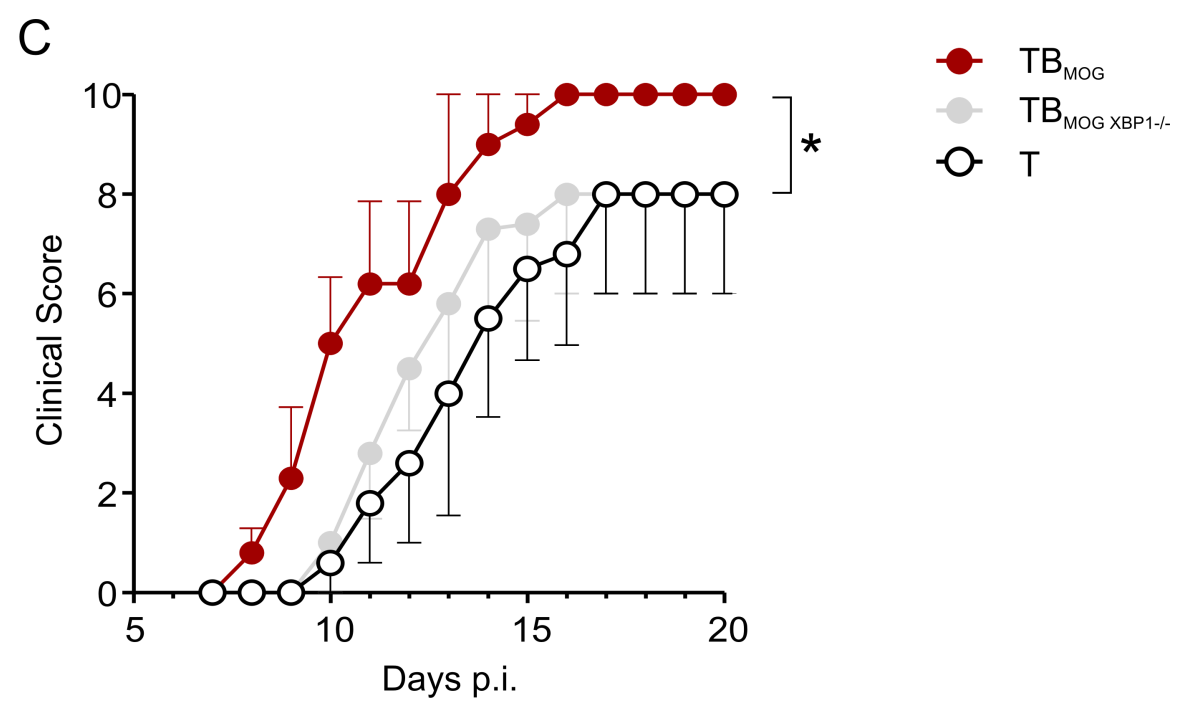

Figure 4.21: $\mathrm{B}_{\mathrm{MOG-XBP-1}-1_{-}^{-}}$cells fail to secrete anti-MOG $\lg$ in response to rrMOG challenge and lose their disease-promoting capability. $3.5 \times 10^{6} \mathrm{~T}_{\text {MOG }}$ cells were transferred either

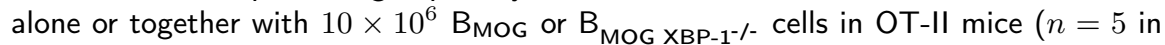
each group). Two days later recipients were immunized with $20 \mu \mathrm{g} \mathrm{rMOG}$ and injected PTX i.p. on d0 and d2 p.i. Statistical significance was tested by Mann-Whitney $\mathrm{U}$ nonparametric two-tailed test. (A) Total anti-rrMOG $\lg M$ and $\lg G$ in the serum was measured by ELISA on the day of disease onset. The difference in IgG titer was statistically significant with ${ }^{*} P=0.0159$ for $\mathrm{TB}_{\mathrm{MOG}}$ versus $\mathrm{TB}_{\mathrm{MOG} \times \mathrm{XBP}_{-1}-\text { - }}$ and with ${ }^{* *} P=0.0079$ for $\mathrm{TB}_{\mathrm{MOG}}$ versus $\mathrm{T}$. (B) Mice with $\mathrm{TB}_{\mathrm{MOG}}$ cells produced significantly higher amount of $\lg \mathrm{G} 2 \mathrm{a}$. $\lg \mathrm{G} 1{ }^{*} P \leq 0.05$ for ${ }^{\mathrm{T}} \mathrm{B}$ MOG versus $\mathrm{T}$; $\operatorname{lgG} 2 \mathrm{a}$ : ${ }^{* * *} P \leq 0.001$

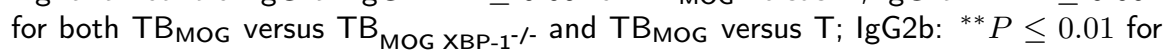

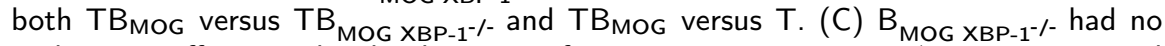
pathogenic effect on the development of EAE. TBMOG versus $\mathrm{T}^{*} P \stackrel{*}{=} 0.0230$ and $\mathrm{TB}_{\mathrm{MOG}}$ versus $\mathrm{TB}_{\mathrm{MOG} \times \mathrm{XBP}^{-1}{ }^{--}}{ }^{*} \mathrm{P}=0.0462$.

To confirm that the accelerating effect of $\mathrm{B}_{\mathrm{MOG}}$ cells was due to the production of anti-MOG antibody, we tested whether an i.v. administration of the purified monoclonal anti-MOG antibody (8.18-C5) (Linnington et al., 1984) would accelerate the disease onset. The 8.18-C5 clone is the antibody used to generate $\mathrm{B}_{\mathrm{MOG}}$ cells (Litzenburger et al., 1998). OT-II mice were injected $\mathrm{T}_{\mathrm{MOG}}$ cells and immunized. On d5 p.i. the recipients were treated with $100 \mu \mathrm{g}$ 8.18-C5 antibody or PBS as a control. The infiltration of T cells into the CNS was compared on d9 p.i. by $2 \mathrm{PM}$. Strikingly, we observed a massive infiltration of $\mathrm{T}$ cells into the CNS in 8.18-C5-treated animals (Fig. 4.22) whereas in the PBS-injected controls T cells failed to invade the CNS at d9 (Fig. 4.22) or d10 p.i. (not shown). Thus, treatment with anti-MOG antibody appeared to have the same accelerating effect on $\mathrm{T}$ cell invasion into the CNS as MOG-specific B cells. 
$\mathrm{T}_{\text {MOG }}+$ anti-MOG mAb

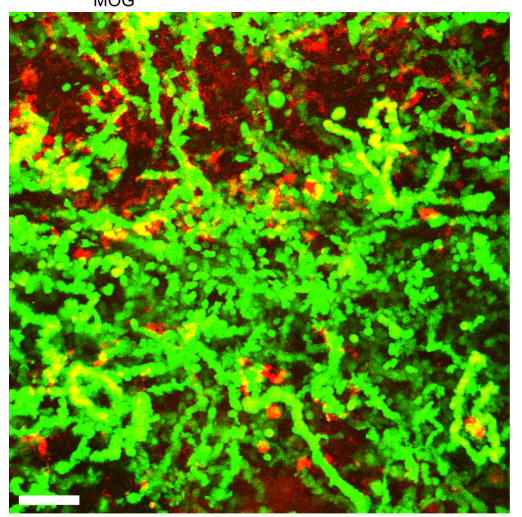

$\mathrm{T}_{\text {MOG }}+\mathrm{PBS}$

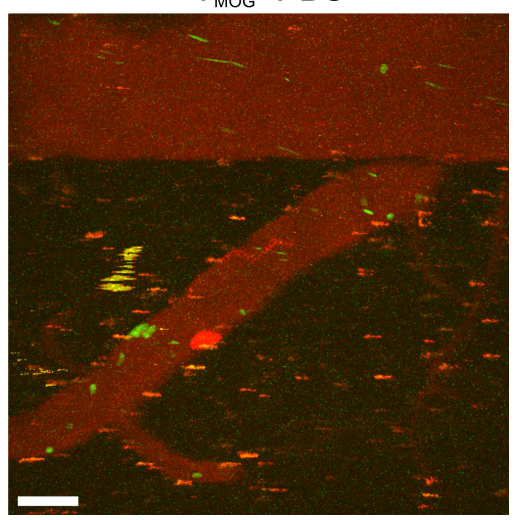

Figure 4.22: $3.5 \times 10^{6} \mathrm{~T}_{\mathrm{MOG}}$ cells were transferred i.v. in OT-II mice. Mice were immunized with $20 \mu \mathrm{g}$ rrMOG and received PTX (200 ng, i.p., d0 and d2 p.i). On d5 p.i. $100 \mu \mathrm{g}$ 8.18-C5 monoclonal antibody was administered i.v. Controls were treated with PBS. Time projections of 30 min time-lapse movies recorded in the spinal cord by 2PM on d9 p.i. Blood vessels were visualized by i.v. injection of $70 \mathrm{kDa}$ Texas Red dextran.

\subsection{Meningeal phagocytic cells accumulate anti-MOG antibody}

If the secretion of anti-MOG antibodies is the disease-promoting function of MOGspecific B cells, where is their anatomical site of action? Is the anti-MOG antibody able to cross an intact $\mathrm{BBB}$ and bind to the extracellular domain of the endogenous MOG protein? In an attempt to answer these questions we labeled anti-MOG monoclonal antibody with a fluorescent dye and tracked its distribution in vivo in naive mice. $24 \mathrm{~h}$ after the antibody i.v. intravital imaging was performed in the lower thoracic spinal cord. The fluorescence was clearly visible in phagocytic cells within the meninges (Fig. 4.23) but no fluorescence could be observed lining the myelin fibers in the parenchyma, indicating that the antibody does not breach the BBB. 


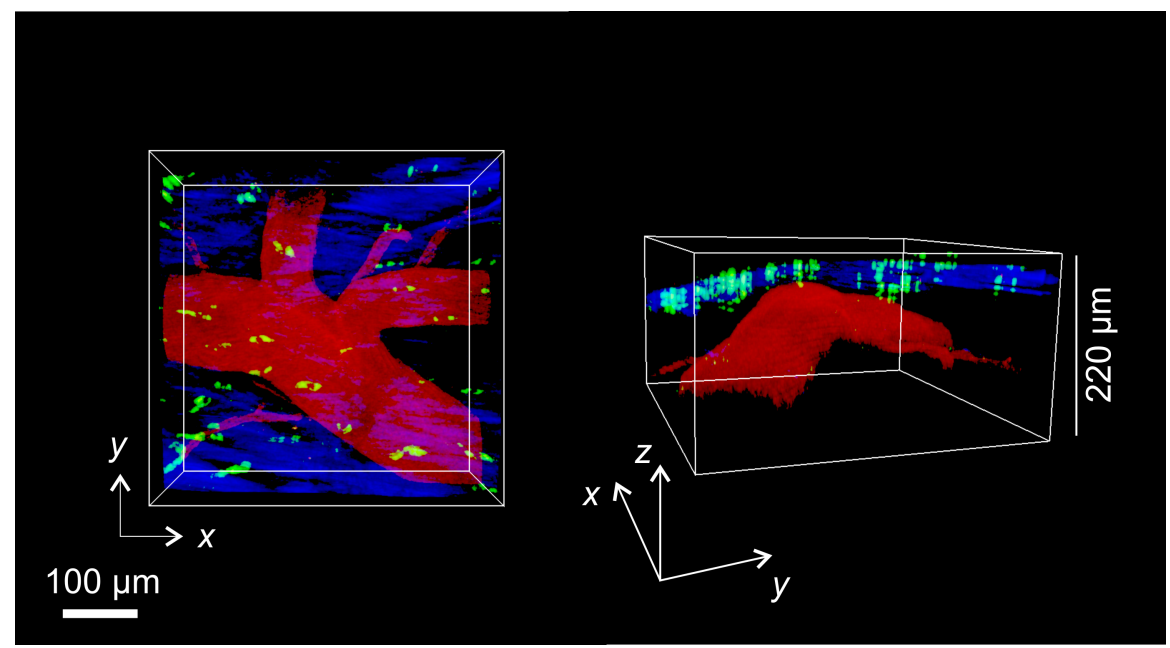

Figure 4.23: Anti-MOG antibody accumulates within the meningeal cells. $50 \mu \mathrm{gg}$ anti-MOG monoclonal antibody conjugated to SeTau-647 were administered i.v. into the C57BL/6J wt mice $24 \mathrm{~h}$ prior intravital imaging in the lower thoracic spinal cord. The fluorescence of SeTau-647 is shown in green. The leptomeningeal blood vessels were visualized by an i.v. injection of $70 \mathrm{kDa}$ Texas Red dextran. In blue is the second harmonic generation signal from the collagen fibers.

\subsection{Interactions with meningeal APCs in vitro lead to an activation of $\mathrm{T}$ cells}

The accumulation of anti-MOG antibody in the meningeal cells led us to the following hypothesis: anti-MOG antibody might coat endogenous soluble myelin antigen in the subarchanoid space, the opsonized antigen would then be taken up efficiently via Fc receptor-mediated endocytosis by antigen-nonspecific meningeal phagocytic cells, and these would present $\mathrm{Ag}$ to effector $\mathrm{T}$ cells, re-activate them and initiate an infiltration of $\mathrm{T}$ cells into the CNS. To test antigen-presentation capacity of meningeal cells, we co-cultured cells isolated from the meninges of naive $\mathrm{GFP}^{+} \mathrm{C} 57 \mathrm{BL} / 6$ mice with the effector $\mathrm{T}_{\mathrm{MOG}}$ cells containing fluorescent NFAT-H2B sensor (Lodygin et al., 2013). We performed live cell imaging using 2PM. Fig. 4.24 shows representative T-cellAPCs contacts in sequential images. We did not observe nuclear translocation of NFAT sensor in $\mathrm{T}$ cells in the absence of antigen (Fig. 4.24, A). However, after adding $\mathrm{MOG}_{35-55}$ to the co-culture a substantial number of $\mathrm{T}$ cells showed stable nuclear NFAT translocation after contact with meningeal $\mathrm{GFP}^{+}$cells (Fig. 4.24, B). 


\section{Results}
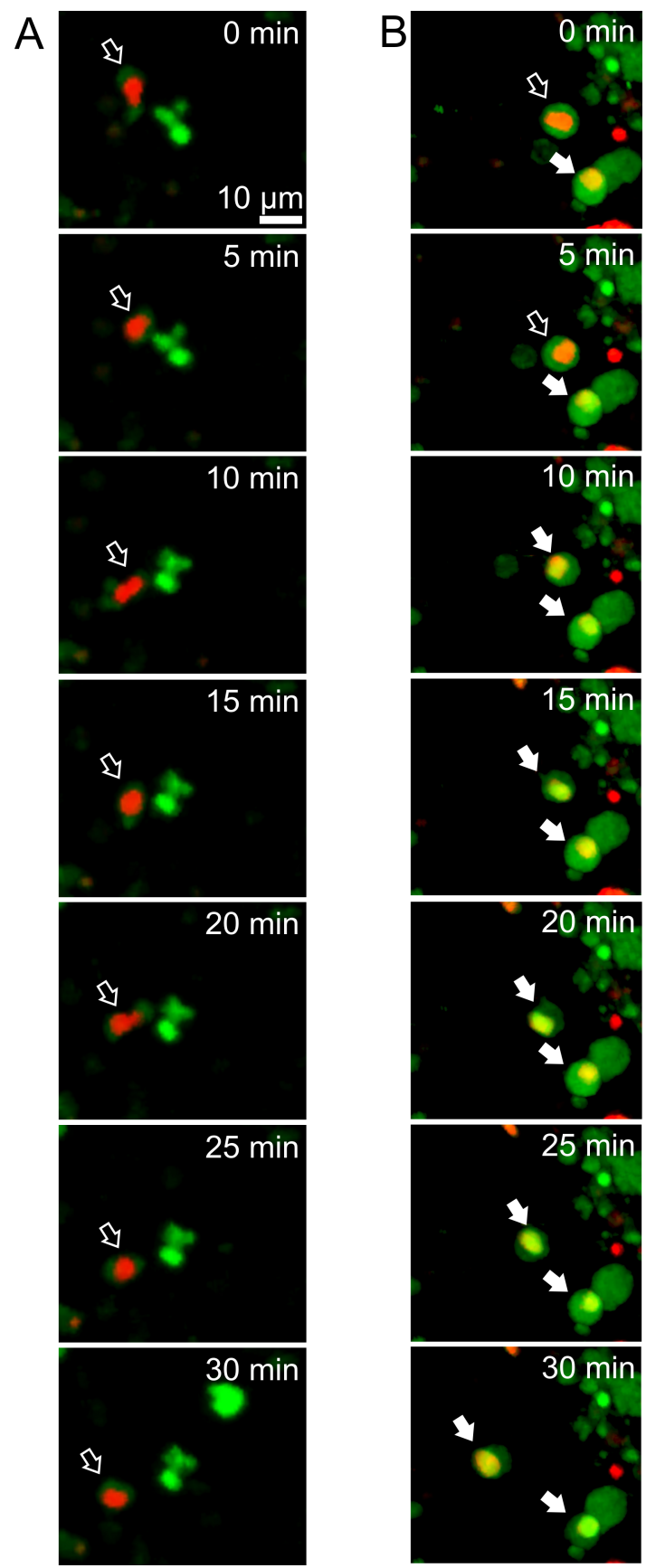

Figure 4.24: Interactions with meningeal APCs in vitro lead to a nuclear translocation of NFAT sensor in effector T cells. Meningeal APCs were isolated from the CNS of naive GFP ${ }^{+}$ mice and co-cultured with $\mathrm{T}_{\text {MOG-NFAT/YFP-mCherry/H2B }}$ cells in the presence of $50 \mu \mathrm{g} / \mathrm{mL}$ $M_{35-55}$. Single frame series of a time lapse movie recorded by $2 P M$ are shown before $(A)$ and after $(B)$ the antigen was added. Open and filled arrowheads indicated

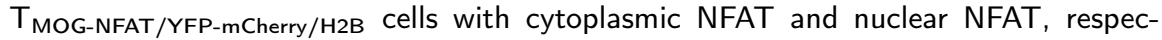
tively. 


\section{Results}

The green cytoplasmic NFAT translocated rapidly into the red nucleus, which then appeared bright yellow. These preliminary results demonstrate that the meningeal phagocytes are potent APCs and are able to re-activate MOG-specific T cells when they have access to MOG antigen. Further experiments will be required to confirm an accumulation of myelin antigen in the meningeal APCs and their enhanced antigenpresentation capacity in the presence of anti-MOG antibody. 


\section{Discussion}

The function of B cells in the pathogenesis of MS remains controversial. Studies in the animal model EAE suggest a dual role of B cells. Through production of autoantibodies, secretion of pro-inflammatory cytokines or antigen-presentation B cells might trigger and/or enhance CNS autoimmunity. On the contrary, B cells have also been shown to suppress EAE and contribute to the recovery from EAE through secretion of anti-inflammatory cytokines. The aim of our study was to identify the function of myelin-reactive B cells in rrMOG-induced EAE. Our data provide evidence for a pathogenic role of CNS-reactive B cells via an autoantibody-mediated accelerated invasion of encephalitogenic $\mathrm{T}$ cells into the CNS.

The development of spontaneous EAE in double tg $\mathrm{TCR}^{\mathrm{MOG}} \times \mathrm{IgG}^{\mathrm{MOG}}$ but not in single tg TCR ${ }^{\mathrm{MOG}}$ mice confirmed the pathogenic capacity of myelin-reactive B cells (Bettelli et al., 2006; Krishnamoorthy et al., 2006). While this tg model provided convincing evidence for the requirement of myelin-reactive B cells in spontaneous development of CNS autoimmunity, the major drawback of this system is that the entire adoptive immune system is potentially autoreactive. This, however, does not reflect a physiological immune repertoire. Other EAE models in B-cell deficient mice or in mice on a RAG-deficient background (i.e. in the absence of endogenous $\mathrm{T}$ and B cells) (Lafaille et al., 1994; Madsen et al., 1999a; Gregersen et al., 2006; Na et al., 2008) suffer from the limitation that they are completely devoid of regulatory B cells or both $\mathrm{T}$ and $\mathrm{B}$ cells, respectively. In addition, it is well recognized that supplemented lymphocytes in lymphopenic mice undergo homeostatic proliferation to maintain a balanced level of lymphocytes and even in the absence of antigenic challenge $\mathrm{T}$ cells differentiate preferentially towards the Th1 phenotype (Moxham et al., 2008).

Here we created a mouse model that we believe more accurately reflects a physiological immunocompetent system with a limited number of autoimmune $\mathrm{T}$ and $\mathrm{B}$ lymphocytes in an otherwise intact adaptive immune repertoire. Prior to immunization we transferred MOG-specific T and B cells, isolated from naive TCR ${ }^{\mathrm{MOG}}$ (Bettelli et al., 2003) and $\mathrm{IgG}^{\mathrm{MOG}}$ (Litzenburger et al., 1998) donor mice, into wt recipients. 


\section{Discussion}

The expression of fluorescent proteins, GFP (Okabe et al., 1997) or tdRFP (Luche et al., 2007), by transferred T and B cells allowed us to track these cells in vivo using intravital two-photon imaging and furthermore re-isolate them for bio-molecular analysis at any time point during EAE development. A further advantage of our model is that we reduced the amount of rrMOG more than 13-fold: instead of $100 \mu \mathrm{g}$ rrMOG commonly used in other laboratories we immunized mice with $7.5 \mu \mathrm{g}$. Triggering the disease with a mild antigenic challenge is crucial to more accurately mimicking a physiological immune response since an exaggerated antigenic challenge may distort the immune reaction. To further refine our model we implemented OT-II mice (Barnden et al., 1998) with a non-autoimmune endogenous $\mathrm{T}$ cell repertoire. This allowed us to exclude the contribution of endogenous encephalitogenic $\mathrm{T}$ cells to the immune response.

Our first aim was to try to determine which role MOG-specific B cells play in the pathogenesis of EAE development - whether pathogenic or regulatory. We observed that in wt mice a transfer of $\mathrm{T}_{\mathrm{MOG}}$ together with $\mathrm{B}_{\mathrm{MOG}}$ cells significantly accelerated the disease onset and moreover it doubled the risk of clinical manifestation of the disease compared to control mice receiving $\mathrm{T}_{\mathrm{MOG}}$ cells alone or PBS. The pathogenicity of MOG-specific B cells was even more pronounced when we transferred $\mathrm{T}_{\mathrm{MOG}}$ cells together with $\mathrm{B}_{\mathrm{MOG}}$ cells in OT-II recipients: mice with $\mathrm{T}_{\mathrm{MOG}}$ cells alone had no symptoms of EAE for 25 days p.i. while mice injected with $\mathrm{T}_{\mathrm{MOG}}$ together with $\mathrm{B}_{\mathrm{MOG}}$ cells developed severe EAE starting from $\mathrm{d} 7$ p.i. To investigate the disease onset in the presence or absence of $\mathrm{B}_{\mathrm{MOG}}$ cells we increased the antigen dose to $20 \mathrm{\mu g}$ rrMOG in OT-II mice because the incidence with $7.5 \mathrm{\mu g}$ was below $50 \%$. With $20 \mathrm{\mu g}$ rrMOG of rrMOG we still had a significant acceleration of disease onset and mice developed EAE with nearly $100 \%$ incidence.

Taking these findings together, in our mouse model MOG-specific B cells evidently had a pathogenic effect on the development of clinical disease in EAE in response to mild rrMOG challenge. Importantly, in OT-II mouse model this effect did not manifest itself by enhancing the severity of EAE since all mice that developed EAE, independently of the presence or absence of $\mathrm{B}_{\mathrm{MOG}}$ cells, developed a severe and rapidly progressing disease course with fatal outcome in most cases. Instead, $\mathrm{B}_{\mathrm{MOG}}$ cells influenced the onset of EAE, suggesting that their primary function consists in triggering the disease onset. These findings are in line with previous studies (Bettelli et al., 2006; Krishnamoorthy et al., 2006) which pointed out that the presence of MOG-specific B cells triggered spontaneous EAE, also indicating a crucial role of B cells in initiating CNS autoimmunity. 
To access the mechanisms underlying an accelerated disease onset in the presence of $\mathrm{B}_{\mathrm{MOG}}$ cells at the cellular level we performed intravital imaging of the lower thoracic spinal cord in mice supplemented with $\mathrm{T}_{\mathrm{MOG}}$ and $\mathrm{B}_{\mathrm{MOG}}$ cells. In the pre-clinical phase $\mathrm{T}_{\mathrm{MOG}}$ cells associated with leptomeningeal blood vessels before any body weight loss or neurological signs of EAE were apparent. Their crawling behavior along the intraluminal surface preferentially against the blood flow before they extravasated was in agreement with previously described migration of encephalitogenic $\mathrm{T}$ cells in transfer EAE in Lewis rats (Bartholomäus et al., 2009). Remarkably, when we imaged mice supplemented with $\mathrm{T}$ cells and the control $\mathrm{B}_{\mathrm{NP}}$ cells on the same day, we observed $\mathrm{T}_{\mathrm{MOG}}$ cells merely passively transported by the blood flow. Furthermore, in contrast to the $\mathrm{TB}_{\mathrm{MOG}}$ system, in $\mathrm{TB}_{\mathrm{NP}}$ mice there was no evidence for a disrupted $\mathrm{BBB}$ such as we had detected by the leakage of fluorescent dextran in $\mathrm{TB}_{\mathrm{MOG}}$ mice. Several days later, in the absence of $\mathrm{B}_{\mathrm{MOG}}$ cells we could also detect encephalitogenic $\mathrm{T}$ cells crawling within the leptomeningeal blood vessels. Although this process was delayed by several days, the migration pattern of invading $\mathrm{T}$ cells was similar to the pattern observed in the presence of $\mathrm{B}_{\mathrm{MOG}}$ cells. Therefore, we could conclude that MOGspecific B cells accelerated the infiltration of encephalitogenic T cells into the CNS, however, they had no effect on the migratory properties of these T cells.

The well-known capacity of B cells to recognize low amount of antigen by specific binding via their BCR and to present it in the context of MHC class II to T cells led us to hypothesize that the disease-promoting effect of $\mathrm{B}$ cells might be due to accelerated and/or enhanced $\mathrm{T}_{\mathrm{MOG}}$ cell priming. However, an intravital imaging analysis demonstrated that $\mathrm{B}_{\mathrm{MOG}}$ cells did not affect the migration of $\mathrm{T}$ cells in the draining lymph nodes within the priming phase. By tracking and analyzing the motility of $\mathrm{T}_{\mathrm{MOG}}$ cells over time we identified the three distinct stages of $\mathrm{T}$ cell activation that were previously described by Mempel et al. (Mempel et al., 2004). In our EAE model in response to immunization with $7.5 \mathrm{\mu g}$ rMOG protein, both in the presence or absence of MOG-specific B cells, following kinetic could be identified:

1. Within the first $30 \mathrm{~h}$ p.i., $\mathrm{T}$ cells remained small in size and no clustering of cells was observed. Rapidly migrating T cells started to slow down around $20 \mathrm{~h}$ p.i. and $\mathrm{T}$ cell velocity continuously decreased thereafter (activation phase).

2. Between 30 - $40 \mathrm{~h}$ p.i. T cells turned into blasts and formed dynamic and long lasting clusters (possibly indicating interactions with DCs). In this phase T cells 


\section{Discussion}

moved at their lowest speed and started to divide (cytokines secretion phase).

3. From about $40 \mathrm{~h}$ p.i. T cells proliferated rapidly and resumed their fast migration (proliferation phase).

The kinetic of these three stages differs from that described previously: Mempel et al. detected phase 2 already $8 \mathrm{~h}$ after $\mathrm{T}$ cells came into contact with their antigen (Mempel et al., 2004). Based on our observation the kinetic strongly depends on the method of antigen delivery, namely, whether DCs are loaded with antigen in vitro and transferred s.c. or via immunization of emulsified antigen (unpublished data).

Although the motility behavior of $\mathrm{T}_{\mathrm{MOG}}$ cells after immunization did not differ in the presence or absence of $\mathrm{B}_{\mathrm{MOG}}$ cells, we frequently observed a few motile $\mathrm{T}_{\mathrm{MOG}^{-}}$ $\mathrm{B}_{\mathrm{MOG}}$ conjugates at the interphases between the $\mathrm{T}$ cell zone and the $\mathrm{B}$ cell follicles already a few hours after immunization. In agreement with previous publications (Okada et al., 2005) these conjugates were motile, with B cell moving at the front, dragging the $\mathrm{T}$ cell behind. We speculated that $\mathrm{B}$ cells might enhance activation and/or proliferation of $\mathrm{T}$ cells via antigen-presentation to $\mathrm{T}$ cells. However, a flow cytometric analysis of cell size, activation markers and CFSE dilution did not provide any evidence to support this hypothesis. Furthermore, there was no significant difference in regards to the gene expression level of pro-inflammatory cytokines. These findings do not support a recently published study that claimed that the pathogenic function of $\mathrm{B}$ cells consists of their antigen-presentation to encephalitogenic $\mathrm{T}$ cells leading to a significantly higher production of pro-inflammatory cytokines (Pierson et al., 2014). However, this study was based on a B-cell deficient mouse model ( $\mu$ MT mouse). In contrast, here we demonstrate that within an intact immune repertoire MOG-specific B cells are dispensable for the priming of encephalitogenic T cells.

Since no evidence for the pathogenic effect of $\mathrm{B}_{\mathrm{MOG}}$ cells was detectable in the periphery, we focused on a potential antigen-presentation function of B cells directly in the CNS. Pierson et al. demonstrated that the majority of $\mathrm{MHC}$ class $\mathrm{II}^{+}$cells in the naive CNS were CD19 ${ }^{+}$B cells (Pierson et al., 2014) and suggested that they were the predominant type of APC for the re-activation of initial encephalitogenic $\mathrm{T}$ cells within the non-inflamed CNS environment. This study concurs well with previously noted aggregates of $\mathrm{B} 220^{+} \mathrm{B}$ cells in the $\mathrm{CNS}$ of $\mathrm{TCR}^{\mathrm{MOG}} \times \mathrm{IgG}^{\mathrm{MOG}}$ mice (Bettelli et al., 2006). Furthermore, a recent study argued that MHC class II-dependent antigen presentation function of B cells is a requirement for EAE induction (Molnarfi et al., 2013) suggesting a critical role for B cells via the re-activation of encephalitogenic 


\section{Discussion}

$\mathrm{T}$ cells. However, using intravital imaging in the spinal cord, we provide evidence that the supplemented pathogenic $\mathrm{B}_{\mathrm{MOG}}$ cells did not enter the CNS compartment at any time point of EAE. Neither could we detect $\mathrm{RFP}^{+} \mathrm{B}_{\mathrm{MOG}}$ cells in the pre-clinical phase nor in the acute phase in the CNS with a full-blown inflammation. We confirmed this finding by a careful histological examination of the brain and the spinal cord with the meninges kept intact between the bony skull and vertebral column and the parenchyma. At first this finding seemed to contradict to previously claimed presence of B cells in large numbers in the CNS. However, it is important to note that the conclusion by Bettelli et al. that B cells form meningeal ectopic follicles was based on the histopathological detection of $\mathrm{B} 220^{+}$cells in spinal cord sections. No other additional surface markers were included to confirm the identity of B cells. In line with this report, when we stained spinal cord paraffin sections for B220 molecule we could also detect aggregates of $\mathrm{B} 220^{+}$cells in the meninges, similar to that demonstrated by Bettelli et al. However, they were present in all EAE-affected mice, independent of the presence or absence of MOG-specific B cells. Moreover, we could detect a large number of $\mathrm{B} 220^{+}$cells in the CNS by flow cytometry in EAE-affected mice, but none of the $\mathrm{B}_{220^{+}}$cells were $\mathrm{RFP}^{+}$. It is well known that not all $\mathrm{B} 220^{+}$cells are from the $\mathrm{B}$ cell lineage (Nikolic et al., 2002). A subpopulation of B220 ${ }^{+}$cells has been reported to contain $\mathrm{B} 220^{+} \mathrm{CD} 19^{-} \mathrm{CD}^{-} \mathrm{c}^{+}$plasmacytoid DCs (Nikolic et al., 2002), although this population does not included $\mathrm{CD} 19^{+} \mathrm{B}$ cells detected by Pierson et al. (Pierson et al., 2014). Although the function of $\mathrm{CD}_{1} 9^{+}$and $\mathrm{B} 220^{+}$populations within the CNS is not yet clear, our results clearly exclude the presence of the supplemented disease-promoting $\mathrm{B}_{\mathrm{MOG}}$ cells in the CNS compartment and therefore rule out their cellular role as APCs to effector T cells.

Previous studies suggested the secretion of pro-inflammatory cytokines (IL-6, TNF $\alpha$ and LT) by B cells as a trigger of encephalitogenic T cell activation (Korn et al., 2008; Bar-Or et al., 2010; Barr et al., 2012). In contrast to antigen-presentation function, cytokine production can be induced by microbial products via Toll-like receptors, independent of the BCR specificity (Barr et al., 2012). The source of such microbial nonspecific stimuli in EAE might be the complete Freund's adjuvant (CFA) (Freund et al., 1947) that contains heat-inactivated Mycobacterium tuberculosis. In our EAE model administration of $\mathrm{B}_{\mathrm{NP}}$ cells prior to immunization with rrMOG emulsified in CFA had no disease-promoting effect, providing evidence that antigen-specificity of B cells was crucial for its pathogenic role. Furthermore, a recent study in our lab demonstrated that antigen-activated $\mathrm{B}_{\mathrm{NP}}$ cells had no disease-promoting effect 


\section{Discussion}

on $\mathrm{MOG}_{35-55}$-induced EAE either (Flach, 2014). The NP hapten was conjugated to OVA so that supplemented TOVA cells could provide help to $\mathrm{B}_{\mathrm{NP}}$ cells. Indeed, $\mathrm{B}_{\mathrm{NP}}$ cells were activated and produced high titers of anti-NP antibody, however, they failed to accelerate EAE onset in contrast to $\mathrm{B}_{\mathrm{MOG}}$ cells. Thus, our results suggest that the production of cytokines was not the mode of action of pathogenic $\mathrm{B}_{\mathrm{MOG}}$ cells.

Numerous studies associated myelin-reactive antibodies with EAE. However, it remains widely debated whether their presence is part of the cause or a secondary phenomenon as a result of an ongoing CNS inflammation and the mechanisms of their action in EAE are largely unknown. We tested whether the secretion of autoantibodies by MOG-specific B cells accounts for their pathogenic effect by supplementing mice with MOG-specific B cells deficient in the transcription factor XBP-1 which is required for the development of mature B cells to antibody-secreting plasma cells (Reimold et al., 2001). At the onset of EAE we detected a similar level of anti-rrMOG IgG in the sera of mice supplemented with $\mathrm{T}_{\mathrm{MOG}}$ cells alone or in combination with $\mathrm{B}_{\mathrm{MOG} \mathrm{XBP}-1^{-/}}$. In contrast, in the presence of XBP-1-intact $\mathrm{B}_{\mathrm{MOG}}$ cells we detected significantly higher titers of anti-rrMOG IgG in the serum. We deliberately chose to take blood samples at the onset of the disease and not at the end of the clinical experiment because we could not exclude a contribution of the endogenous MOG-specific B cells to the production of autoantibodies in the acute phase of EAE. Indeed, the fact that we detected equal titers of anti-rrMOG IgM antibodies in the sera of all tested animals, suggests a possible engagement of the endogenous autoimmune B cell repertoire. Strikingly, together with losing the capacity to secrete IgG, $\mathrm{B}_{\mathrm{MOG}-\mathrm{XBP}-1^{-/-}}$cells also failed to promote the disease onset. To further corroborate the pathogenicity of autoantibodies, we injected i.v. anti-MOG monoclonal antibody 8.18-C5 (Linnington et al., 1984). The antibody was administered on $\mathrm{d} 5$ p.i. because previous studies in our lab showed that IgG was detectable in the serum of $\mathrm{TB}_{\mathrm{MOG}}$ mice at this time point (unpublished data). Intravital imaging in the spinal cord in the pre-clinical phase showed that indeed an injection of 8.18-C5 had the same accelerated effect on $\mathrm{T}$ cell invasion than the $\mathrm{B}_{\mathrm{MOG}}$ cells: while mice that received $\mathrm{T}_{\mathrm{MOG}}$ cells alone showed no T cells invading the CNS at d9 p.i., 8.18-C5-treated animals presented a large number of extravasated encephalitogenic T cells. This finding is consistent with the previously reported pathogenic effect of anti-MOG antibody (Schluesener et al., 1987). However, it is important to note that Schluesener et al. injected an extremely high dose of antibody with $200 \mathrm{\mu g} / \mathrm{g}$ body weight, i.e. ca $5 \mathrm{mg}$ per mouse. Since such amount of antibody cannot be produced endogenously, the relevance of this finding 
has been questioned (Lehmann-Horn et al., 2013). Our findings demonstrated that even a small dose of anti-rrMOG antibody - 50 - $100 \mu \mathrm{g}$ per mouse i.v. - had a disease-promoting effect.

Our study showed that mice facing mild antigenic challenge exhibited an unimpaired activation, proliferation and differentiation of encephalitogenic $\mathrm{T}$ cells but largely failed to develop neurological signs of EAE, whereas peripherally generated or administered autoantibodies led to a clinical manifestation of the disease. Thus, these findings strongly suggest a causal relationship between autoantibodies and the development of clinical symptoms of EAE. The question regarding the mechanism of autoantibody-mediated T cell invasion into the CNS remains unanswered, however, our preliminary results indicate that peripherally circulating antibody accumulated within the meningeal cells and did not cross the BBB in a non-inflamed CNS. These antibody-ingested meningeal cells located in the arachnoid - between the dura mater and the subarachnoid space filled with the CSF. Thus, the meningeal cells are in direct contact with the CSF which recirculates through the CNS and could possibly contain myelin debris. Live cell imaging of cells isolated from the meninges with MOG-specific $\mathrm{T}_{\mathrm{NFAT} / \mathrm{YFP}-\mathrm{mCherry} / \mathrm{H} 2 \mathrm{~B}}$ cells provided evidence that meningeal cells were capable of antigen presentation and re-activation of encephalitogenic T cells. Previous studies also suggested that the meningeal APCs facilitate the initial re-activation of $\mathrm{T}$ cells during EAE (Kivisäkk et al., 2009). The observation that anti-MOG antibody gained access from the peripheral blood circulation to the CNS-associated cells with antigen presentation capacity and the unique location of meningeal APCs at the boundary between the CSF and the periphery suggest that anti-MOG antibody might "bridge" the meningeal APCs and the myelin. Endogenous soluble myelin particles might occur in the CSF in form of exosomes - small membrane vesicles secreted by oligodendrocytes (Fitzner et al., 2011). A subset of microglia seemingly lacking antigen presentation capacity has been reported to internalize exosomes efficiently via micropinocytosis in an immunologically "silent" manner (Fitzner et al., 2011). Specific binding of anti-MOG-IgG to the exosomes might facilitate myelin antigen uptake via Fc gamma receptors by cells with pronounced antigen presentation capacity and thus disturb the immunologically "silent" clearance of exosomes. Furthermore, it is possible that myelin uptake by non-specific meningeal APCs is enhanced when Fc gamma receptors recognize the Fc domain of $\mathrm{IgG}$, which in turn binds with high affinity to MOG protein. Fc receptor-mediated internalized myelin antigen can be degraded inside the endosomes and its peptides presented in the context of MHC class II on the 


\section{Discussion}

cell surface to encephalitogenic T cells. An antibody-mediated accumulation of myelin antigens in the CNS-associated APCs might enhance antigen presentation capacity to encephalitogenic $\mathrm{T}$ cells, leading to an accelerated disease onset. To validate this hypothesis, the antigen presentation capacity of meningeal cells isolated from mice in the pre-clinical phase in the presence or absence of peripherally circulating antibody will need to be addressed. 


\section{Summary}

To establish the role of $\mathrm{B}$ cells in EAE we created a novel EAE model with a limited number of autoimmune $\mathrm{T}$ and $\mathrm{B}$ cells in an otherwise intact adoptive immune repertoire. Due to their expression of fluorescent proteins we were able to track these cells in vivo using two-photon imaging and isolate them for ex vivo analysis. MOGspecific B cells accelerated the onset of EAE induced by rrMOG protein. Remarkably, in animals facing a mild antigenic challenge, B cells increased the risk of clinical manifestation of the disease. Using intravital imaging in the spinal cord we demonstrated that an accelerated disease onset was associated with an accelerated infiltration of $\mathrm{T}$ cells into the CNS. We have shown that this was not a consequence of differential priming of $\mathrm{T}$ cells. Furthermore, we could exclude that $\mathrm{B}_{\mathrm{MOG}}$ cells facilitated reactivation of $\mathrm{T}$ cells in the CNS by antigen-presentation as the supplemented B cells did not enter the CNS compartment. Instead, we provide evidence that $\mathrm{B}_{\mathrm{MOG}}$ cells secrete autoantibodies which accumulate in the meningeal APCs and possibly help to trigger the invasion of $\mathrm{T}$ cells into the CNS. 


\section{Acknowledgment}

I would like to thank many people for their support, without whose help this work would have not been possible. First, I thank the director of our institute Prof. Dr. Alexander Flügel for his guidance and support throughout this project. I thank my thesis committee members Prof. Dr. Jürgen Wienands and Prof. Dr. Mikael Simons for their invaluable suggestions and discussion at the thesis committee meetings. I would also like to thank additional examination board members, Prof. Dr. Tiago Outeiro, Prof. Dr. Martin Oppermann and Prof. Dr. Holger Reichardt, for kindly accepting invitation to my dissertation defense.

I am grateful to my supervisor Dr. Fred Lühder for all his support throughout the four years of my project. Moreover, I gratefully acknowledge help provided by Dr. Francesca Odoardi with all the obstacles I came across while establishing intravital imaging in the mouse system in our lab. I wish to thank Dr. Dmitri Lodygin for his help with generation of mouse $\mathrm{T}$ cell line and all invaluable scientific discussions. I thank my B-cell colleague, Dr. Anne Flach for an amazing collaboration on this project and for all her technical help. I thank Dr. Christian Schläger for his help with the microscope and image analysis software. I thank Judith Strauß and Michael Haberl for their help with antibody labeling. I thank Adriane Stas, Simone Hamann, Nancy Meyer, Martina Weig, Birgit Curdt and Simon Mole for their excellent technical assistance. I also want to thank the whole IMSF team for a fun and friendly environment and their support.

I also wish to thank Christopher Sie for all his invaluable help with the world of computers in particular with writing macros for image processing. I thank Dr. Stephan Halle and Rieke Schwegmann from Hannover Medical School for teaching me surgical procedures for intravital imaging. I thank Peter Wenig from the medical technical service for building and fixing all my imaging setups.

I am particularly grateful to my friend and colleague Cathy Ludwig for her endless support and for proofreading this thesis. I wish to thank Dr. Anna Karabinskaya for being an amazing friend. I thank Jasemin Dannheim for her support. I thank Ruthaline Foucgouo for all her care and her most delicious African cooking. I wish 


\section{Acknowledgment}

to thank Dr. med. Ernest Tsiaze and my family for their endless understanding and support. 


\section{Bibliography}

Amor, S., N. Groome, C. Linington, M. M. Morris, K. Dornmair, M. V. Gardinier, J. M. Matthieu, and D. Baker: 1994, 'Identification of epitopes of myelin oligodendrocyte glycoprotein for the induction of experimental allergic encephalomyelitis in SJL and Biozzi AB/H mice'. The Journal of Immunology 153(10), 4349-4356.

Archambault, A., J. Carrero, L. Barnett, N. McGee, J. Sim, J. Wright, T. Raabe, P. Chen, H. Ding, E. Allenspach, I. Dragatsis, T. Laufer, and G. Wu: 2013, 'Cutting Edge: Conditional MHC Class II Expression Reveals a Limited Role for B Cell Antigen Presentation in Primary and Secondary CD4 T Cell Responses'. The Journal of Immunology 191(2), 545-550.

Avasarala, J., A. Cross, and J. Trotter: 2001, 'Oligoclonal band number as a marker for prognosis in multiple sclerosis'. Archives of Neurology 58(12), 2044-2045.

Bar-Or, A., P. A. J. Calabresi, D. Arnold, C. Markowitz, S. Shafer, L. H. Kasper, E. Waubant, S. Gazda, R. J. Fox, M. Panzara, N. Sarkar, S. Agarwal, and C. Smith: 2008, 'Rituximab in relapsing-remitting multiple sclerosis: A 72-week, open-label, phase I trial'. Annals of Neurology 63(3), 395-400.

Bar-Or, A., L. Fawaz, B. Fan, P. Darlington, A. Rieger, C. Ghorayeb, P. Calabresi, E. Waubant, S. Hauser, J. Zhang, and C. Smith: 2010, 'Abnormal B-cell cytokine responses a trigger of T-cell-mediated disease in MS?'. Annals of Neurology 67(4), $452-461$.

Barcellos, L., J. Oksenberg, A. Begovich, E. Martin, S. Schmidt, E. Vittinghoff, D. Goodin, D. Pelletier, R. Lincoln, P. Bucher, A. Swerdlin, M. Pericak-Vance, J. Haines, and S. Hauser: 2003, 'HLA-DR2 Dose Effect on Susceptibility to Multiple Sclerosis and Influence on Disease Course'. The American Journal of Human Genetics 72(3), 710-716.

Barnden, M., J. Allison, W. Heath, and F. Carbone: 1998, 'Defective TCR expression in transgenic mice constructed using cDNA-based alpha- and beta-chain genes un- 


\section{BIBLIOGRAPHY}

der the control of heterologous regulatory elements'. Immunology and Cell Biology 76(1), 34-40.

Barr, T., P. Shen, S. Brown, V. Lampropoulou, T. Roch, S. Lawrie, B. Fan, R. O'Connor, S. Anderton, A. Bar-Or, S. Fillatreau, and D. Gray: 2012, 'B cell depletion therapy ameliorates autoimmune disease through ablation of IL-6-producing B cells'. The Journal of Experimental Medicine 209(5), 1001-1010.

Bartholomäus, I., N. Kawakami, F. Odoardi, C. Schläger, D. Miljkovic, J. Ellwart, W. Klinkert, C. Flügel-Koch, T. Issekutz, H. Wekerle, and A. Flügel: 2009, 'Effector $\mathrm{T}$ cell interactions with meningeal vascular structures in nascent autoimmune CNS lesions'. Nature 462(7269), 94-98.

Ben-Nun, A., H. Wekerle, and I. Cohen: 1981, 'The rapid isolation of clonable antigenspecific $\mathrm{T}$ lymphocyte lines capable of mediating autoimmune encephalomyelitis'. European Journal of Immunology 11(3), 195-199.

Berer, K., H. Wekerle, and G. Krishnamoorthy: 2011, 'B cells in spontaneous autoimmune diseases of the central nervous system'. Molecular Immunology 48(11), $1332-1337$.

Bettelli, E., D. Baeten, A. Jäger, R. Sobel, and V. Kuchroo: 2006, 'Myelin oligodendrocyte glycoprotein-specific T and B cells cooperate to induce a Devic-like disease in mice'. The Journal of Clinical Investigation 116(9), 2393-2402.

Bettelli, E., M. Pagany, H. Weiner, C. Linington, R. Sobel, and V. Kuchroo: 2003, 'Myelin oligodendrocyte glycoprotein-specific T cell receptor transgenic mice develop spontaneous autoimmune optic neuritis'. The Journal of Experimental Medicine 197(9), 1073-1081.

Bornstein, M. and S. Appel: 1961, 'The application of tissue culture to the study of experimental "allergic" encephalomyelitis. I. Patterns of demyelination'. Journal of Neuropathology and Experimental Neurology 20, 141-147.

Bousso, P., N. R. Bhakta, R. S. Lewis, and E. Robey: 2002, 'Dynamics of Thymocyte-Stromal Cell Interactions Visualized by Two-Photon Microscopy'. Science 296(5574), 1876-1880.

Breithaupt, C., A. Schubart, H. Zander, A. Skerra, R. Huber, C. Linington, and U. Jacob: 2003, 'Structural insights into the antigenicity of myelin oligodendrocyte glycoprotein'. Proceedings of the National Academy of Sciences 100(16), 9446-9451. 


\section{BIBLIOGRAPHY}

Brosnan, C. F., G. L. Stoner, B. R. Bloom, and H. M. Wisniewski: 1977, 'Studies on demyelination by activated lymphocytes in the rabbit eye: II. Antibody-dependent cell-Mediated demyelination'. The Journal of Immunology 118(6), 2103-2110.

Burns, J., A. Rosenzweig, B. Zweiman, and R. P. Lisak: 1983, 'Isolation of myelin basic protein-reactive T-cell lines from normal human blood'. Cellular Immunology 81(2), 435-440.

Carrasco, Y. and F. Batista: 2007, 'B cells acquire particulate antigen in a macrophage-rich area at the boundary between the follicle and the subcapsular sinus of the lymph node'. Immunity 27(1), 160-171.

Charcor, J.-M.: 1868, 'Histologie de la sclerose en plaques'. Gazette des hopitaux 41, $554-555$.

Cohen, Y., A. Polliack, O. Zelig, and A. Goldfarb: 2001, 'Monotherapy with rituximab induces rapid remission of recurrent cold agglutinin-mediated hemolytic anemia in a patient with indolent lympho-plasmacytic lymphoma'. Leukemia \& Lymphoma 42(6), 1405-1408.

Colombo, M., M. Dono, P. Gazzola, S. Roncella, A. Valetto, N. Chiorazzi, G. L. Mancardi, and M. Ferrarini: 2000, 'Accumulation of Clonally Related B Lymphocytes in the Cerebrospinal Fluid of Multiple Sclerosis Patients'. The Journal of Immunology 164(5), 2782-2789.

Compston, A., C. Confavreux, H. Lassmann, I. McDonald, D. Miller, J. Noseworthy, K. Smith, and H. Wekerle: 2006, McAlpine's Multiple Sclerosis. Elsevier, fourth edition.

Constant, S., N. Schweitzer, J. West, P. Ranney, and K. Bottomly: 1995, 'B lymphocytes can be competent antigen-presenting cells for priming CD4 $+\mathrm{T}$ cells to protein antigens in vivo'. The Journal of Immunology 155(8), 3734-3741.

Denk, W., J. Strickler, and W. Webb: 1990, 'Two-photon laser scanning fluorescence microscopy'. Science 248(4951), 73-76.

Diaspro, A., G. Chirico, and M. Collini: 2005, 'Two-photon fluorescence excitation and related techniques in biological microscopy'. Quarterly reviews of biophysics 38(2), 97-166. 


\section{BIBLIOGRAPHY}

Duddy, M., M. Niino, F. Adatia, S. Hebert, M. Freedman, H. Atkins, H. J. Kim, and A. Bar-Or: 2007, 'Distinct effector cytokine profiles of memory and naive human B cell subsets and implication in multiple sclerosis'. The Journal of Immunology 178(10), 6092-6099.

Edwards, J., L. Szczepanski, J. Szechinski, A. Filipowicz-Sosnowska, P. Emery, D. Close, R. Stevens, and T. Shaw: 2004, 'Efficacy of B-cell-targeted therapy with rituximab in patients with rheumatoid arthritis'. New England Journal of Medicine 350(25), 2572-2581.

Eugster, H., K. Frei, M. Kopf, H. Lassmann, and A. Fontana: 1998, 'IL-6deficient mice resist myelin oligodendrocyte glycoprotein-induced autoimmune encephalomyelitis'. European Jornal of Immunology 28(7), 2178-2187.

Fillatreau, S., C. Sweenie, M. McGeachy, D. Gray, and S. Anderton: 2002, 'B cells regulate autoimmunity by provision of IL-10'. Nature Immunology 3(10), 944-950.

Fitzner, D., M. Schnaars, D. van Rossum, G. Krishnamoorthy, P. Dibaj, M. Bakhti, T. Regen, U.-K. Hanisch, and M. Simons: 2011, 'Selective transfer of exosomes from oligodendrocytes to microglia by macropinocytosis'. Journal of Cell Science 124(3), 447-458.

Flach, A.: 2014, 'Autoimmune T cell - B cell Interaction in Experimental Autoimmune Encephalomyelitis'. Ph.D. thesis, UMG, Göttingen.

Freund, J., E. Stern, and T. Pisani: 1947, 'Isoallergic encephalomyelitis and radiculitis in guinea pigs after one injection of brain and Mycobacteria in water-in-oil emulsion'. The Journal of Immunology 57(2), 179-194.

Gay, F., T. Drye, G. Dick, and M. Esiri: 1997, 'The application of multifactorial cluster analysis in the staging of plaques in early multiple sclerosis. Identification and characterization of the primary demyelinating lesion'. Brain 120(8), 1461-1483.

Genain, C., B. Cannella, S. Hauser, and C. Raine: 1999, 'Identification of autoantibodies associated with myelin damage in multiple sclerosis'. Nature Medicine 5(2), $170-175$.

Girard, J.-P. and T. A. Springer: 1995, 'High endothelial venules (HEVs): specialized endothelium for lymphocyte migration'. Immunology Today 16(9), 449-457. 


\section{BIBLIOGRAPHY}

Gold, R., C. Linington, and H. Lassmann: 2006, 'Understanding pathogenesis and therapy of multiple sclerosis via animal models: 70 years of merits and culprits in experimental autoimmune encephalomyelitis research'. Brain 129(Pt 8), 1953-1971.

Gregersen, J., K. Kranc, X. Ke, P. Svendsen, L. Madsen, A. Thomsen, L. Cardon, J. Bell, and L. Fugger: 2006, 'Functional epistasis on a common MHC haplotype associated with multiple sclerosis'. Nature 443(7111), 574-577.

Göppert-Mayer, M.: 1931, 'Über Elementarakte mit zwei Quantensprüngen'. Annalen der Physik 401(3), 273-294.

Handel, A., G. Giovannoni, G. Ebers, and S. Ramagopalan: 2010, 'Environmental factors and their timing in adult-onset multiple sclerosis'. Nature Reviews Neurology 6(3), 156-166.

Hauser, S. and J. Oksenberg: 2006, 'The Neurobiology of Multiple Sclerosis: Genes, Inflammation, and Neurodegeneration'. Neuron 52(1), 61-76.

Hauser, S., E. Waubant, D. Arnold, T. Vollmer, J. Antel, R. Fox, A. Bar-Or, M. Panzara, N. Sarkar, S. Agarwal, A. Langer-Gould, and C. Smith: 2008, 'B-cell depletion with rituximab in relapsing-remitting multiple sclerosis'. New England Journal of Medicine 358(7), 676-688.

Hetz, C., A.-H. Lee, D. Gonzalez-Romero, P. Thielen, J. Castilla, C. Soto, and L. Glimcher: 2008, 'Unfolded protein response transcription factor XBP-1 does not influence prion replication or pathogenesis'. Proceedings of the National Academy of Sciences 105(2), 757-762.

Hobeika, E., S. Thiemann, B. Storch, H. Jumaa, P. J. Nielsen, R. Pelanda, and M. Reth: 2006, 'Testing gene function early in the B cell lineage in mb1-cre mice'. Proceedings of the National Academy of Sciences 103(37), 13789-13794.

Hohlfeld, R. and H. Wekerle: 2004, 'Autoimmune concepts of multiple sclerosis as a basis for selective immunotherapy: From pipe dreams to (therapeutic) pipelines'. Proceedings of the National Academy of Sciences 101, 14599-14606.

Joseph, F., C. Hirst, T. Pickersgill, Y. Ben-Shlomo, N. Robertson, and N. Scolding: 2009, 'CSF oligoclonal band status informs prognosis in multiple sclerosis: a case control study of 100 patients'. Journal of Neurology, Neurosurgery $\&$ Psychiatry 80(3), 292-296. 


\section{BIBLIOGRAPHY}

Junt, T., E. A. Moseman, M. Iannacone, S. Massberg, P. A. Lang, M. Boes, K. Fink, S. E. Henrickson, D. M. Shayakhmetov, N. C. D. Paolo, N. van Rooijen, T. R. Mempel, S. P. Whelan, and U. H. von Andrian: 2007, 'Subcapsular sinus macrophages in lymph nodes clear lymph-borne viruses and present them to antiviral B cells'. Nature 450, 110-114.

Kabat, E. A., D. Moore, and H. Landow: 1942, 'An electrophoretic study of the protein components in cerebrospinal fluid and their relationship to the serum proteins'. The Journal of Clinical Investigation 21(5), 571-577.

Kappos, L., D. Li, P. Calabresi, P. O'Connor, A. Bar-Or, F. Barkhof, M. Yin, D. Leppert, R. Glanzman, J. Tinbergen, and S. Hauser: 2011, 'Ocrelizumab in relapsingremitting multiple sclerosis: a phase 2, randomised, placebo-controlled, multicentre trial'. The Lancet 378(9805), 1779-1787.

Keegan, M., F. König, R. McClelland, W. Brück, Y. Morales, A. Bitsch, H. Panitch, H. Lassmann, B. Weinshenker, M. Rodriguez, J. Parisi, and C. F. Lucchinetti: 2005, 'Relation between humoral pathological changes in multiple sclerosis and response to therapeutic plasma exchange'. The Lancet 366(9485), 579-582.

Kitamura, D., J. Roes, R. Kühn, and K. Rajewsky: 1991, 'A B cell-deficient mouse by targeted disruption of the membrane exon of the immunoglobulin mu chain gene'. Nature 350, 423-426.

Kivisäkk, P., J. Imitola, S. Rasmussen, W. Elyaman, B. Zhu, R. Ransohoff, and S. Khoury: 2009, 'Localizing central nervous system immune surveillance: meningeal antigen-presenting cells activate $\mathrm{T}$ cells during experimental autoimmune encephalomyelitis'. Annals of Neurology 65(4), 457-469.

Korn, T., M. Mitsdoerffer, A. Croxford, A. Awasthi, V. Dardalhon, G. Galileos, P. Vollmar, G. Stritesky, M. Kaplan, A. Waisman, V. Kuchroo, and M. Oukka: 2008, 'IL-6 controls Th17 immunity in vivo by inhibiting the conversion of conventional $\mathrm{T}$ cells into Foxp3+ regulatory $\mathrm{T}$ cells'. Proceedings of the National Academy of Sciences 105(47), 18460-18465.

Krishnamoorthy, G., H. Lassmann, H. Wekerle, and A. Holz: 2006, 'Spontaneous opticospinal encephalomyelitis in a double-transgenic mouse model of autoimmune T cell/B cell cooperation'. Journal of Clinical Investigation 116(9), 2385-2392. 


\section{BIBLIOGRAPHY}

Lafaille, J., K. Nagashima, M. Katsuki, and S. Tonegawa: 1994, 'High incidence of spontaneous autoimmune encephalomyelitis in immunodeficient anti-myelin basic protein T cell receptor transgenic mice'. Cell 78(3), 399-408.

Lampropoulou, V., K. Hoehlig, T. Roch, P. Neves, G. E. Calderon, C. Sweenie, Y. Hao, A. Freitas, U. Steinhoff, S. Anderton, and S. Fillatreau: 2008, 'TLRactivated B cells suppress T cell-mediated autoimmunity'. The Journal of Immunology 180(7), 4763-4773.

Lanzavecchia, A.: 1985, 'Antigen-specific interaction between T and B cells'. Nature 314, 537-539.

Lassmann, H., C. Brunner, M. Bradl, and C. Linington: 1988, 'Experimental allergic encephalomyelitis: the balance between encephalitogenic $\mathrm{T}$ lymphocytes and demyelinating antibodies determines size and structure of demyelinated lesions'. Acta Neuropathol 75(6), 566-576.

Lassmann, H., K. Kitz, and H. Wisniewski: 1981, 'In vivo effect of sera from animals with chronic relapsing experimental allergic encephalomyelitis on central and peripheral myelin'. Acta Neuropathologica 55(4), 297-306.

Lehmann-Horn, K., H. Kronsbein, and M. Weber: 2013, 'Targeting B cells in the treatment of multiple sclerosis: recent advances and remaining challenges'. Therapeutic Advances in Neurological Disorders 6(3), 161-173.

Lennon, V., T. Kryzer, S. Pittock, A. Verkman, and S. Hinson: 2005, 'IgG marker of optic-spinal multiple sclerosis binds to the aquaporin-4 water channel'. The Journal of Experimental Medicine 202(4), 473-477.

Linington, C., M. Bradl, C. Lassmann, H.and Brunner, and V. K.: 1988, 'Augmentation of demyelination in rat acute allergic encephalomyelitis by circulating mouse monoclonal antibodies directed against a myelin/oligodendrocyte glycoprotein'. American Journal of Pathology 130(3), 443-454.

Linnington, C., M. Webb, and P. L. Woodhams: 1984, 'A novel myelin-associated glycoprotein defined by a mouse monoclonal antibody'. Journal of Neuroimmunology 6(6), 387-396.

Litzenburger, T., R. Fassler, J. Bauer, H. Lassmann, C. Linington, H. Wekerle, and A. Iglesias: 1998, 'B lymphocytes producing demyelinating autoantibodies: develop- 


\section{BIBLIOGRAPHY}

ment and function in gene-targeted transgenic mice'. The Journal of Experimental Medicine 188(1), 169-180.

Lodygin, D., F. Odoardi, C. Schläger, H. Körner, A. Kitz, M. Nosov, J. van den Brandt, H. Reichardt, M. Haberl, and A. Flügel: 2013, 'A combination of fluorescent NFAT and H2B sensors uncovers dynamics of $\mathrm{T}$ cell activation in real time during CNS autoimmunity'. Nature Medicine 19(6), 784-790.

Lowenthal, A., M. V. Sande, and D. Karcher: 1960, 'The differential diagnosis of neurological diseases by fractionating electrophoretically the CSF gamma-globulins'. Journal of Neurochemistry 6(1), 51-56.

Lucchinetti, C., W. Brück, J. Parisi, B. Scheithauer, M. Rodriguez, and H. Lassmann: 2000, 'Heterogeneity of multiple sclerosis lesions: implications for the pathogenesis of demyelination'. Annals of Neurology 47(6), 707-717.

Luche, H., O. Weber, R. T. Nageswara, C. Blum, and H. Fehling: 2007, 'Faithful activation of an extra-bright red fluorescent protein in "knock-in" Cre-reporter mice ideally suited for lineage tracing studies'. European Journal of Immunology 37(1), $43-53$.

Lyons, A.: 2000, 'Analysing cell division in vivo and in vitro using flow cytometric measurement of CFSE dye dilution'. Journal of Immunological Methods 243, 147154.

Lyons, A. and C. Parish: 1994, 'Determination of lymphocyte division by flow cytometry'. Journal of Immunological Methods 171(1), 131-137.

Lyons, J.-A., M. Ramsbottom, and A. Cross: 2002, 'Critical role of antigen-specific antibody in experimental autoimmune encephalomyelitis induced by recombinant myelin oligodendrocyte glycoprotein'. European Journal of Immunology 32(7), 1905-1913.

Lyons, J.-A., M. San, M. Happ, and A. Cross: 1999, 'B cells are critical to induction of experimental allergic encephalomyelitis by protein but not by a short encephalitogenic peptide'. European Journal of Immunology 29(11), 3432-3439.

Madsen, L., E. Andersson, L. Jansson, M. krogsgaard, C. Andersen, J. Engberg, J. Strominger, A. Svejgaard, J. Hjorth, R. Holmdahl, K. Wucherpfennig, and L. Fugger: 1999a, 'A humanized model for multiple sclerosis using HLA-DR2 and a human T-cell receptor'. Nature Genetics 23(3), 343-347. 


\section{BIBLIOGRAPHY}

Madsen, L., N. Labrecque, J. Engberg, A. Dierich, A. Svejgaard, C. Benoist, D. Mathis, and L. Fugger: 1999b, 'Mice lacking all conventional MHC class II genes'. Proceedings of the National Academy of Sciences 96(18), 10338-10343.

Magliozzi, R., O. Howell, A. Vora, B. Serafini, R. Nicholas, M. Puopolo, R. Reynolds, and F. Aloisi: 2007, 'Meningeal B-cell follicles in secondary progressive multiple sclerosis associate with early onset of disease and severe cortical pathology'. Brain 130(4), 1089-1104.

Maloney, D., T. Liles, D. Czerwinski, C. Waldichuk, J. Rosenberg, A. Grillo-Lopez, and R. Levy: 1994, 'Phase I clinical trial using escalating single-dose infusion of chimeric anti-CD20 monoclonal antibody (IDEC-C2B8) in patients with recurrent B-cell lymphoma'. Blood 84(8), 2457-2466.

Marchesi, V. and J. Gowans: 1964, 'The migration of lymphocytes through the endothelium of venules in lymph nodes: an electron microscope study'. Proceedings of the Royal Society of London 159, 283-290.

Markowitz, D., S. Goff, and A. Bank: 1988, 'Safe and efficient ecotropic and amphotropic packaging lines for use in gene transfer experiments'. Transactions of the Association of American Physicians 101, 212-218.

Marrie, R.: 2004, 'Environmental risk factors in multiple sclerosis aetiology'. The Lancet Neurology 3(12), 709-718.

Matsushita, T., M. Horikawa, Y. Iwata, and T. Tedder: 2010, 'Regulatory B cells (B10 cells) and regulatory $\mathrm{T}$ cells have independent roles in controlling experimental autoimmune encephalomyelitis initiation and late-phase immunopathogenesis'. The Journal of Immunology 185(4), 2240-2252.

Matsushita, T., K. Yanaba, J. Bouaziz, M. Fujimoto, and T. Tedder: 2008, 'Regulatory B cells inhibit EAE initiation in mice while other B cells promote disease progression'. Journal of Clinical Investigation 118(10), 3420-3430.

Mempel, T.: 2010, 'Single-cell analysis of cytotoxic T cell function by intravital multiphoton microscopy'. Methods in Molecular Biology 616, 181-192.

Mempel, T., S. Henrickson, and U. Von Andrian: 2004, 'T-cell priming by dendritic cells in lymph nodes occurs in three distinct phases'. Nature 427(6970), 154-159. 


\section{BIBLIOGRAPHY}

Mendel, I., A. Katz, N. Kozak, A. Ben-Nun, and M. Revel: 1998, 'Interleukin-6 functions in autoimmune encephalomyelitis: a study in gene-targeted mice'. European Journal of Immunology 28(5), 1727-1737.

Merkler, D., B. Schmelting, B. Czeh, E. Fuchs, C. Stadelmann, and W. Brück: 2006, 'Myelin oligodendrocyte glycoprotein-induced experimental autoimmune encephalomyelitis in the common marmoset reflects the immunopathology of pattern II multiple sclerosis lesions'. Multiple Sclerosis 12(4), 369-374.

Miller, M., O. Safrina, I. Parker, and M. Cahalan: 2004, 'Imaging the single cell dynamics of CD4 $+\mathrm{T}$ cell activation by dendritic cells in lymph nodes'. The Journal of Experimental Medicine 200(7), 847-856.

Miller, M. J., S. H. Wei, I. Parker, and M. D. Cahalan: 2002, 'Two-Photon Imaging of Lymphocyte Motility and Antigen Response in Intact Lymph Node'. Science 296(5574), 1869-1873.

Mills, D. M. and J. Cambier: 2003, 'B lymphocyte activation during cognate interactions with CD4+ T lymphocytes: molecular dynamics and immunologic consequences'. Seminars in Immunology 15(6), 325-329.

Molnarfi, N., U. Schulze-Topphoff, M. Weber, J. Patarroyo, T. Prod'homme, M. Varrin-Doyer, A. Shetty, C. Linington, A. Slavin, J. Hidalgo, D. Jenne, H. Wekerle, R. Sobel, C. Bernard, M. Shlomchik, and S. Zamvil: 2013, 'MHC class II-dependent $\mathrm{B}$ cell APC function is required for induction of CNS autoimmunity independent of myelin-specific antibodies'. The Journal of Experimental Medicine 210(13), 29212937.

Moxham, V. F., J. Karegli, R. E. Phillips, K. L. Brown, T. T. Tapmeier, R. Hangartner, S. H. Sacks, and W. Wong: 2008, 'Homeostatic proliferation of lymphocytes results in augmented memory-like function and accelerated allograft rejection'. The Journal of Immunology 180(6), 3910-3918.

Na, S., Y. Cao, C. Toben, L. Nitschke, C. Stadelmann, R. Gold, A. Schimpl, and T. Hunig: 2008, 'Naive CD8 T-cells initiate spontaneous autoimmunity to a sequestered model antigen of the central nervous system'. Brain 131(Pt 9), 23532365 .

Nikolic, T., G. Dingjan, P. Leenen, and R. Hendriks: 2002, 'A subfraction of B220(+) cells in murine bone marrow and spleen does not belong to the $\mathrm{B}$ cell lineage but has dendritic cell characteristics'. European Journal of Immunology 32(3), 686-692. 


\section{BIBLIOGRAPHY}

Obermeier, B., R. Mentele, J. Malotka, J. Kellermann, T. Kümpfel, H. Wekerle, F. Lottspeich, R. Hohlfeld, and K. Dornmair: 2008, 'Matching of oligoclonal immunoglobulin transcriptomes and proteomes of cerebrospinal fluid in multiple sclerosis'. Nature Medicine 14(6), 688-693.

Odoardi, F., C. Sie, K. Streyl, V. Ulaganathan, C. Schläger, D. Lodygin, K. Heckelsmiller, W. Nietfeld, J. Ellwart, W. Klinkert, C. Lottaz, M. Nosov, V. Brinkmann, R. Spang, H. Lehrach, M. Vingron, H. Wekerle, C. Flügel-Koch, and A. Flügel: 2012, ' $T$ cells become licensed in the lung to enter the central nervous system'. Nature 488, 675-679.

Okabe, M., M. Ikawa, K. Kominami, T. Nakanishi, and Y. Nishimune: 1997, 'Green mice' as a source of ubiquitous green cells'. FEBS Letters 407(3), 313-319.

Okada, T., M. Miller, I. Parker, M. Krummel, M. Neighbors, S. Hartley, A. O'Garra, M. Cahalan, and J. Cyster: 2005, 'Antigen-Engaged B Cells Undergo Chemotaxis toward the T Zone and Form Motile Conjugates with Helper T Cells'. PLoS Biology 3(6), 1047-1061.

Okuda, Y., S. Sakoda, C. C. Bernard, H. Fujimura, Y. Saeki, T. Kishimoto, and T. Yanagihara: 1998, 'IL-6-deficient mice are resistant to the induction of experimental autoimmune encephalomyelitis provoked by myelin oligodendrocyte glycoprotein'. International Immunology 10(5), 703-708.

Oliver, A., G. Lyon, and N. Ruddle: 2003, 'Rat and Human Myelin Oligodendrocyte Glycoproteins Induce Experimental Autoimmune Encephalomyelitis by Different Mechanisms in C57BL/6 Mice'. The Journal of Immunology 171(1), 462-468.

Owens, G. P., J. L. Bennett, D. H. Gilden, and M. P. Burgoon: 2006, 'The B cell response in multiple sclerosis'. Neurological Research 28(3), 236-244.

Owens, G. P., J. L. Bennett, H. Lassmann, K. C. O'Connor, A. M. Ritchie, A. Shearer, C. Lam, X. Yu, M. Birlea, C. DuPree, R. A. Williamson, D. A. Hafler, M. P. Burgoon, and D. Gilden: 2009, 'Antibodies produced by clonally expanded plasma cells in multiple sclerosis cerebrospinal fluid'. Annals of Neurology 65(6), 639-649.

Pesic, M., I. Bartholomäus, N. Kyratsous, V. Heissmeyer, H. Wekerle, and N. Kawakami: 2013, '2-photon imaging of phagocyte-mediated $\mathrm{T}$ cell activation in the CNS'. Journal of Clinical Investigation 123(3), 1192-1201. 


\section{BIBLIOGRAPHY}

Pierson, E., I. Stromnes, and J. Goverman: 2014, 'B Cells Promote Induction of Experimental Autoimmune Encephalomyelitis by Facilitating Reactivation of T Cells in the Central Nervous System'. The Journal of Immunology 192(3), 929-939.

Prineas, J. and F. Connell: 1978, 'The fine structure of chronically active multiple sclerosis plaques'. Neurology 28(9), 68-75.

Prineas, J. W. and J. S. Graham: 1981, 'Multiple sclerosis: Capping of surface immunoglobulin G on macrophages engaged in myelin breakdown'. Annals of Neurology 10(2), 149-158.

Pöllinger, B., G. Krishnamoorthy, K. Berer, H. Lassmann, M. Bösl, R. Dunn, H. Domingues, A. Holz, F. Kurschus, and H. Wekerle: 2009, 'Spontaneous relapsingremitting EAE in the SJL/J mouse: MOG-reactive transgenic T cells recruit endogenous MOG-specific B cells'. The Journal of Experimental Medicine 206(6), 1303-1316.

Qi, H., J. G. Egen, A. Y. C. Huang, and R. N. Germain: 2006, 'Extrafollicular activation of lymph node B cells by antigen-bearing dendritic cells'. Science $\mathbf{3 1 2}$ (5780), $1672-1676$.

Ransohoff, R. and B. Engelhardt: 2012, 'The anatomical and cellular basis of immune surveillance in the central nervous system'. Nature Reviews Immunology 12(9), 623635 .

Reimold, A., N. Iwakoshi, J. Manis, P. Vallabhajosyula, E. Szomolanyi-Tsuda, E. Gravallese, D. Friend, M. Grusby, F. Alt, and L. Glimcher: 2001, 'Plasma cell differentiation requires the transcription factor XBP-1'. Nature 412(6844), 300307.

Rivers, T., D. Sprunt, and G. Berry: 1933, 'Observations on attempts to produce acute disseminated encephalomyelitis in monkeys'. The Journal of Experimental Medicine 58(1), 39-53.

Rommer, P. S., A. Dudesek, O. Stüve, and U. Zettl: 2014, 'Monoclonal antibodies in treatment of multiple sclerosis'. Clinical \& Experimental Immunology 175(3), $373-384$.

Samoilova, E., J. Horton, B. Hilliard, T.-S. Liu, and Y. Chen: 1998, 'IL-6-deficient mice are resistant to experimental autoimmune encephalomyelitis: roles of IL-6 in 


\section{BIBLIOGRAPHY}

the activation and differentiation of autoreactive T cells'. The Journal of Immunology 161(12), 6480-6486.

Schluesener, H., R. Sobel, C. Linington, and H. Weiner: 1987, 'A monoclonal antibody against a myelin oligodendrocyte glycoprotein induces relapses and demyelination in central nervous system autoimmune disease'. The Journal of Immunology 139(12), 4016-4021.

Seil, F., G. Falk, M. Kies, and E. Alvord: 1968, 'The in vitro demyelinating activity of sera from guinea pigs sensitized with whole CNS and with purified encephalitogen'. Experimental Neurology 22(4), 545-555.

Serafini, B., B. Rosicarelli, R. Magliozzi, E. Stigliano, and F. Aloisi: 2004, 'Detection of ectopic B-cell follicles with germinal centers in the meninges of patients with secondary progressive multiple sclerosis'. Brain Pathology 14(2), 164-174.

Shen, P., T. Roch, V. Lampropoulou, R. O'Connor, U. Stervbo, E. Hilgenberg, S. Ries, V. Dang, Y. Jaimes, C. Daridon, R. Li, L. Jouneau, P. Boudinot, S. Wilantri, I. Sakwa, Y. Miyazaki, M. Leech, R. McPherson, S. Wirtz, M. Neurath, K. Hoehlig, E. Meinl, A. Grützkau, J. Grün, K. Horn, A. Kühl, T. Dörner, A. Bar-Or, S. Kaufmann, S. Anderton, and S. Fillatreau: 2014, 'IL-35-producing B cells are critical regulators of immunity during autoimmune and infectious diseases'. Nature 507(7492), 366-370.

Soelberg Sorensen, P., J. Drulovic, E. Havrdova, S. Lisby, O. Graff, and S. Shackelford: 2010, 'Magnetic resonance imaging (MRI) efficacy of ofatumumab in relapsingremitting multiple sclerosis (RRMS) - 24-week results of a phase II study'. Presented at ECTRIMS; Gothenburg, Sweden.

Sonoda, E., Y. Pewzner-Jung, S. Schwers, S. Taki, S. Jung, D. Eilat, and K. Rajewsky: 1997, 'B cell development under the condition of allelic inclusion'. Immunity. 6(3), $225-233$.

Srivastava, R., M. Aslam, S. Kalluri, L. Schirmer, D. Buck, B. Tackenberg, V. Rothhammer, A. Chan, R. Gold, A. Berthele, J. Bennett, T. Korn, and B. Hemmer: 2012, 'Potassium channel KIR4.1 as an immune target in multiple sclerosis'. New England Journal of Medicine 367(2), 115-123.

Steinman, L. and S. Zamvil: 2006, 'How to successfully apply animal studies in experimental allergic encephalomyelitis to research on multiple sclerosis'. Annals of Neurology 60(1), 12-21. 


\section{BIBLIOGRAPHY}

Stoll, S., J. Delon, T. M. Brotz, and R. N. Germain: 2002, 'Dynamic Imaging of T Cell-Dendritic Cell Interactions in Lymph Nodes'. Science 296(5574), 1873-1876.

Storch, M. K., S. Piddlesden, M. Haltia, M.and Iivanainen, P. Morgan, and H. Lassmann: 1998, 'Multiple sclerosis: In situ evidence for antibody- and complementmediated demyelination'. Annals of Neurology 43(4), 465-471.

Suzuki, K., I. Grigorova, T. G. Phan, L. M. Kelly, and J. G. Cyster: 2009, 'Visualizing B cell capture of cognate antigen from follicular dendritic cells'. The Journal of Experimental Medicine 206(7), 1485-1493.

Svoboda, K. and R. Yasuda: 2006, 'Principles of two-photon excitation microscopy and its applications to neuroscience.'. Neuron 50(6), 823-839.

Walsh, M. J., W. W. Tourtellotte, J. Roman, and W. Dreyer: 1985, 'Immunoglobulin G, A, and M - Clonal restriction in multiple sclerosis cerebrospinal fluid and serum - Analysis by two-dimensional electrophoresis'. Clinical Immunology and Immunopathology 35(3), 313-327.

Willer, C. J., D. A. Dyment, N. J. Risch, A. D. Sadovnick, G. C. Ebers, and T. C. C. S. Group: 2003, 'Twin concordance and sibling recurrence rates in multiple sclerosis'. Proceedings of the National Academy of Sciences 100(22), 12877-12882.

Wolf, S., B. Dittel, F. Hardardottir, and J. Janeway, C.A.: 1996, 'Experimental autoimmune encephalomyelitis induction in genetically B cell-deficient mice'. The Journal of Experimental Medicine 184(6), 2271-2278.

Yuseff, M.-I., P. Pierobon, A. Reversat, and A.-M. Lennon-Duménil: 2013, 'How B cells capture, process and present antigens: a crucial role for cell polarity'. Nature Reviews Immunology 13, 475-486. 


\title{
Curriculum Vitae
}

\author{
Name: $\quad$ Tanja Litke \\ Address: Institute for Multiple Sclerosis Research \\ Department of Neuroimmunology \\ Georg-August University Göttingen \\ Waldweg 33, 37073 Göttingen, Germany
}

Phone: +495513913344

Email:_tanja.litke@med.uni-goettingen.de

\section{Education:}

2010- Institute for Multiple Sclerosis Research (IMSF)

Georg-August University Göttingen

$\mathrm{PhD}$ student in the Department of Neuroimmunology.

2009-2010 Imperial College London, UK, Master in Research in Bioimaging Sciences.

2004-2008 Bielefeld University, Bachelor in Chemistry. 